

\section{DISCLAIMER}

This report was prepared as an account of work sponsored by an agency of the United States Government. Neither the United States Government nor any agency Thereof, nor any of their employees, makes any warranty, express or implied, or assumes any legal liability or responsibility for the accuracy, completeness, or usefulness of any information, apparatus, product, or process disclosed, or represents that its use would not infringe privately owned rights. Reference herein to any specific commercial product, process, or service by trade name, trademark, manufacturer, or otherwise does not necessarily constitute or imply its endorsement, recommendation, or favoring by the United States Government or any agency thereof. The views and opinions of authors expressed herein do not necessarily state or reflect those of the United States Government or any agency thereof. 


\section{DISCLAIMER}

Portions of this document may be illegible in electronic image products. Images are produced from the best available original document. 


\section{NOTICE}

This report was prepared as an account of work sponsored by the United Statcs Government. Neither the United States nor the United States Energy Research and Development Administration, nor any of their employees, nor any of their contractors, subcontractors, or their employees, makes any warranty, express or implied, or assumes any legal liability or responsibility for the accuracy, completeness or usefulness of any information, apparatus, product or process disclosed, or represents that its use would not infringe privately owned rights.

This report has been reproduced directly from the best available copy.

Available from the National Technical Information Service, U. S. Department of Commerce, Springfield, Virginia 22161

Price: Paper Copy $\$ 5.00$ (domestic)

$\$ 7.50$ (foreign)

Microfiche $\$ 3.00$ (domestic)

$\$ 1.50$ (foreign) 


\title{
CHEMICAL VAPOR DEPOSITION GROWTH
}

\section{QUARTERLY REPORT NO. 4}

\author{
1 April 1977
}

By

R. P. Ruth, H. M. Manasevit, A. G. Campbell,

R. E. Johnson, L. A. Moudy, G. L. Shaw, and

W. I. Simpson

\section{Contract No. 954372}

"This work was performed for the Jet Propulsion Laboratory, California Institute of Technology, under NASA Contract NAS7-100 for the U.S. Energy Research and Development Administration, Division of Solar Energy.

The JPL Low-Cost Silicon Solar Array Project is funded by ERDA and forms part of the ERDA Photovoltaic Conversion Program to initiate a major effort toward the development of low-cost solar arrays."

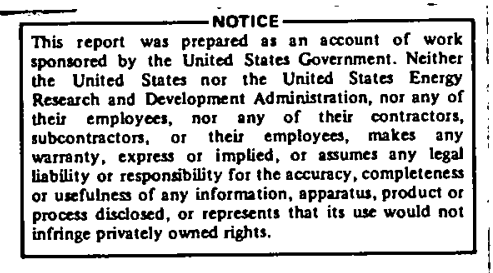

This report was prepared as an account of work cor any of subcontractors. warranty, express or implied, or assumes ans legal or usefulness of any information, apparatus, product or infringe privately ouned rights.

ROCKWELL INTERNATIONAL

Electronic Devices Division

Electronics Research Center

Anaheim, CA 92803 


\section{THIS PAGE , WAS INTENTIONALLY LEFT BLANK}




\begin{abstract}
The technical objective of this contract is the development of chemical vapor deposition (CVD) techniques for the growth of large areas of Si sheet on inexpensive substrate materials, with sheet properties suitable for fabricating solar cells meeting the technical goals of the Low Cost Silicon Solar Array Project. The work of the fifth quarter is summarized.

The contract activities during the quarter were concentrated in the following areas: (1) preparation of polished substrates of three new experimental glasses received in raw billet form from the manufacturer; (2) exploratory Si CVD growth on two experimental glazes (on aluminas), at temperatures below and above the softening points; (3) evaluation of several different surface cleaning procedures for glass substrates, with a procedure involving an acid-cleaning step being adopted as standard; (4) determination of Si film crystallographic properties on glasses (and sapphire) as a function of deposition temperature and thickness in three different thickness ranges; (5) determination of the effect of $\mathrm{HC} \ell$ additions to $\mathrm{SiH}_{4}$ on the net growth rates and the properties of Si films grown by a two-step process at two different deposition temperatures; (6) investigation of the reproducibility of $\mathrm{Si}$ film growth rates when the $\mathrm{SiH}_{4}$ flow rate is cont rolled by a) the mass-flow controller and b) the conventional rotameter; (7) determination of further carrier density vs added dopant concentration data for B-doped $\mathrm{Si}$ films grown in He at low temperatures $\left(\sim 850^{\circ} \mathrm{C}\right) ;(8)$ preparation of p-type B-doped Si films in a range of carrier densities on substrates of single-crystal Si, sapphire, and several glasses for fabrication of experimental solar cell structures; (9) preparation of $\mathrm{p} / \mathrm{p}^{+}$films on substrates of sapphire and single-crystal Si for solar cell fabrication; (10) evaluation of the electrical properties of the various films prepared; and (11) fabrication and characterization of experimental cells made by $P$ diffusion into the $p$-type and the $\mathrm{p} / \mathrm{p}^{+} \mathrm{CVD}$ layers.
\end{abstract}

Details of these investigations are given. Conclusions and recommendations are summa rized, and plans for the next quarter are outlined. 


\section{CONTENTS}

Abstract ................................... i ii

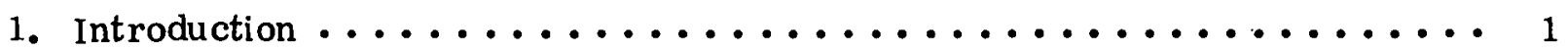

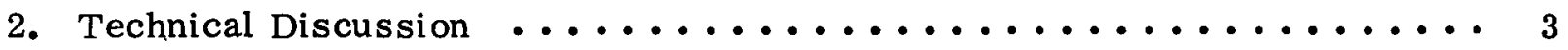

2. 1 Task 1. Modification and Test of Existing CVD Reactor

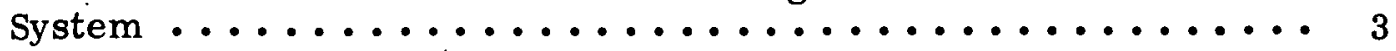

2. 2 Task 2. Identification/Development of Suitable Substrate Materials .............................. 4

2.2.1 Rationale and Procedure for Material Selection ........ 4

2.2. 2 Candidate Substrate Materials Recently Rcccived ..... 5

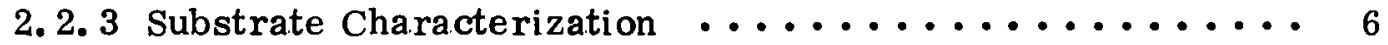

2. 2.4 Substrate Surface Preparation $\ldots \ldots \ldots \ldots \ldots$

2. 3 Task 3. Experimental Investigation of Si CVD Process

parameters ............................. 9

2.3.1 Effect of $\mathrm{HCl}$ Additions to $\mathrm{SiH}_{4}$ on Si Film Growth Rate

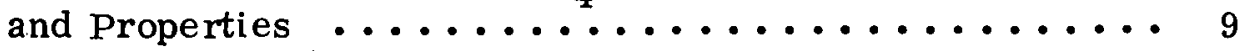

2.3.2 Control of Si Film Growth Rates ................ 11

2.3.3 Determination of Preferred CVD Parameters for Solar Cell structures. . . . . . . . . . . . . . . 12

2.3.4 Growth of Very Thick Si Sheet by CVD .......... 15

2.4 Task 4. Preparation of Si Sheet Samples ............. 17

2. 5 Task 5. Evaluation of Si Sheet Material Properties ........ 18

2. 5. 1 Crystallographic Properties of Si Sheet Grown by $\mathrm{SiH}_{4}$

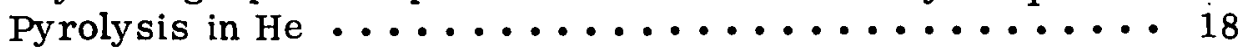

2. 5. 2 Properties of Si Sheet Grown by Two-Step Process

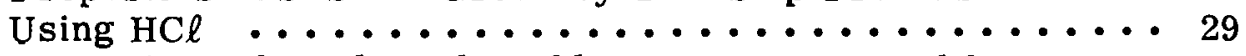

2. 5. 3 Properties of Single and Double Layers Prepared for

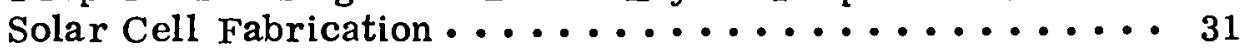

2.5.4 Properties of Very Thick Si Layers ............. 35

2.5.5 Electrical Properties of Polycrystalline CVD Si Films ... 40

2. 6 Task 6. Fabrication and Evaluation of Solar Cell Structures ... 43

2. 6. 1 Solar Cell Processing Procedures ............. 43

2.6.2 Characteristics of Experimental Solar Cells in CVD Si Sheet Material ....................... 44

3. Conclusions and Recommendations .................... 63 


\section{CONTENTS (Cont)}

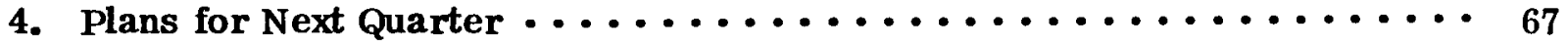

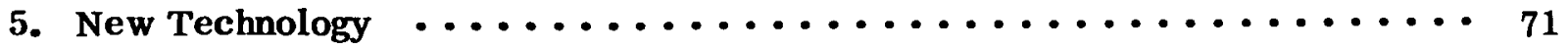

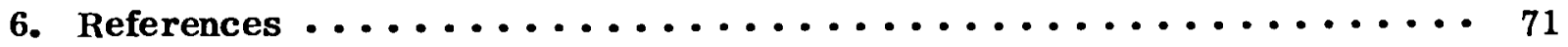
Appendix A. Manpower and Funding Expenditures $\ldots \ldots \ldots \ldots \ldots \ldots \ldots$ Appendix B. Updated Technical Program Plan ................. B-1 


\section{ILLUSTRATIONS}

2-1. SEM Photographs of Surfaces of CVD Si Layers Deposited on Two Different $\mathrm{Pb}$-f ree Ferro Glazes at $\sim 1025^{\circ} \mathrm{C}$ in $\mathrm{H}_{2} \ldots \ldots \ldots . \ldots 8$

2-2. Changes in Si Net Growth Rate Caused by Additions of $\mathrm{HC} \ell$ to $\mathrm{SiH}_{4}$ in $\mathrm{H}_{2}$ at $1025^{\circ} \mathrm{C}$ and in $\mathrm{He}$ at $850^{\circ} \mathrm{C} \ldots \ldots \ldots . . \ldots 10$

2-3. RED Patterns for CVD Si Films Grown on Corning Code 1715 Glass at $\sim 850^{\circ} \mathrm{C}$ in $\mathrm{He}$, in Three Thickness Ranges . . . . . . . . . 19

2-4. RED Patterns for CVD Si Films Grown on Owens-Illinois GS211 Glass at $\sim 850^{\circ} \mathrm{C}$ in $\mathrm{He}$, in Three Thickness Ranges . . . . . . 20

2-5. RED Patterns for CVD Si Films Grown on Owens-Illinois GS213 Glass at $\sim 850^{\circ} \mathrm{C}$ in $\mathrm{He}$, in Three Thickness Ranges .......... 21

2-6. RED Patterns for CVD Si Films Grown on (0112)-oriented Sapphire at $\sim 850^{\circ} \mathrm{C}$ in $\mathrm{He}$, in Three Thickness Ranges. . . . . . . . 22

2-7. RED Patterns for CVD Si Films Grown on Corning Code 1715 Glass at $\sim 950^{\circ} \mathrm{C}$ in $\mathrm{He}$, in Three Thickness Ranges .............. 24

2-8. RED Patterns for CVD Si Films Grown on Owens-Illinois GS211 Glass at $\sim 950^{\circ} \mathrm{C}$ in $\mathrm{He}$, in Three Thickness Ranges ......... 25

2-9. RED Patterns for CVD Si Films Grown on Owens-Illinois GS213 Glass at $\sim 950^{\circ} \mathrm{C}$ in $\mathrm{He}$, in Three Thickness Ranges . . . . . . 26

2-10. RED Patterns for CVD Si Films Grown on (0112)-oriented Sapphire at $\sim 950^{\circ} \mathrm{C}$ in $\mathrm{He}$, in Three Thickness Ranges ........ 27

2-11. Spreading Resistance Probe Scans Showing Calculated Carrier Concentration versus Depth in Three $p / p^{+}$Si Films Grown on Sapphire Substrates at $\sim 1025^{\circ} \mathrm{C}$ in $\mathrm{H}_{2} \ldots \ldots \ldots \ldots \ldots \ldots \ldots$

2-12. Spreading Resistance Probe Scans Showing Calculated Carrier Concentration versus Depth in Three $\mathrm{p} / \mathrm{p}^{+}$Si Films Grown on Single-crystal $\mathrm{Si}$ Substrates at $\sim 1025^{\circ} \mathrm{C}$ in $\mathrm{H}_{2} \ldots \ldots \ldots \ldots$

2-13. Spreading Resistance Probe Scans Showing Resistivity as Function of Distance from Interface for Three Pairs of CVD Si Films Grown Simultaneously on GS2 11 Glass and (0112) Sapphire at $-850^{\circ} \mathrm{C}$ in He, for Diborane Flow Rates of a) $5 \mathrm{ccpm}$, b) $150 \mathrm{ccpm}$,

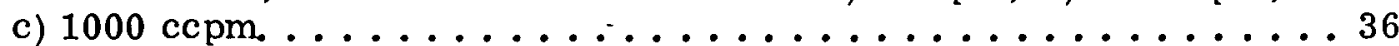

2-14. SEM Photographs of Surface of $85-90 \mu \mathrm{m}$ Thick Doped CVD Si Layer Grown on Polycrystalline Alumina (Vistal) Substrate

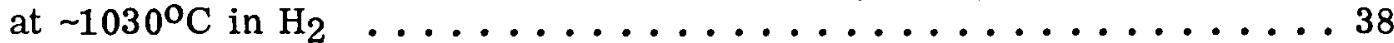

2-15. SEM Photographs of Unpolished Fracture Cross Sections of Sample of Figure 2-14, Showing Rough Surface Texture and a) Si Growth into Voids in Substrate Surface and b) Crack in Layer near Interface . . . . . . . . . . . . . . . . . . . . . 39

2-16. Spreading Resistance Probe Scans Showing Resistivity as Function of Horizontal Displacement Parallel to Interface, at Two Constant Depths in Layer of Figure 2-14.

2-17. SEM Photographs of 75-80 $\mu \mathrm{m}$ Thick Doped CVD Si Layer Grown on (01/2) Sapphire Simultaneously with Sample of

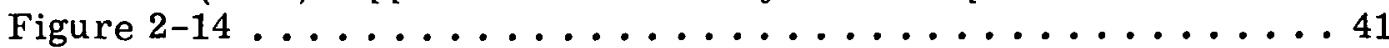

2-18. Dark and Light Forward and Reverse I-V Characteristics for 4 Separate Mesa Devices on Samples Processed Simultaneously

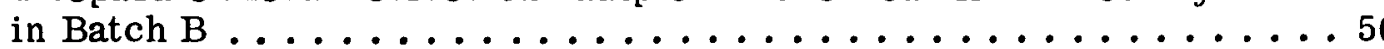




\section{ILLUSTRATIONS (Cont)}

Figure

$\underline{\text { Page }}$

2-19. Relative Photovoltaic Spectral Response for 2 Separate Mesa

Devices on Samples OCLI-35-2, OCLI-27, OCLI-30, and

Single-crystal Si Control Cell

2-20. Fourth Quadrant of I-V Characteristic for Individual Mesa

Devices on Samples OCLI-30, OCLI-27, OCLI-35-2, and

Single-Crystal Si Control, for AMO Solar Simulator

Illumination .......................... 53 


\section{TABLES}

Table

2-1. Properties of B-doped CVD Si Sheet Samples Submitted to OCLI in Fourth Quarter for Solar Cell Processing and Measurement . . . . . . 46

2-2. Photovoltage Response of P-diffused $n / p$ Mesa-type Solar Cells Fabricated in B-doped C.VD Si Sheet Material on Various

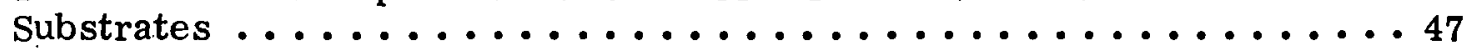

2-3. Photovoltaic Response of P-diffused $n / p$ Mesa-type Solar Cells Fabricated in B-doped CVD Si Sheet Material on Various

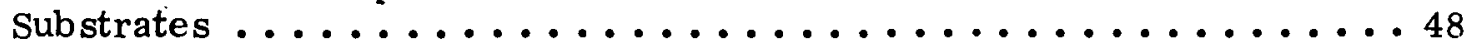

2-4. Minority-carrier Diffusion Lengths $L_{n}$ for $P$-diffused $n / p$ Mesatype Solar Cell Structures in B-doped CVD Si Sheet Material on Various Substrates ........................... . . 52

2-5. Photovoltaic Properties for Individual Mesa Solar Cells in Three CVD Si Sheet Samples and Single-crystal Si Control Sample, from I-V Characteristics of Figure 2-20 (AMO Solar Simulator

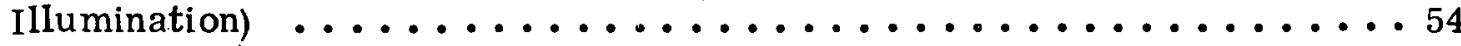

2-6. B-Doped CVD Si sheet Samples Submitted to OC LI During Fifth Quarter for Solar Cell Processing and Measurement .......... . 56

2-7. Photovoltaic Response of P-diffused $n / p$ Full-area Solar Cells Fabricated in B-doped CVD Si Sheet Material on Single-crystal

Si and Sapphire Substrates ......................... 59 


\section{INTRODUCTION}

This contract began 29 December 1975, and is of 18-month duration. This quarterly report covers the three-month period from 1 January through 1 April 1977.

The purpose of the contract is to explore the chemical vapor deposition (CVD) method for the growth of $\mathrm{Si}$ sheet on inexpensive substrate materials. The work is carried out at the Rockwell Electronics Research Center in Anaheim, and also involves some experimental solar cell fabrication and evaluation by the Photoelectronics Group of Optical Coating Laboratory, Inc. (OCLI), in City of Industry, California.

The formal objective of the contract is development of CVD techniques for producing large areas of $\mathrm{Si}$ sheet on inexpensive substrate materials, with sheet properties suitable for fabricating solar cells meeting the technical goals of the Low Cost Silicon Solar Array Project (LCSSAP). The techniques developed are to be directed toward (1) minimum-cost processing, (2) production of sheet having properties adequate to result in cells with terrestrial array efficiency of.10 percent or more, and (3) eventual scale-up to largequantity production.

The CVD method as applied to $\mathrm{Si}$ sheet growth involves pyrolysis or reduction of a suitable Si compound at elevated temperature and (approximately) atmospheric pressure in a flow-through (open-tube) system. A carrier gas is used to transport the reactants to the deposition chamber, in which the substrate is mounted on a sic-coated carbon pedestal heated by $r f$ from outside the chamber. The properties of the $\mathrm{Si}$ sheet are determined by deposition temperature, reactant concentrations, the nature of the carrier gas, the Si source compound used, growth rate, doping impurities (added by introduction of appropriate compounds into the carrier gas stream), and the properties of the substrate.

The specific technical goals established for the contract include the following:

$\begin{array}{ll}\mathrm{Si} \text { sheet area (per sample) } & 30 \mathrm{~cm}^{2} \\ \text { Si sheet deposition rate } & 5 \mu \mathrm{m} \text { per min } \\ \text { Si sheet thickness } & 20 \text { to } 100 \mu \mathrm{m} \\ \text { Si sheet crystal structure } & 100 \mu \mathrm{m} \text { average grain size } \\ \text { Intragrain dislocation density } & <10^{4} \text { per } \mathrm{cm}^{2}\end{array}$

The principal technical problems to be solved are (1) establishing preferred CVD process parameters (temperature, reactant concentrations, carrier gas composition, doping impurities, growth rate) for optimized intragrain properties for the $\mathrm{Si}$ sheet grown on various substrate materials; (2) identifying suitable substrate materials that will survive the environment of the CVD process and be potentially inexpensive and available in large areas, yet be as favorable as possible to $\mathrm{Si}$ grain growth; and (3) achieving adequate grain size in the Si sheet to provide satisfactory solar cell properties. 
Many characteristics of the CVD method indicate that it has considerable promise for achieving the 1986 technical and cost goals of the LCSSAP: (1) it produces only that amount of $\mathrm{Si}$ that is actually required for the photovoltaic effect, without the requirement of additional Si for purely structural reasons; (2) it is a relatively low-temperature process and thus is energy-conservative, not requiring melting of $\mathrm{Si}$ at any stage; (3) it does not require refined/purified polycrystalline si starting material, using instead a high-purity compound of $\mathrm{Si}$ that can be a product of one of the early steps in the preparation of polycrystalline semiconductor-grade $\mathrm{Si}$; (4) it is inherently a large-area process, capable of potential scale-up to areas that are practical for large array fabrication in the LCSSAP; (5) impurity doping for junction formation can be carried out during CVD growth of the Si sheet; (6) thicknesses are closely controllable by reactant flowrate adjustments; and (7) it has the capability for eventual development of a continuous fabrication process, in which the Si material, the junction or barrier, and the required contacts are all fabricated in a single integrated series of operations in one apparatus.

Si sheet growth by CVD on inexpensive substrates will almost certainly be polycrystalline, because such substrates will be either amorphous or microcrystalline and will thus provide little or no ordering influence on the growth mechanism. However, the prospects of at least closely approaching the project goal of 10 percent terrestrial array efficiency are considered good. The chances of obtaining sufficient cost reduction per unit area of active cell surface appear strong enough that a cost-per-watt figure within the project goals should be achievable with this process.

The contract program is composed of six main technical tasks: (1) modification and test of an existing CVD reactor system; (2) identification and/or development of suitable inexpensive substrate materials; (3) experimental investigation of CVD process parameters using various candidate substrate materials; (4) preparation of $\mathrm{Si}$ sheet samples for various special studies, including solar cell fabrication; (5) evaluation of the properties of the Si sheet material produced by the CVD process; and (6) fabrication and evaluation of experimental solar cell structures, using standard and near-standard processing techniques.

The progress achieved during the fifth quarter is described by task in the following section, followed by a summary of conclusions and recommendations and an outline of the work planned for the next three months. This is followed by the New Technology statement and a listing of references used in this report.

The manpower and funding expenditures to date are summarized in Appendix A, and the Updated Technical Program Plan is included as Appendix B. 
This section contains a summary of the results obtained during the fifth quarter in performance of the statement of work of this contract, with interpretation of the results where appropriate. This discussion is arranged by task, although interlocking of the tasks is such that this distinction cannot always be made.

\subsection{TASK 1. MODIFICATION AND TEST OF EXISTING CVD REACTOR SYSTEM}

The principal planned activity on this task was completed in April 1976. Since that time various additional modifications of a minor nature have been made in the apparatus, and these have been described in previous reports.

No major changes were made in the CVD reactor system during the fifth quarter, so the apparatus remains largely as shown schematically in Figure 2-2 of the Annual Report (Ref 1). A minor but significant modification made during the quarter was to remove the mass flow controller (MFC) temporarily from the $\mathrm{SiH}_{4}$ reactant line and to install a micrometer metering valve in that same line. This change is discussed further in section 2.3.2. 


\subsection{TASK 2. IDENTIFICATION/DEVELOPMENT OF SUITABLE SUBSTRATE MATERIALS}

The 1986 cost goals of the ICSSAP are such that single-crystal materials (other than perhaps Si itself) probably cannot be used for the substrate for low-cost large-area Si solar arrays meeting the technical performance goals of the project. Although future developments could alter this outlook, the requirements of this contract are such that other materials far less favorable to $S i$ crystal growth must be considered and evaluated. This was the starting premise in the search for candidate substrate materials.

\subsubsection{Rationale and Procedure for Material Selection}

In identifying candidate substrate materials for CVD growth of $\mathrm{Si}$ sheet which will meet the technical goals of this contract, several considerations are necessary. First of all, the material must be potentially inexpensive. As an absolute upper limit, in today's market as well as in 1986, it must be less expensive than $\mathrm{Si}$ itself for comparable sizes and shapes.

Next, it must be available in relatively large areas - if not now, then at least by 1986. In addition, the properties of the substrate material must be compatible with those of $\mathrm{Si}$. Its linear thermal expansion coefficient (TEC) behavior should duplicate that of $\mathrm{Si}$ as closely as possible, from at least the $\mathrm{Si}$ sheet deposition temperature down to room temperature.

The Si film must also be chemically stable with respect to the substrate surface, so that any transition layer at the interface does not cause separation or other adverse interaction of the two components. The substrate must also be stable relative to the carrier gas and the products of $\mathrm{Si}$ formation - notably, $\mathrm{H}_{2}$ when $\mathrm{SiH}_{4}$ is the source of $\mathrm{Si}$, and $\mathrm{HCl}$ when the $\mathrm{Si}-$ containing halides are used to produce the Si.

Only a few classes of materials now readily available can be considered as candidate substrate materials, based on cost, availability, and reported properties. These include the amorphous glasses, glass-ceramics, and various polycrystalline ceramics. Many glasses are available in large sheet form, and others are potentially susceptible to fabrication into large sheets. It is believed that flat glass substrates could be produced in most cases by techniques well-known in the glass industry if the need were demonstrated. Some glass-ceramics are also now produced in large sheets (the order of square meters), and many low-cost polycrystalline ceramic materials are now available in areas up to about $300 \mathrm{~cm}^{2}$.

A combination of two of the above classes, namely, a glass film produced on a polycrystalline ceramic, i.e., a glazed ceramic, is also considered as a potential substrate for $\mathrm{Si}$ sheet growth. The typical glaze formed on ceramic offers a surface finish better than that which can be achieved on the ceramic itself (in an as-fired condition) without polishing. The glaze tends to fill in the pores of the surface and can be used with a relatively inexpensive non-smooth substrate of purity lower than that which might otherwise be required. 
Although the decrease in viscosity and rapid increase in TEC that occurs for a glass upon increase of its temperature into the annealing range might appear to eliminate it from consideration as a substrate for $\mathrm{Si}$ sheet growth, there have been instances of successful si layer growth on such surfaces in the past (Ref 2). However, because previous studies of polycrystalline Si growth on $\mathrm{SiO}_{2}$ indicate that higher temperatures lead to larger grain sizes (Ref 3), initial experiments with glass substrates in this program have involved those with relatively high softening points.

Once a substrate material has been identified as a candidate for experimental use in this work its surface and internal structural properties are characterized by various analytical methods and it is then used for exploratory $S i$ CVD growth in both $\mathrm{H}_{2}$ and He atmospheres at temperatures consistent with its known properties. A relatively thick $(\geq 20 \mu \mathrm{m}) \mathrm{Si}$ film is usually grown on the candidate material, in the presence of a small wafer of sapphire which serves effectively as a monitor of the particular deposition parameters used as well as an indicator of the stability of the candidate material in the CVD environment.

\subsubsection{Candidate Substrate Materials Recently Received}

Since the second contract-supported trip to visit vendors in August 1976, follow-up contacts have continued with those suppliers that have demonstrated definite interest in having their materials evaluated as potential substrates for the growth of Si sheet for solar cell fabrication. During the fifth quarter the following additional substrate materials have been received for use in this program:

1. Corning Glass: (a) additional samples of polished glass-ceramics Code 9606 and Code 9608, with surface finishes superior to those previously submitted; (b) additional raw glass plates of Code 1715, for subsequent processing by Rockwell into substrates.

2. Owens-Illinois: (2) three billets of experimental glasses $(5 \mathrm{~cm}$ dia. $\mathbf{x}$ $\sim 0.15 \mathrm{~cm}$ thick), designated EE-2, EE-5, and GS238, with average TEC values of $4.2 ; 3.1$, and $3.7 \times 10^{-6}$ per deg $C$, respectively, and annealing points within $25 \mathrm{deg} \mathrm{C}$ of $800^{\circ} \mathrm{C}$; (b) 5 each polished substrates of GS2ll and GS213 glasses.

3. 3M Co: (a) additional wafers of standard aluminas ASM805 and ASM838; (b) wafers of ASM665, a polycrystalline steatite (MgO.SiO ) potentialiy useful because of its lower cost compared with that of the polycrystalline aluminas.

The glass billets from Owens-Illinois and the Corning Code 1715 glass plates have been processed by a Rockwell glass fabricating laboratory into polished substrates about $750 \mu \mathrm{m}$ ( $0.030 \mathrm{in.)}$ thick. Final polishing to a "felt" finish with $\mathrm{CeO}_{2}$ has produced surfaces which appear to be void-free and superior to those previously supplied by either manufacturer. Substrates of the new Owens-Illinois glasses that have been cleaned with a Caro's etch have been compared with those cleaned only with organic solvents; SEM photographs show 
that the surfaces are essentially identical in the two cases, so Caro's etch will continue to be used in the standard substrate cleaning procedure.

Samples of the steatite from 3M Co. are to be polished and will probably be evaluated for compatibility with Si CVD early in the next quarter. Its high TEC value $\left(\sim 8 \times 10^{-6}\right.$ per deg $\left.C\right)$ makes it less attractive than the glasses for $\mathrm{Si}$ film growth, but it may be more stable in $\mathrm{H}_{2}$ at higher temperatures than the glasses and may provide films with larger grains than those found in films grown on the lower-cost aluminas.

Both Owens-Illinois and Corning are currently preparing additional glasses for this program. Owens-Illinois is to prepare higher purity samples of GS2ll and GS213 in billet form for subsequent processing by Rockwell into substrates. The original substrates of GS213 and GS211 are slightly colored, and the impurities in the glass may be the cause of some of the electrical characteristics measured in some of the films grown on these glasses. Corning is also preparing a special glass for this program, identified as corning Code 191CCA. It is to have an annealing point about $25 \mathrm{deg} C$ higher than that of code 1715 glass and a TEC of $-3.6 \times 10^{-6}$ per deg $C$. This glass is more amenable to being drawn into ribbons than is code 1715 .

\subsubsection{Substrate Characterization}

Because the Owens-Illinois glasses EE-2, EE-5, and GS128 only recently became available in usable substrate form evaluation of these materials was initiated late in the quarter. Compatibility with Si CVD growth was examined earlier, however, for the two different glazes prepared by Ferro corporation, Specialty Glass Products Division (Cleveland, $\mathrm{OH}$ ), and received late in the previous quarter. Testing was performed under standard CVD growth conditions and also under high-temperature "fluid" conditions, as described below.

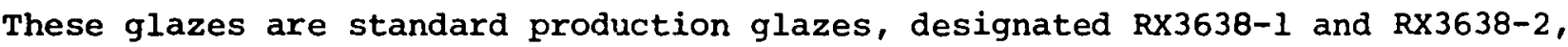
and were prepared by Ferro on several substrates of 97- and 99.5-percent purity polycrystalline alumina substrates supplied by Rockwell. $R \times 3638-1$ is a lead-free, alkali-containing low-temperature-fired glaze with a TEC value of $\sim 7.1 \times 10^{-6}$ per deg $C$, and $\mathrm{RX3638-2}$ is both lead-free and alkali-free, with a TEC of $\sim 7.7 \times 10^{-6}$ per deg $c$. The compositions of these glazes are proprietary with Ferro.

$\mathrm{Si}$ growth in He at $\sim 860^{\circ} \mathrm{C}$ on the alkali-free glaze (No. 2) was adherent, but for growth at $950^{\circ} \mathrm{C}$ in He flaking of the film was evident. Glaze No. 1 (alkali-containing) bubbled when heated to $850^{\circ} \mathrm{C}$ in $\mathrm{He}$, and the bubbles persisted even when the (observed) temperature was increased to $1050^{\circ} \mathrm{C}$. Si growth on the resulting molten surface remained only partially adherent.

However, when $\mathrm{H}_{2}$ was used as the gas atmosphere in an experiment with both glazes in the chamber the surfaces of both remained smooth at $1025^{\circ} \mathrm{C}$; both appeared to be molten. Exposure to $\mathrm{SiH}_{4}$ in $\mathrm{H}_{2}$ at $1025^{\circ} \mathrm{C}$ resulted in partially reflective films at the growth temperature. On cooling, the film on the alkali-containing glaze rippled severely, but the film on the alkali-free 
glaze contained some large crystallites (up to 20pm across). SEM photographs of the film surfaces are shown in Figure 2-1.

A thinner film ( $2 \mu \mathrm{m})$ grown later on glaze No. 2 wrinkled, however, suggesting considerable strain is present in the films grown on both of the glazes. It is not clear if the large crystallites obtained on glaze No. 2 were the result of the influence of the substrate or were caused by possible contaminants in the gas phase. Further experiments with these glazes are planned.

A preliminary evaluation of the three new Owens-Illinois glasses was undertaken at the end of the quarter. In one experiment polished samples of EE-2, $\mathrm{EE}-5$, and GS238 glasses were used (together with a sapphire monitor wafer) for deposition of undoped $\mathrm{Si}$ by pyrolysis of $\mathrm{SiH}_{4}$ (flow rate $\sim 11.5 \mathrm{ccpm}$ ) in He (1.5 lpm) at $\sim 845^{\circ} \mathrm{C}$ (observed) for $30 \mathrm{~min}$, resulting in a layer $\sim 24 \mu \mathrm{m}$ thick on the $\mathrm{Si}$ and corresponding to a growth rate of $\sim 0.8 \mu \mathrm{m} / \mathrm{min}$. The growth progressed well, without incident, and the films on all three glasses appeared to be uniform and clean. There was no evidence of any cross-contamination from the glasses to the sapphire substrate, on which the film appeared to nucleate properly and grow without perturbation. The films are being analyzed and will be described in later reports.

A second deposition experiment was done with these same glasses, this time with the addition of a substrate of GS213 glass to provide a known reference substrate in addition to the customary sapphire. Deposition was done at $\sim 860^{\circ} \mathrm{C}$ (observed) with a lower $\mathrm{SiH}$ flow rate $(\sim 10 \mathrm{ccpm})$ and a He flow rate of $1.5 \mathrm{lpm}$ for $80 \mathrm{~min}$, resulting in a film $\sim 38 \mu \mathrm{m}$ thick on the sapphire (growth rate $\sim 0.5 \mu \mathrm{m} / \mathrm{min}$ ). This run also progressed well, with no evidence of significant contamination or other problems of film nucleation and growth. There was indication of some difference in growth features of the films on two of the glasses (EE-2 and EE-5) near the edges of the substrates, but this may have been the result of thermal gradients or reactant gas flow patterns near the periphery of the sample pedestal. These samples are also being analyzed, and results will be reported subsequently.

\subsubsection{Substrate Surface Preparation}

In the previous Quarterly Report (Ref 4) it was indicated that substrate surface cleaning for glass substrates had been limited mainly to the use of organic solvents, namely trichloroethane, acetone, and Freon, in that order, partly because manufacturers of the glasses suggest that acids and bases not be used in cleaning processes. It is probable, however, that the glass surfaces are contaminated by oils, fingerprints, residual salts from less-thanelectronic-grade water, waxes, and other impurities resulting from the manufacturing and/or polishing procedures used.

Subsequently, as an experiment, part of the standard procedure used for cleaning sapphire substrates was then applied to the glasses being used for Si growth. The cleaning procedure as applied to the glasses involved first the "standard" organic cleaning followed by hot $\mathrm{H}_{2} \mathrm{O}_{2}: \mathrm{H}_{2} \mathrm{SO}_{4}$, hot $\mathrm{HCl}: \mathrm{H}_{2} \mathrm{O}_{2}: 6 \mathrm{H}_{2} \mathrm{O}$, 
and $\mathrm{H}_{2} \mathrm{O}$ rinses. SEM photographs of the glass surfaces indicated no observable differences between the acid-treated surfaces and those only organically cleaned. Thin films of Si grown simultaneously on glass surfaces cleaned both ways also showed no detectable differences in adherence or other gross properties. Therefore, as a precautionary measure, the acid-cleaning method is being used routinely for glasses that have been shown to be stable to the method. As indicated in Section 2.2.1, the three new glasses from OwensIllinois have been found to be stable to the acid treatment.
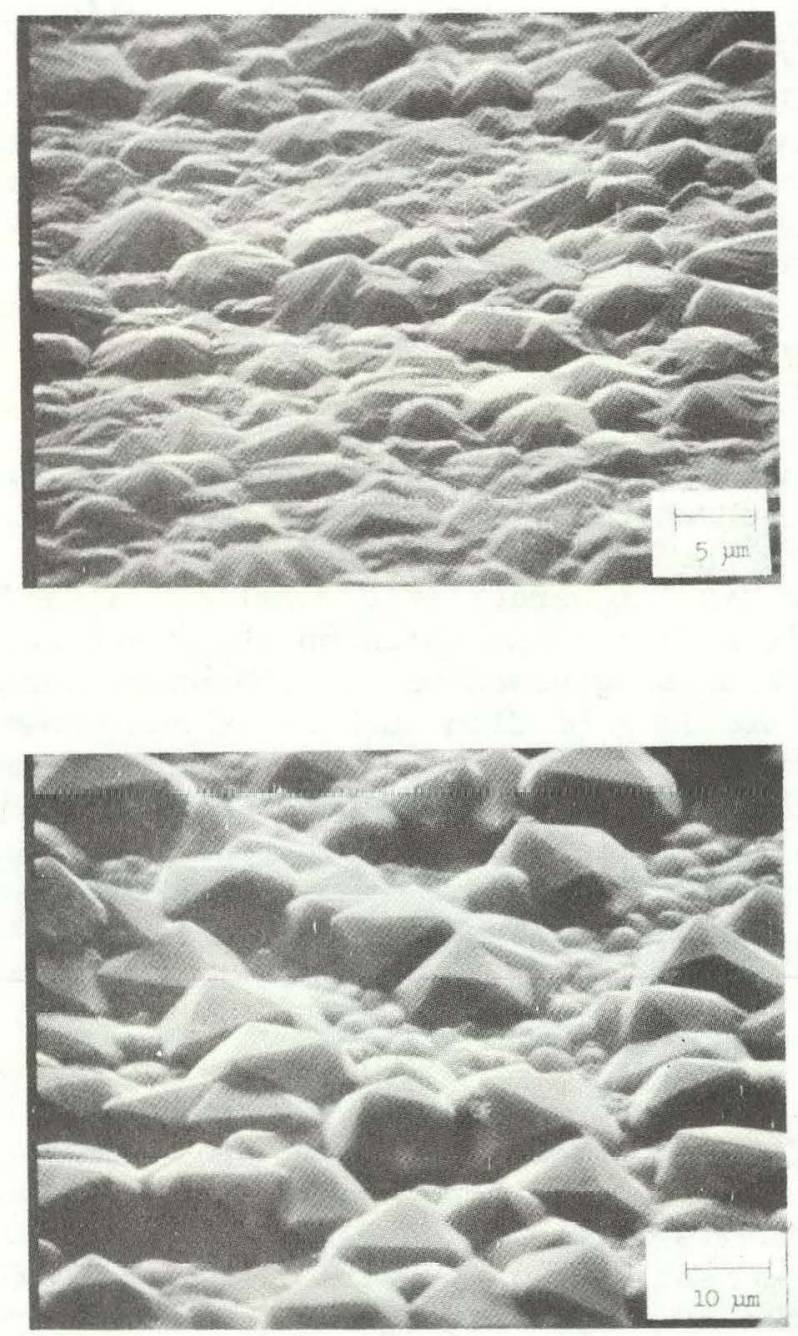

Figure 2-1. SEM Photographs of Surfaces of CVD Si Layers Deposited on Two Different $\mathrm{Pb}$-free Ferro Glazes at $\sim 1025^{\circ} \mathrm{C}$ in $\mathrm{H}_{2}$. a) Film on Glaze Containing Alkali; b) Film on Alkali-free Glaze. 


\subsection{TASK 3. EXPERIMENTAL INVESTIGATION OF Si CVD PROCESS PARAMETERS}

During the fifth quarter $55 \mathrm{Si}$ deposition experiments were performed on this program in the CVD reactor system, many of which were double-layer growth experiments. The studies encompassed (1) evaluation of glasses and glazed substrates, as described in section 2.2 .3 ; (2) determination of Si film crystallographic properties on glasses (and sapphire) as a function of deposition temperature and thickness in three different thickness ranges; (3) determination of the effect of $\mathrm{HCl}$ additions to $\mathrm{SiH}_{4}$ on the properties of $\mathrm{Si}$ films grown by a two-step process at two different deposition temperatures; (4) investigation of the reproducibility of $\mathrm{Si}$ film growth rates when controlled by the mass-flow controller and by the conventional rotameter; and (5) preparation of $\mathrm{p} / \mathrm{p}^{+}$films on substrates of sapphire, single-crystal silicon, and several glasses for solar cell fabrication. The properties of films produced in these various experiments are discussed in section 2.5 .

\subsubsection{Effect of $\mathrm{HCl}$ Additions to $\mathrm{SiH}_{4}$ on $\mathrm{Si}$ Film Growth Rate and Properties}

Si deposition experiments with substrates of Corning Code 1715, Owens-Illinois GS211, and Owens-Illinois GS213 glasses - begun late in the previous quarter were continued early in this quarter. Growth rates for undoped Si films deposited in He were first established for a rotameter reading corresponding to $10 \mathrm{ccpm}$ flow of $\mathrm{SiH}_{4}$ at observed deposition temperatures of $\sim 850$ and $\sim 950^{\circ} \mathrm{C}$ without $\mathrm{HCl}$ in the system. In each experiment a single-crystal sapphire substrate accompanied the same three glasses. At $850^{\circ} \mathrm{C}$ the growth rates of these relatively thin films on the sapphire substrates were $0.3-0.4 \mu \mathrm{m} / \mathrm{min}$ for the above parameters; at $\sim 950^{\circ} \mathrm{C}$ they were $0.12-0.17 \mu \mathrm{m} / \mathrm{min}$. The values at $\sim 850^{\circ} \mathrm{C}$ are slightly higher than the rates observed $(0.2-0.3 \mu \mathrm{m} / \mathrm{min})$ for doped films grown on sapphire substrates in the presence of the same glasses in the earlier series of experiments involving similar deposition parameters (Ref 4, p. 21), but still below the average growth rate of $\sim 0.5 \mu \mathrm{m} / \mathrm{min}$ observed for these deposition parameters when sapphire substrates alone are used.

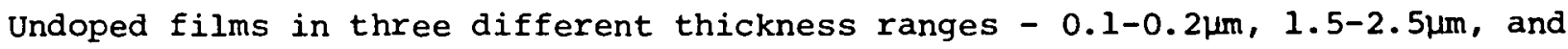
$6-10 \mu \mathrm{m}$ - were then prepared in He at $\sim 850$ and $\sim 950^{\circ} \mathrm{C}$. The polycrystalline films were analyzed by reflection electron diffraction (RED) and $x$-ray diffraction procedures to examine the extent of preferred orientation variation with film thickness and deposition temperature. The results of these deposition experiments, in terms of properties of the films prepared, are discussed in Section 2.5.1.

Experiments were then initiated to establish net $\mathrm{Si}$ growth rates in a He atmosphere in the presence of various concentrations of HCl at growth temperatures typically used for film growth on glasses, i.e., $\sim 850^{\circ} \mathrm{C}$. Sapphire substrates were used for these experiments, which were done in preparation for the subsequent examination of a two-step process for growth of $\mathrm{Si}$ on glasses as a possible means for inducing enlarged grains in the pulycrystalline si 
films. At an $\mathrm{HCl}: \mathrm{SiH}_{4}$ concentration ratio of about 7 to $1^{*}$ the $\mathrm{Si}$ deposition rate and the film etch were essentially offsetting - that is, the net growth rate was approximately zero. At a 5-to-l ratio, Si growth was at only about $1 / 3$ its usual rate at $\sim 850^{\circ} \mathrm{C}$, and at 2.5 to 1 , the $\mathrm{Si}$ growth rate was about $2 / 3$ its value in the absence of $\mathrm{HCl}$. Since RED examination of the films grown on these glasses at $\sim 950^{\circ} \mathrm{C}$ had shown them to be inferior structurally to those grown at $\sim 850^{\circ} \mathrm{C}$ (see Section 2.5.1) no $\mathrm{HCl}$ etch-rate information was sought at the higher temperature. The results of these studies are shown in Figure 2-2, which also includes data previously reported (Ref 1, Figure 2-48) for net $\mathrm{Si}$ growth rates in $\mathrm{H}_{2}$ atmospheres, for two different $\mathrm{SiH}_{4}$ flow rates, at $1025^{\circ} \mathrm{C}$.

The two-step Si film growth process that was tested is one involving first the growth of $\mathrm{Si}$ from $\mathrm{SiH}_{4}$ followed by $\mathrm{Si}$ growth from $\mathrm{SiH}$-HCl mixtures. The conditions of the two-step growth experiments were designed to produce films with final thicknesses in the same three ranges as those grown on glass without

*The $\mathrm{HCl}: \mathrm{SiH}_{4}$ flow rate ratios given in the text are in some doubt because it has been found that a discrepancy exists between data provided by Matheson Gas products for HCl flow rates in a Brooks glass rotameter and data provided by Brooks for the same type of rotameter. One set of values is about three times larger than the other. Representatives of Matheson say their charts represent actual measured flow rates; Brooks personnel indicate that their data are based on known physical properties of HCl and calculated results. Rotameter calibrations are obviously required and will be done at a later date.

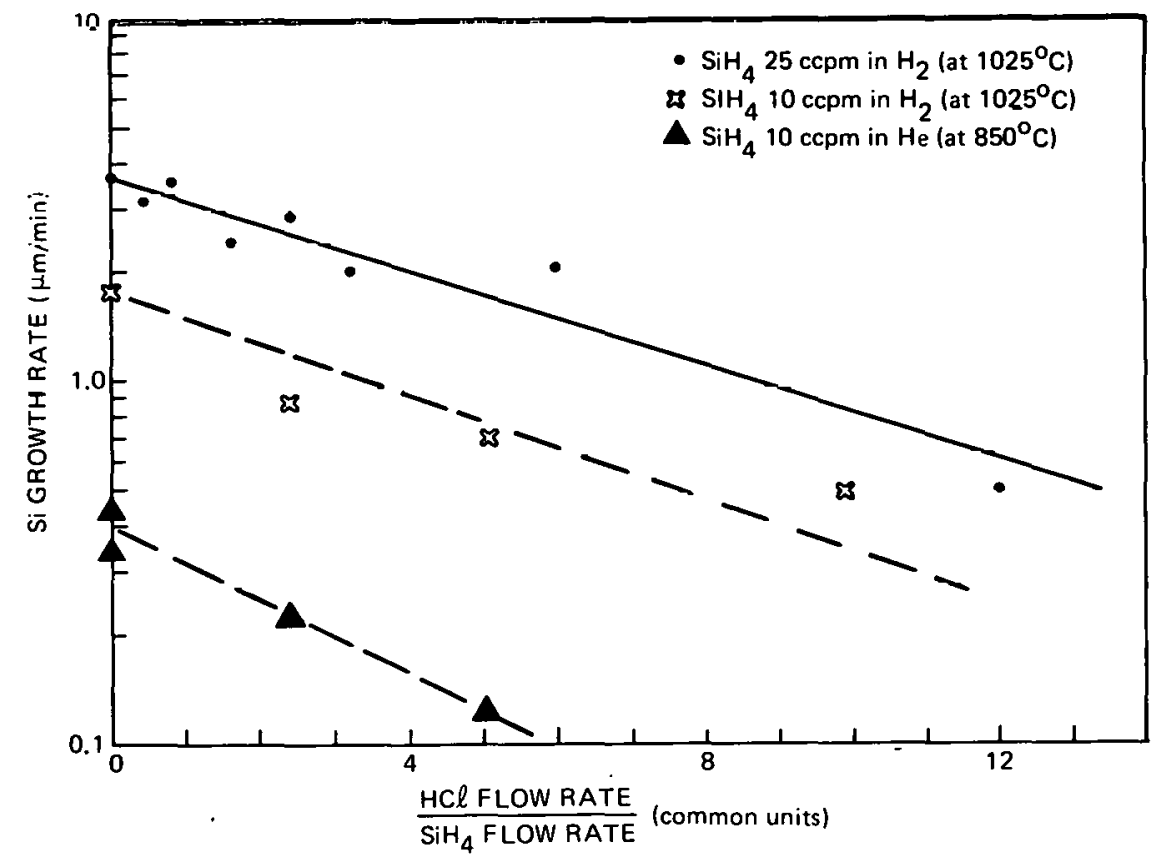

Figure 2-2. Changes in $\mathrm{Si}$ Net Growth Rate Caused by Additions of $\mathrm{HCl}$ to $\mathrm{SiH}_{4}$ in $\mathrm{H}_{2}$ at $1025^{\circ} \mathrm{C}$ and in $\mathrm{He}$ at $850^{\circ} \mathrm{C}$ 
HCl (and referred to above), so that structural comparisons could be made. Two HCl flow rates were chosen for the second step in order to produce two different net growth rates during the second growth step for achieving the same total (two-layer) thickness. Initial (first-step) layers $\sim 0.15$ and $\sim 1.5 \mu \mathrm{m}$ thick, grown without the presence of $\mathrm{HCl}$, were used for the experiments. properties of the resulting films are discussed in section 2.5.2 (Task 5).

The conclusion of the series of experiments, however, is that there is no improvement in either overall film quality or average grain size in those films prepared by this particular two-step process relative to those same properties in films of comparable thickness grown in a single step without $\mathrm{HCl}$. Subsequent experiments are planned, however, in which the etching effects of $\mathrm{HCl}$ vapor on partial-coverage Si films (i.e., films consisting of separate islands of various sizes, not yet fully coalesced into a continuous layer) will be investigated, to determine if such attack will result in an increased proportion of larger islands to serve as nuclei for further growth of the layer.

Prior to the two-step growth experiments with HCl the three glasses of primary interest - and those that were to be used in the two-step experiments - were exposed (together with a sapphire wafer) simultaneously to HCl vapor in a He atmosphere at $850^{\circ} \mathrm{C}$ for $30 \mathrm{~min}$ without introduction of $\mathrm{SiH}^{\circ}$. The HCl flow was estimated to be about $70 \mathrm{ccpm}$, which is higher than that used in the twostep experiments $(\sim 13 \mathrm{ccpm}$ and $\sim 50 \mathrm{ccpm})$. No attack was evident on the glasses when viewed at low and high magnification in the scanning electron microscope (SEM), but the surface of the sapphire appeared coated or etched after the exposure, having lost its reflective surface. This suggests that the gaseous $\mathrm{hCl}$ might be a useful surface cleaning agent for glasses before Si growth by CVD.

\subsubsection{Control of Si Film Growth Rates}

Previous reports on this contract have contained references to various problems with the performance of the mass flow controller (MFC) in use in the 100percent $\mathrm{SiH}_{4}$ gas line, particularly with regard to the occasional lack of correlation between $\mathrm{SiH}_{4}$ flow rates determined by the MFC and those indicated simultaneously by a glass rotameter in series with the MFC in the same line.

At one time these differences were associated with back-pressure in the system caused by a partially clogged filter in the $\mathrm{SiH}_{4}$ line, downstream from both the MFC and the rotameter. Removal of the filter, however, was only a temporary solution; the MFC readings subsequently changed again for a constant setting of the flow rate on the rotameter. Because of the necessity for reproducible growth rates in these investigations, several experiments were carried out to determine which was more reliable for such control, the MFC or the glass rotameter.

For a series of undoped $\mathrm{Si}$ depositions on sapphire at $\sim 1025^{\circ} \mathrm{C}$ (observed) with $\mathrm{H}_{2}$ flow rates of $1.5 \mathrm{lpm}$, a rotameter scale setting of 1.4 in each experiment resulted in MFC readings for successive deposition runs of 16.0, 16.0, 17.3, 
18.0, 17.4 and $16.5 \mathrm{ccpm}$.* Corresponding average film growth rates on sapphire were $1.76,1.80,1.89,1.98,1.88$ and $1.93 \mu \mathrm{m} / \mathrm{min}$, respectively. Except in the last case, the observed growth rates vary consistently with the observed MFC readings of $\mathrm{SiH}_{4}$ flow rate. On the other hand, the results may simply represent the overall reproducibility of the present system used in the particular mode in which the rotameter setting accuracy determines flow rate reproducibility. The \pm 6 percent variation in measured thickness (i.e., growth rate) is probably acceptable for the growth of thick films having relatively rough surfaces, under these conditions of flow rate control.

Experiments were next initiated to examine growth rate reproducibility with a constant MFC setting of $10 \mathrm{ccpm}$ with the MFC controlling*t $\mathrm{SiH}_{4}$ flow rate and observations made of the rotameter readings. In a series of five depositions using, the same parameters as indicated above, the rotameter scale readings were $0 \pm 0.1^{\dagger}$ and consecutive growth rates of $0.84,0.89$ and $0.93 \mu \mathrm{m} / \mathrm{min}$ were obtained for undoped films and 0.95 and $0.82 \mu \mathrm{m} / \mathrm{min}$ for films doped at low $\left(\sim 10^{17} \mathrm{~cm}^{-3}\right)$ and high $\left(>10^{19} \mathrm{~cm}^{-3}\right)$ levels, respectively, with $\mathrm{B}$ from $\mathrm{B}_{2} \mathrm{H}_{6}$. The spread in these growth rate values $( \pm 7$ percent) is similar to that found for constant rotameter settings. It thus appears that both devices permit reproducible growth rates when used individually as the means for setting the $\mathrm{SiH}_{4}$ flow rate, even though the actual SiH4 mass flow rate is subject to calibration in both instances.

It should be noted that the observed growth rate in the second series of experiments was just about half of that obtained in the first series. The fact that the MFC failed to produce readings consistent with that observed relationship emphasized the need for recalibration of both devices. Because of the previously encountered problem of periodic buildup of white powder $\left(\mathrm{SiO}_{2}\right)$ in the MFC it was removed from the system and a micrometer metering valve was installed just ahead of the rotameter, to provide means for $\mathrm{SiH}_{4}$ flow rate adjustment pending recalibration of the MFC and the rotameter.

\subsubsection{Determination of Preferred CVD Parameters for Solar Cell Structures}

The results obtained to date with solar cell structures fabricated in CVD Si sheet prepared in this contract have fallen short of expectations (Refs 1,4$)$. Experimental cells have been fabricated in polycrystalline si films on substrates of polycrystalline aluminas and several different glasses, as well as in epitaxial Si grown on single-crystal sapphire (see Section 2.6, Task 6). With every group of $\mathrm{Si}$ sheet samples that has been processed into solar cells by OCLI there have been control wafers of high-lifetime single-crystal $\mathrm{si}$ of

*This rotameter setting corresponds to a 100-Dercent. siH 4 flow rato of 10 copm, based on earlier calibration of a similar (i.e., same model) rotameter at Rockwell. Note, however, that the MFC was controlling flow during these runs.

**Specifications of the manufacturer (Tylan Corp., Torrance, CA) on the MFC include the following: controller will maintain preset mass flow to within \pm 0.25 percent of setting when pressure differential is between 5 and 40 psi; repeatability is \pm 0.2 percent of full scale; accuracy of indication is \pm 1 percent of full scale.

$\dagger_{A}$ rotameter scale reading of 0 corresponds to a $\mathrm{SiH}_{4}$ flow rate of $\sim 5 \mathrm{ccpm}$. 
2-3 ohm-cm resistivity processed simultarieously to provide an indication of the general success of the processing sequence as well as a standard against which to compare the performance of the Si sheet devices. In some instances the photovoltaic performance of the devices in the control slices has also been short of expectations, and appropriate allowances have thus been made for characteristics of the cells in the sheet material.

Evaluation of such a group of solar cell structures fabricated in B-doped CVD Si films on glass, polycrystalline alumina and single-crystal sapphire was completed early in the quarter. $V_{O C}$ values for the epitaxial films on sapphire compared favorably with those of simultaneously processed single-crystal control wafers, but those for the polycrystalline films were much lower. Photogenerated currents for these film samples (including the epitaxial films) were quite low, however, resulting in poor conversion efficiencies. Spectral response measurements indicated short minority carrier diffusion lengths in the range $1-5 \mu \mathrm{m}$. Best results were obtained in cells fabricated in composite $\mathrm{p} / \mathrm{p}^{+} \mathrm{CVD}$ layers; curve fill factors up to 0.65 and a high degree of uniformity in properties were observed for mesa cells in epitaxial material on sapphire. (Additional details are given in Section 2.6.2.)

On the basis of these results a group of deposition experiments was undertaken to prepare a variety of $\mathrm{Si}$ sheet samples--some with uniform p-type layers and some with composite $\mathrm{p} / \mathrm{p}^{+}$layers in three different ratios of thickness of the $p$ and $\mathrm{p}^{+}$regions--for subsequent fabrication of cell structures. The experiments were designed to provide a range of sample properties that would--when photovoltaic characteristics were obtained on the resulting devices--help to clarify some of the technical questions raised by the earlier results mentioned above. The experiments carried out include the following: (1) verification of B-doping curve as a function of diborane (46 ppm $\mathrm{B}_{2} \mathrm{H}_{6}$ in $\mathrm{He}$ ) flow rate for $\mathrm{Si}$ films deposited by pyrolysis of $\mathrm{SiH}_{4}$ (flow rate $10 \mathrm{ccpm}$ ) at $1025^{\circ} \mathrm{C}$ in $\mathrm{H}_{2}$ (flow rate 1.5 lpm), by determination of carrier concentrations in epitaxial films grown on sapphire substrates; (2) preparation of uniformly doped p-type epitaxial si films with carrier concentrations in $10^{17}-10^{18} \mathrm{~cm}^{-3}$ range on p-type single-crystal $\mathrm{Si}$ substrate wafers of solar cell quality (i.e., 2-3 ohm$\mathrm{cm}$ resistivity and carrier diffusion lengths of $\sim 100 \mu \mathrm{m})$ and on higher resistivity ( $>10 \mathrm{ohm}-\mathrm{cm}$ ) p-type single-crystal $\mathrm{Si}$ wafers of good device quality, for solar cell fabrication; (3) preparation of epitaxial double-layer $\mathrm{p} / \mathrm{p}^{+} \mathrm{si}$ sheet samples on sapphire substrates at $1025^{\circ} \mathrm{C}$, with carriex concentrations in the $10^{18}$ and $10^{19} \mathrm{~cm}^{-3}$ ranges, respectively, and thickness ratios $t_{p} / t_{p^{+}}$of $1: 3,1: 1$, and $3: 1$, to evaluate effect of proximity of $\mathrm{p}^{+}$region to the device junction on the photovoltaic performance of the experimental cell formed by diffusion processing; (4) preparation of similar double-jayer $\mathrm{p} / \mathrm{p}^{+}$structures on singlecrystal Si wafers of the two types used in (2) above, for solar cell fabrication; (5) determination of additional data for $B$ doping of Si films deposited by $\mathrm{SiH}_{4}$ pyrolysis in He at $\sim 850^{\circ} \mathrm{C}$ as a function of $\mathrm{B}_{2} \mathrm{H}_{6}$ flow rate, by measurement of carrier concentrations in films grown on sapphire substrates; and (6) proparation of uniformly doped p-tyne polycrystalline si films with carrier concentrations in the $1017-10^{18} \mathrm{~cm}^{-3}$ range on several different glasses, for solar cell processing. 
Some difficulties were encountered in the first attempts to obtain good B-doped Si film growth on the p-type single-crystal Si substrate wafers (resistivity 2-3 ohm-cm) obtained from OCLI for these experiments. These wafers were (100)oriented solar cell blanks $(2 \mathrm{~cm} \times 2 \mathrm{~cm})$ that had been optically polished by standard procedures at OCLI. However, the first Si films deposited on these substrates were of very poor quality; it appeared that the substrate surfaces were not adequately cleaned for use in epitaxy. This was confirmed in several experiments in which clean uncontaminated $\mathrm{Si}$ films were grown simultaneously on companion substrates of (100)-oriented $10 \mathrm{ohm}-\mathrm{cm}$ p-type Si obtained from Rockwell supplies. Various cleaning procedures were used in attempting to produce an adequately clean surface on the solar cell blanks, but none was found to accomplish this.

A second group of similar wafers was then obtained from OCLI, and those appeared to be relatively free of the persistent contaminant.* Epitaxial p-type films with measured carrier concentrations from $10^{17}$ to $>5 \times 10^{19} \mathrm{~cm}^{-3}$ were then grown on substrates of both resistivities.

Because of the observed improvement in photovoltaic performance of earlier samples consisting of deposited $\mathrm{p} / \mathrm{p}^{+}$composite films on sapphire substrates, several sets of such double-layer samples were prepared on Si substrates of both resistivities as well as on sapphire. Since the extent of the influence of a $\mathrm{p}^{+}$gettering layer on the carrier lifetime (and thus diffusion length) in an adjoining p-type $\mathrm{Si}$ layer is not known quantitatively these double layers were prepared with total thicknesses of $15-2 q \mu \mathrm{m}$ and with the bottom $\left(\mathrm{p}^{+}\right)$ layer $\sim 4 \mu \mathrm{m}, \sim 8 \mu \mathrm{m}$, and $\sim 12 \mu \mathrm{m}$ thick, placing the gettering layer respectively $\sim 12 \mu \mathrm{m}, \sim 8 \mu \mathrm{m}$, and $\sim 4 \mu \mathrm{m}$ from the location of the $\mathrm{p}-\mathrm{n}$ junction to be formed subsequently by diffusion of $P$ into the $p$-type upper layer. Carrier concentrations in the p-type reqion were intended to be in the $10^{17}-10^{18} \mathrm{~cm}^{-3}$ range and those in the $\mathrm{p}^{+}$gettering layer were doped in excess of $10^{19} \mathrm{~cm}^{-3}$. Evaluation of these composite structures after deposition, however, indicated that the doping level in the upper ( $p$-type) region in many of the samples was higher than intended, i.e., greater than $10^{18} \mathrm{~cm}^{-3}$. The properties of these films and photovoltaic characteristics of some of the device structures fabricated in them are discussed in Sections 2.5.3 and 2.6.2.

Some additional data on the available carrier concentration in B-doped films grown by $\mathrm{SiH}_{4}$ pyrolysis in He at $\sim 850^{\circ} \mathrm{C}$ was obtained as a function of the diborane flow rate, prior to preparation of p-type polycrystalline films on glasses for solar cell fabrication. This doping data was obtained by making electrical measurements on films deposited on sapphire substrates. X-ray diffraction analysis of several of the films (see section 2.5.3) showed that highly oriented structure (i.e., essentially single-crystal epitaxial growth) was obtained under the growth conditions employed. Thus, the measured carrier concentrations in these films should be closely representative of the

\footnotetext{
*Although not definitely established as the cause of the observed contaminant, it appeared that the individual plastic bags used for transfer of the first group of wafers to Rockwell may have been responsible for the cleaning problem.
} 
maximum carrier concentration (i.e., the impurity doping concentration) available for a given $\mathrm{B}_{2} \mathrm{H}_{6}$-in-He dopant flow rate. As would be expected, a significantly lower degree of $B$ incorporation in the si films is obtained for a given dopant flow rate for growth at $\sim 850^{\circ} \mathrm{C}$ in He than for growth at $\sim 1025^{\circ} \mathrm{C}$ in $\mathrm{H}_{2}$.

Based on these doping data several samples of uniformly doped p-type polycrystalline Si sheet were prepared on substrates of corning code 1715, OwensIIlinois GS213, and Owens-Illinois GS211 glasses, along with the usual companion sapphire substrate in each run. These films were deposited at $\sim 850^{\circ} \mathrm{C}$ in He $(1.5 \mathrm{lpm})$, with a $\mathrm{SiH}_{4}$ flow rate of $\sim 11.5 \mathrm{ccpm}$ (as indicated by the rotameter) and diborane flow rates ranging from 5 to $1000 \mathrm{ccpm}$. Observed film growth rates on the sapphire substrates were in the range $0.3-0.4 \mu \mathrm{m} / \mathrm{min}$, whereas the growth rates obtained on sapphire in the preceding set of doping concentration experiments (see above) under essentially the same deposition conditions but without the glasses present were in the range $0.5-0.7 \mu \mathrm{m} / \mathrm{min}$. This result is consistent with previously reported (Ref 4) observations about film growth rates for the $\mathrm{SiH}_{4}$ pyrolysis process in the presence of certain glasses.

The doping experiments had given evidence that diborane flow rates above about $300 \mathrm{ccpm}$ failed to increase significantly the available carrier concentration in films grown in He at $\sim 850^{\circ} \mathrm{C}$ on sapphire substrates, using the $46 \mathrm{ppm} \mathrm{B}{ }^{\mathrm{H}}{ }^{-i n-H e}$ source that has been employed in all of the doping experiments to date on this program. This indicated either that a saturation concentration of the Si film with $B$ had been reached in the vicinity of $10^{18} \mathrm{~cm}^{-3}$, or that the concentration of $\mathrm{B}_{2} \mathrm{H}_{6}$ in the dopant source tank was insufficient to produce a higher B concentration in the Si film for the other parameters (especially SiH flow rate and carrier gas flow rate) being used. Because of the need for producing experimental $\mathrm{p} / \mathrm{p}^{+}$structures in polycrystalline films on glasses (and other substrates), a new source tank of $\mathrm{B}_{2} \mathrm{H}_{6}$ in a concentration of $1500 \mathrm{ppm}$ in six-9's-purity He was ordered (from Precision Gas Products, Inc.) for subsequent use on this program.

The experiments to prepare uniformly doped p-type si sheet on glass substrates also indicated a similar upper limit on the achievable carrier concentration in the companion films grown on sapphire. Also, as in results described in the last quarterly report (Ref 4, pp.28-3u), the measured carrier concentrations in the poiycrystalline films on the glasses tended to be larger than those in the simultaneously grown films on single-crystal sapphire. This has been suggested as evidence that an impurity from one of the glasses has adversely affected the Si nucleation and/or growth process on the sapphire substrate and perhaps also the growth process, as well as the effective dopant concentration, in the films on the glasses. Composition analyses soon to be performed on several of the glass substrates currently being used in this work may provide some indication of possible causes of these effects.

\subsubsection{Growth of Very Thick Si sheet by CVID}

A series of experiments was begun late in the quarter to grow very thick $(80-100 \mu \mathrm{m}) \mathrm{Si}$ sheet by CVD on various substrates, to examine the structural and electrical properties of such films and to examine some of the problems 
that will probably be encountered in preparing CVD films of the required thickness for adequate absorption of the usable solar spectrum (see Section 1, Introduction).

One of the principal matters of interest in this regard is to determine the extent to which grain sizes in polycrystalline films grown by the CVD process increase with thickness. Various indications have been found in this program that this does, in fact, occur - at least on some substrates. It is important to ascertain if this is a generally occurring phenomenon or one that takes place only on certain substrate materials.

A second important aspect of thick film growth on dissimilar substrate materials is the extent to which physical distortion of the film-substrate composite occurs after deposition and cooling to room temperature, as a result of thermal contraction differences between the two materials. This distortion most often takes the form of bowing or buckling of the composite, with the deposited film in tension or compression depending upon the algebraic sign of the difference in thermal expansion coefficient (TRC) values for the two materials (Ref 4, Section 2.2.1 and Figure 2-1). In more extreme cases the differences in thermal contraction behavior result in locally severe stresses that cause the film to separate from the substrate, either intact or in small pieces, or to remain bonded to the substrate and cause small sections of the substrate material to break away from the main portion.

The first of this series of experiments involved deposition of B-doped Si simultaneously on substrates of polished vistal polycrystalline alumina and polished single-crystal (01̄̄2)-oriented sapphire. The films were grown by $\mathrm{SiH}_{4}$ pyrolysis at $\sim 1030^{\circ} \mathrm{C}$ (observed) in He $(1.5 \mathrm{lpm})$, with the SiH flow rate $\sim 10 \mathrm{ccpm}$ and the diborane flow rate $6 \mathrm{ccpm}$. Both substrates were subjected to the usual predeposition treatment of "baking" at $1250^{\circ} \mathrm{C}$ in $\mathrm{H}_{2}(1.5 \mathrm{lpm})$ for $15 \mathrm{~min}$. Deposition for $100 \mathrm{~min}$ resulted in a relatively smooth layer 75-80 $\mathrm{mm}$ thick on the sapphire and a strongly faceted and relatively rough layer 85-90 $\mathrm{mm}$ thick on the vistal, corresponding to average growth rates of $\sim 0.8$ and $\sim 0.9 \mu \mathrm{m} / \mathrm{min}$, respectively.

The Si/sapphire composite was only very slightly bowed, while the Si/Vistal composite was extensively bowed, convex upward as would be expected for the relative magnitude of the TEC values for $\mathrm{Si}$ and alumina. (Quantitative measurement of the amount of distortion has not been undertaken.) In addition, considerable crazing of the Si-alumina interface was visible through the transparent Vistal substrate; the basic "cell" or module in the crazing pattern appeared to embrace numerous crystal grains rather than single grains.

Various regions of the Si layer on the Vistal substrate appeared to be epitaxial, corresponding to individual substrate grains crystallographically favorable for epitaxial growth, similar to the characteristics of $\mathrm{Si}$ films grown on various vistal substrates earlier in the program. The film on sapphire appeared somewhat "overgrown" but exhibited the outward appearance of an epitaxial (100)-oriented Si film, as expected. Additional properties of these Si films are discussed in Section 2.5.4. 


\subsection{TASK 4. PREPARATION OF Si SHEET SAMPLES}

The work of this task is entirely in support of the activities of Tasks 3, 5, and 6. It consists primarily of the preparation of individual samples or groups of samples of CVD Si on various substrates, utilizing established deposition procedures. These samples are intended for use in film characterization studies (Task 5), to examine the variation in si properties with systematic deposition parameter variations (Task 3), or for use in fabrication of exploratory solar cell structures at OCLI (Task 6). Occasionally, special samples of a non-routine nature are prepared which do not require extensive evaluation; such work is also a part of this task. Preparation of samples strictly for demonstration purposes or exclusively for delivery to JPL is also considered part of this task.

Of over $260 \mathrm{Si}$ CVD experiments done in the reactor system during the first 15 months, at most about 40 have utilized standard procedures strictly for preparation of samples for analysis, processing, demonstration, or delivery to JPL. All other experiments have been exploratory in nature.

During the past quarter a large group of single- and double-layer si sheet samples was prepared for use in fabricating solar cell structures at OCLI. Substrates of single-crystal Si, single-crystal sapphire, and several different glasses were used in these experiments, as described in Section 2.3.3. Sixteen of the deposition experiments done in the past quarter (many of them involving two consecutive depositions, consisting of $\mathrm{p}^{+}$followed by $\mathrm{p}$ material) were devoted to preparation of these samples.

There were no samples delivered to JPL during the past quarter. However, several solar cell samples from the group of cells characterized early in the quarter (see section 2.6) have been identified for delivery to the JPL Technical Manager early in the coming quarter. 


\subsection{TASK 5. EVALdATION OF Si SHEET MATERIAL PROPERTIES}

As indicated in Section 2.3 the emphasis of the past quarter's CVD experiments has been on determination of Si film crystallographic properties on glasses and sapphire as a function of deposition temperature and thickness in three different thickness ranges, determination of the effect of HCl additions to SiH on the properties of Si films grown by a two-step process at two different deposition temperatures, and preparation of $p / p^{+}$films on substrates of sapphire, single-crystal $\mathrm{Si}$, and several glasses for solar cell fabrication. The properties of films produced in these experiments have been evaluated by reflection electron diffraction (RED) analysis, scanning electron microscope (SEM) examination, x-ray diffraction analysis, and measurement of electrical properties by the van der Pauw method and by spreading resistance probe measurements. Properties of photovoltaic structures fabricated in some of the sheet samples are discussed in Section 2.6.

\subsubsection{Crystallographic Properties of Si Sheet Grown by SiH Pyrolysis in He}

Previous results obtained with polycrystalline si films deposited on Corning Code 1715 glass in this program have indicated that variations in preferred orientation occur both with film thickness and with deposition temperature. Studies of polycrystalline Si on other amorphous substrate materials by other investigators (Refs 5,6) have given similar results. To investigate this dependence further, because of its possible influence on the photovoltaic properties of the polycrystalline films, two groups of undoped film samples were prepared, one deposited at $\sim 850^{\circ} \mathrm{C}$ and one at $\sim 950^{\circ} \mathrm{C}$ (both in He), each

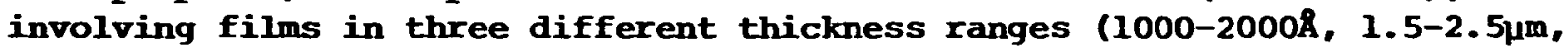
and 6-10 (m) . RED analysis was then used in the evaluation of the properties of these films. Substrates of Corning Code 17.15, Owens-Tlininois GSpl1, and Owens-I11inois GS213 glasses and single-crystal (0112)-oriented sapphire were used. The specific objective was to determine if any differences in preferred orientation could be detected among films grown at a given temperature in the three thickness ranges or between films of similar thickness grown at the two different temperatures.

The RED patterns obtained for the three thicknesses of films grown at $\sim 850^{\circ} \mathrm{C}$ in He are shown in Figures 2-3 through 2-6 for films on substrates of 1715 , GS211, and GS213 glasses and single-crystal sapphire, respectively There is evidence of preferred orientation in the thinnest film and more strongly preferred orientation in the thicker films, for the case of all three glass substrates.

The thinnest films (0.1-0.2 $\mu \mathrm{m})$ on all three glasses exhibited surprisingly good structural quality, with the degree of preferred orientation in the films on GS211 and GS213 glasses significantly greater than in the film on 1715 glass (Figures 2-4a, 2-5a, 2-3a, respectively). The latter showed only slight evidence of any preferred orientation. Thicker films $(\sim 1.6 \mu \mathrm{m})$ were structurally better in all three polycrystalline cases (Figures 2-3b, 2-4b, 2-5b), the increase in preferred orientation being most noticeable in the film on 1715 glass; the two films were structurally similar on the other two glasses, that 


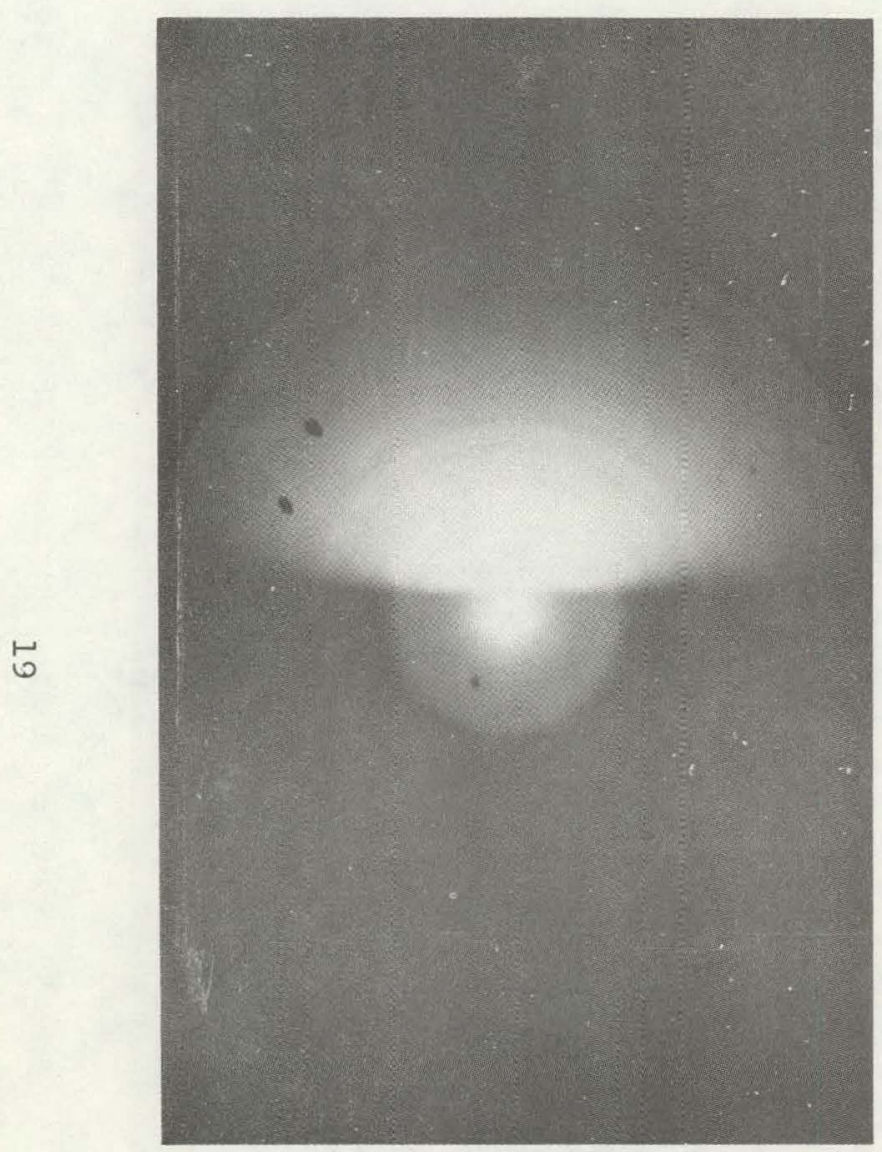

(a)

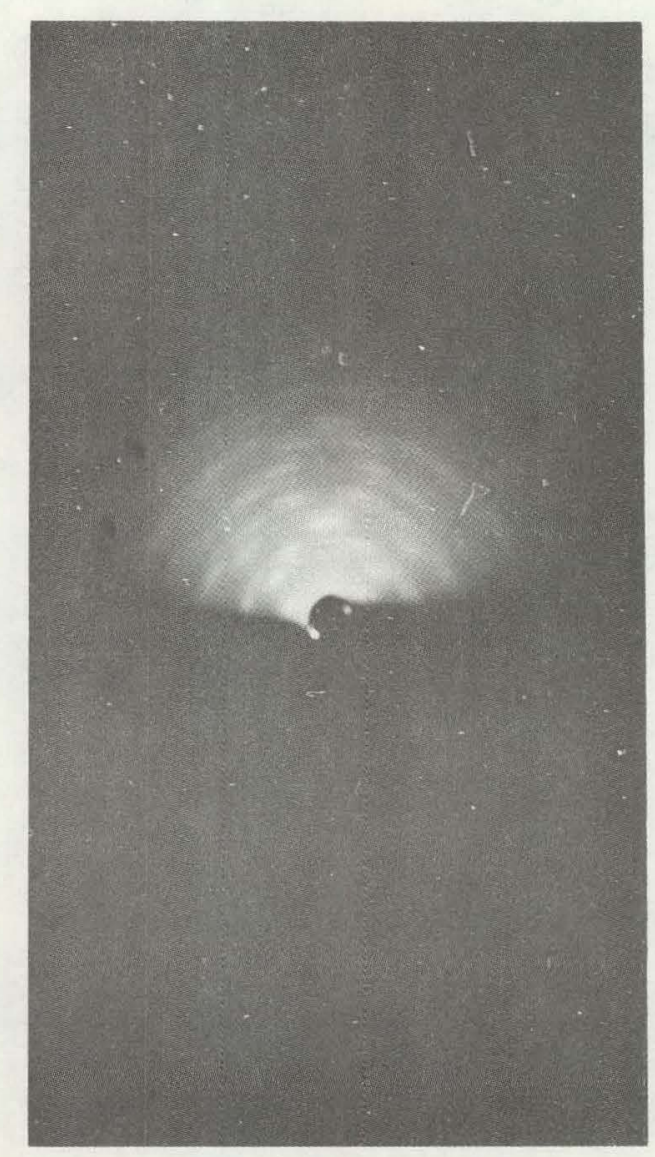

(b)

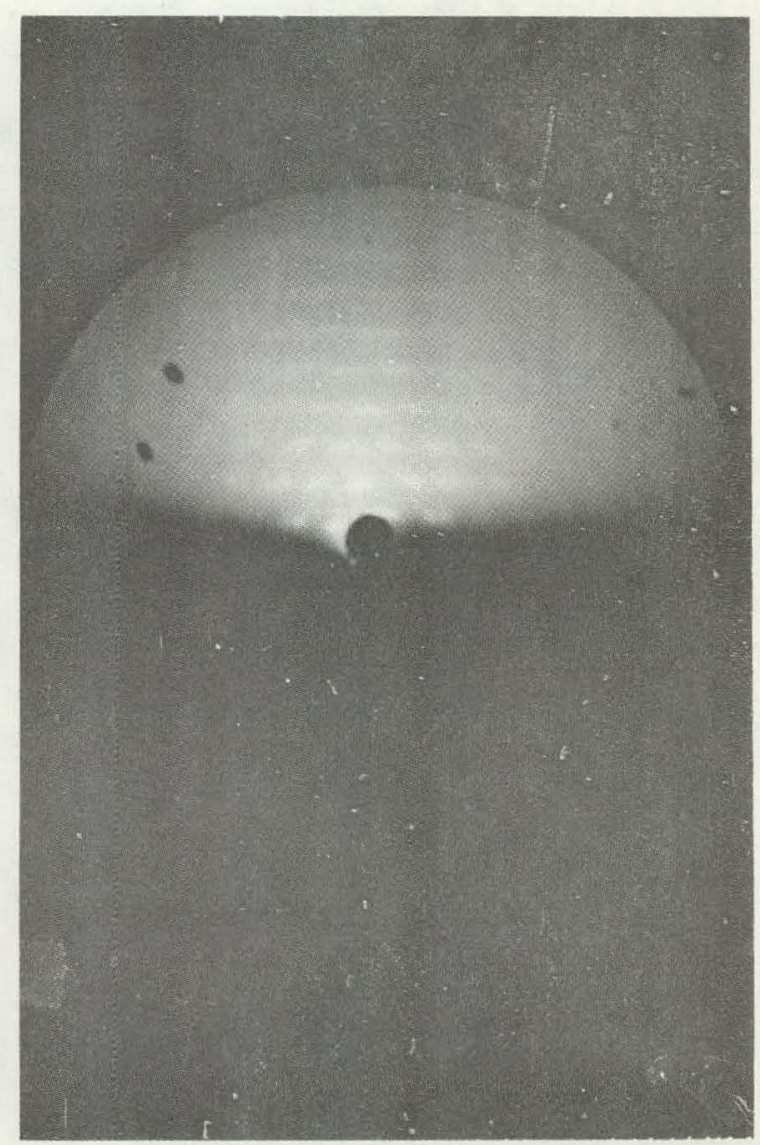

(c)

Figure 2-3. RED Patterns for CVD Si Films Grown on Corning Code 1715 Glass at $\sim 850^{\circ} \mathrm{C}$ in $\mathrm{He}$, in Three Thickness Ranges. a) $0.1-0.2 \mu \mathrm{m}$, b) $\left.1.7-2.5 \mu \mathrm{m}, \mathrm{c}\right) 8-9 \mu \mathrm{m}$. 


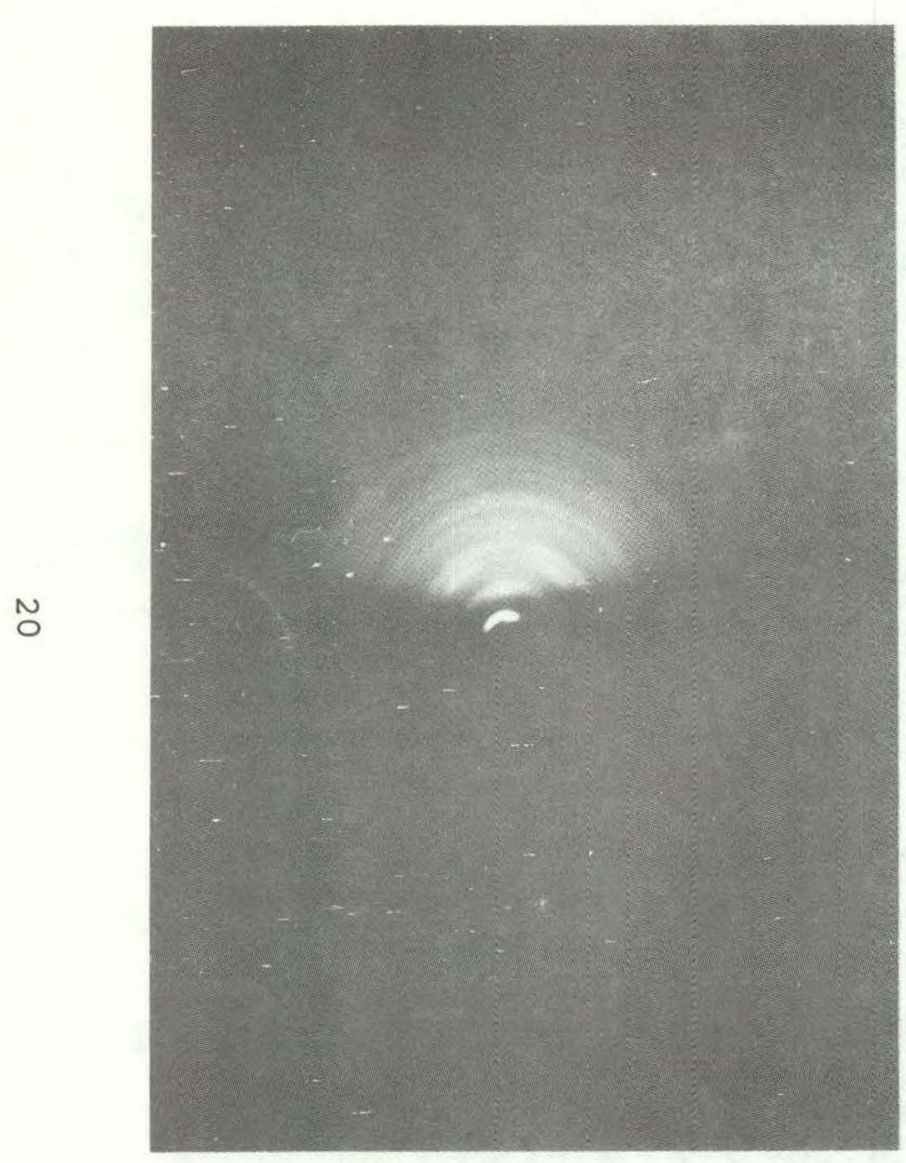

(a)

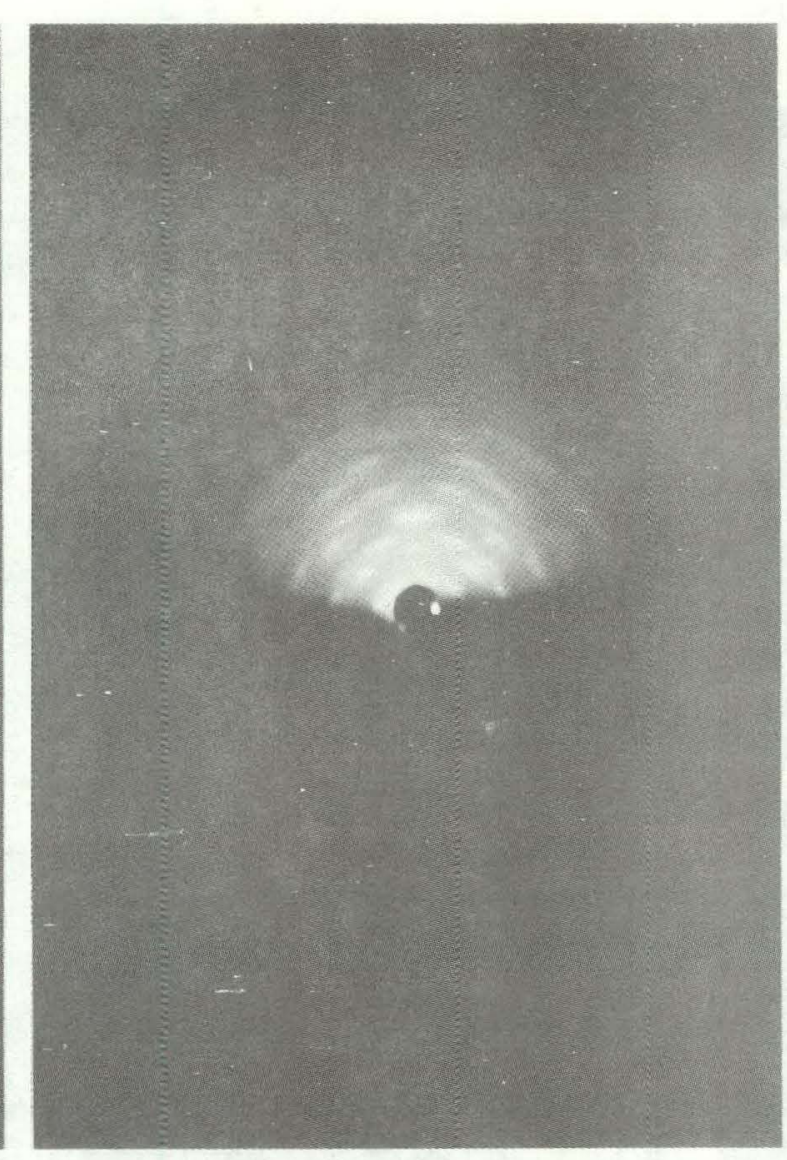

(b)

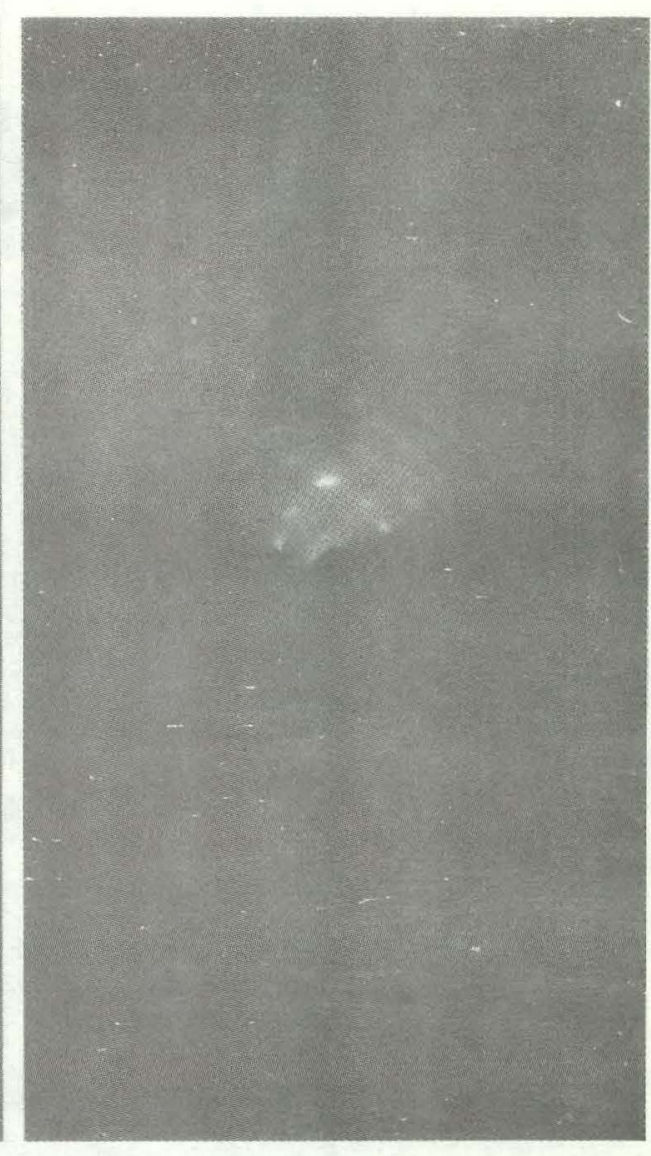

(c)

Figure 2-4. RED Patterns for CVD Si Films Grown on Owens-Illinois GS211 Glass

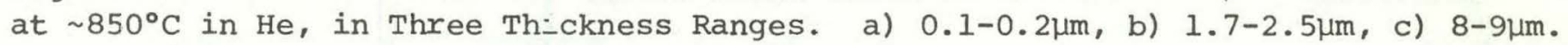




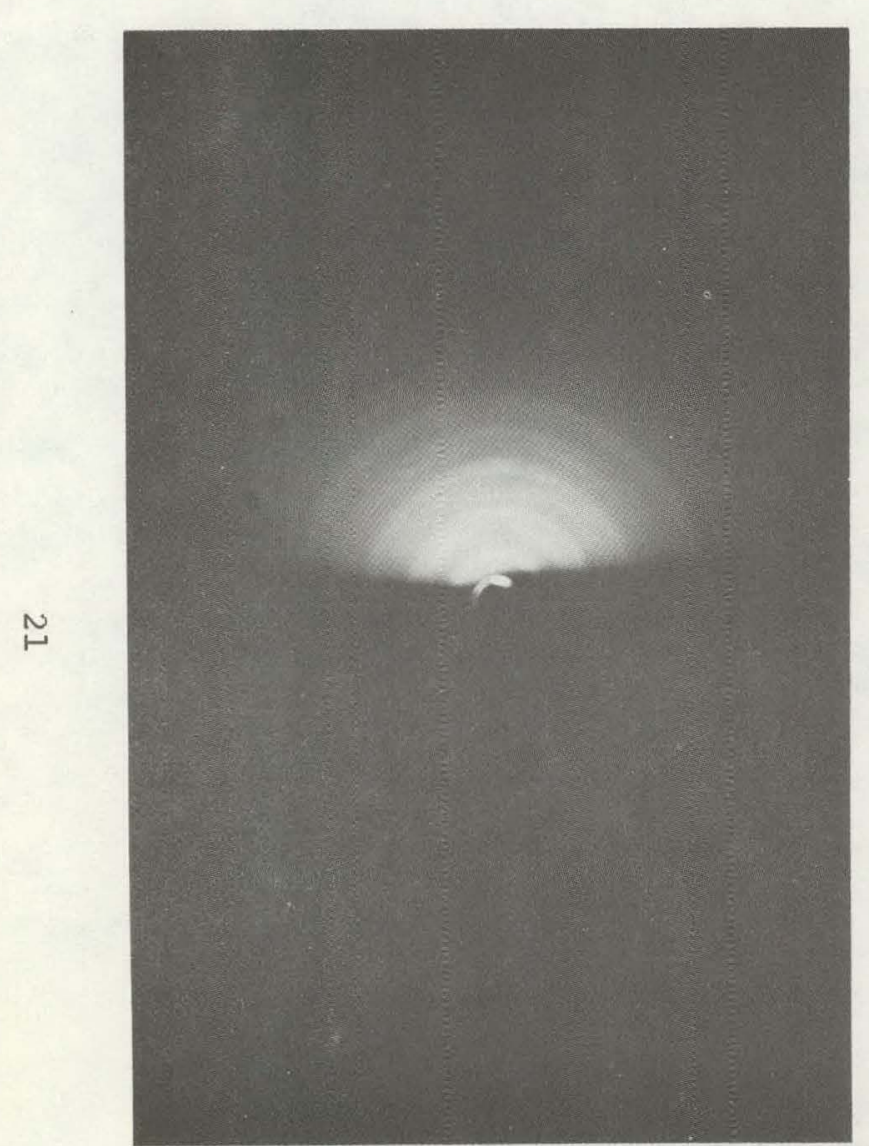

(a)

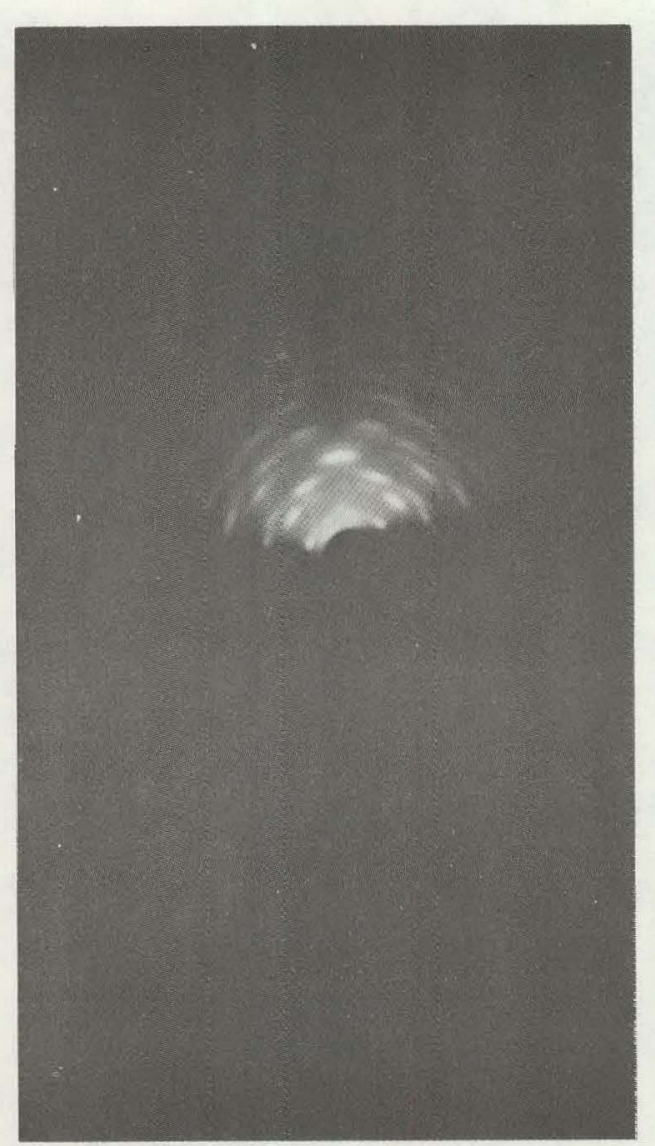

(b)

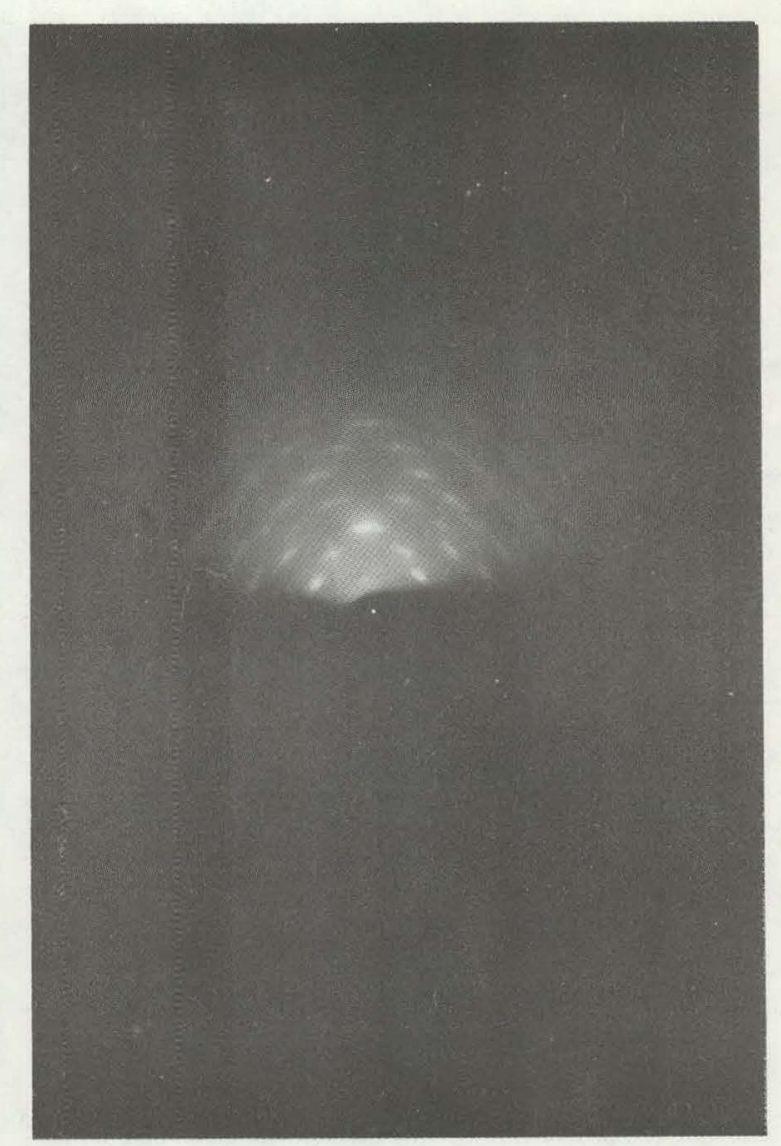

(c)

Figure 2-5. RED Patterns for CVD Si Films Grown on Owens-Illinois GS213 Glass

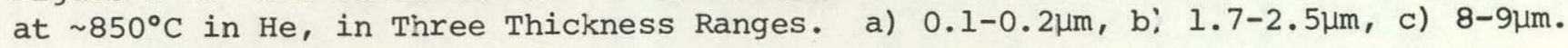




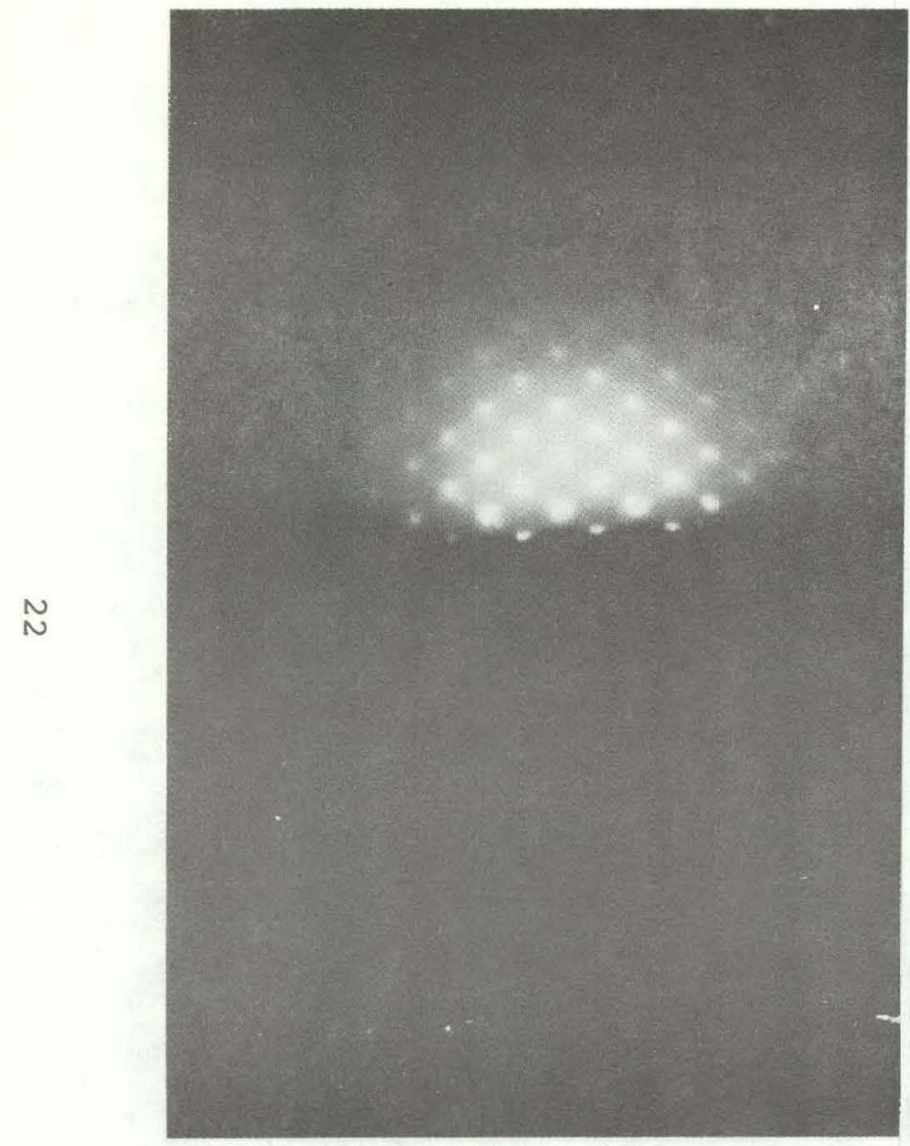

(a)

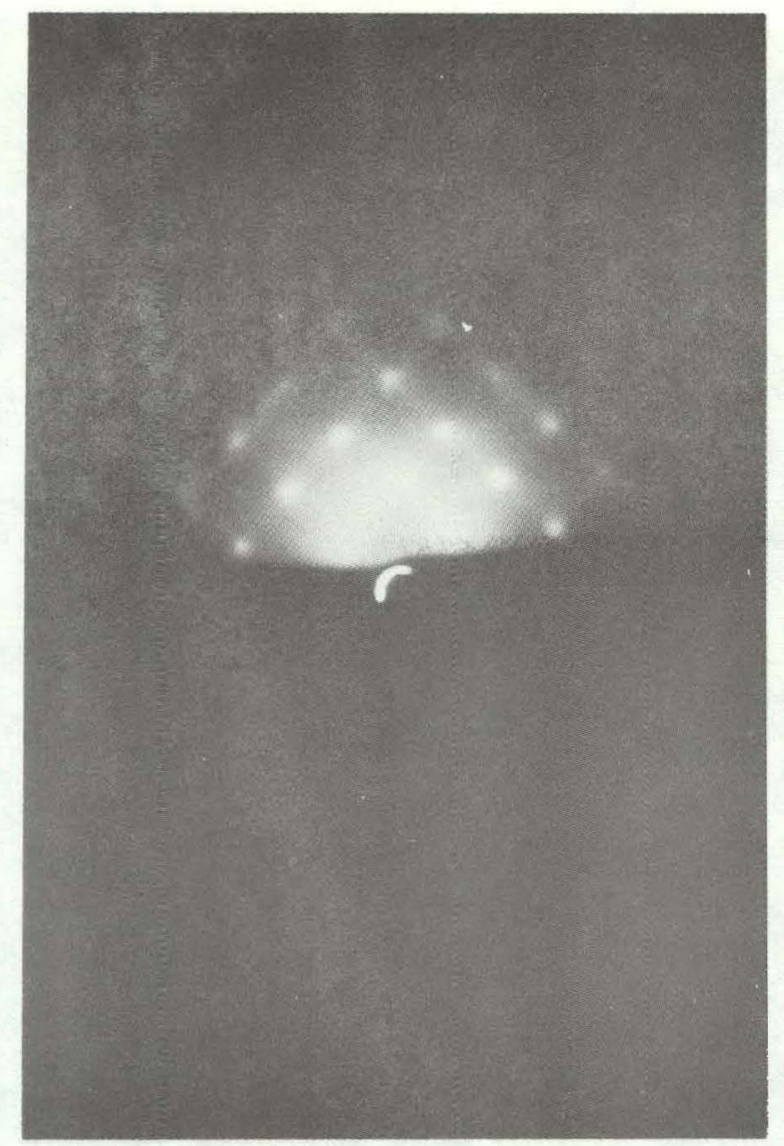

(b)

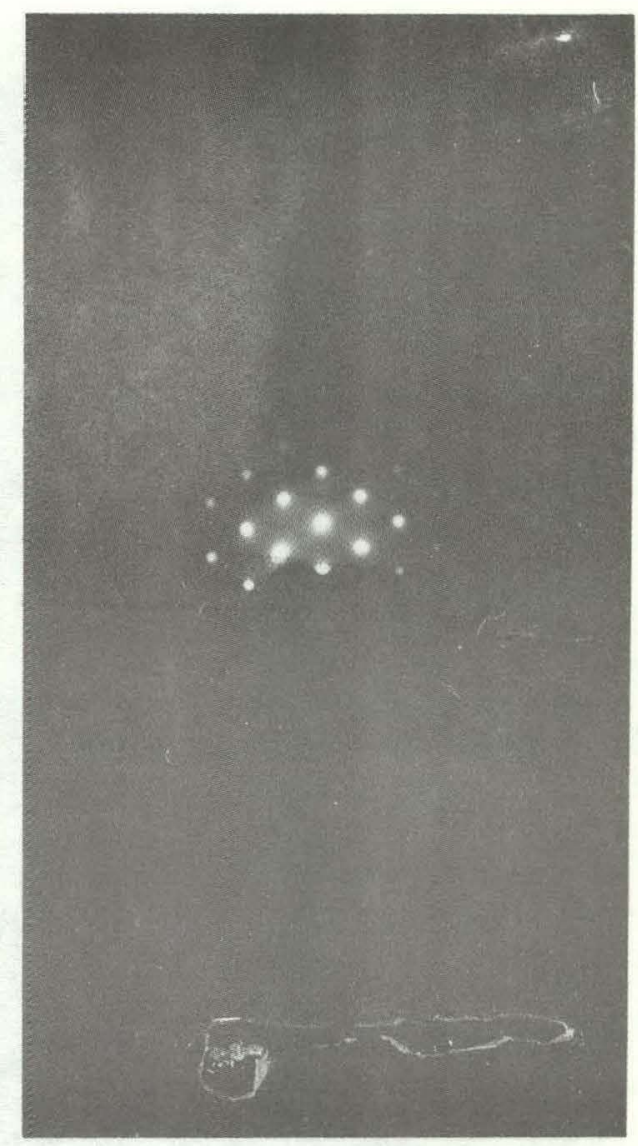

(c)

Figure 2-6. RED Patterns for IVD Si Films Grown on (01ī2)-oriented Sapphire at $\sim 850^{\circ} \mathrm{C}$ in $\mathrm{He}$, in Three Thickness Ranges. a) $0.1-0.2 \mu \mathrm{m}$, b) $\left.1.7-2.5 \mu \mathrm{m}, \mathrm{c}\right) 8-9 \mu \mathrm{m}$. 
on GS213 exhibiting slightly stronger preferred orientation than the film on GS211.

The thickest films (Figures 2-3c, 2-4c, 2-5c) showed still greater preferred orientation in all three polycrystalline cases, again with the greatest improvement occurring in the film on 1715 glass; the RED pattern in the latter case resembles that of a twinned epitaxial sample. In all three thickness ranges the films on the companion sapphire substrates appeared epitaxial with excellent structural perfection indicated by the RED patterns.

Figures 2-7 through 2-10 show the RED patterns obtained for the four sets of films grown at $\sim 950^{\circ} \mathrm{C}$ (observed) in He. These films were generally not as good structurally--with the exception of the films on sapphire, which appeared even better epitaxial single-crystal layers (at all three thicknesses) than those grown at $\sim 850^{\circ} \mathrm{C}$. The $\sim 0.15 \mu \mathrm{m}$ film on 1715 glass (Figure 2-7a) produced a pattern with only a few polycrystalline rings on a background of a near continuum; the patterns from the films on GS213 and GS2ll consisted of prominent polycrystalline rings with no evidence of the segmenting that is associated with strong preferred orientation, thus distinguishing these films from the $\sim 0.1 \mu \mathrm{m}$ films grown on these two glasses at $\sim 850^{\circ} \mathrm{C}$.

The thicker films $(\sim 1.7 \mu \mathrm{m}$, Figures $2-7 \mathrm{~b}, 2-8 \mathrm{~b}, 2-9 \mathrm{~b})$ on all three glasses showed segmenting in the rings of the RED patterns, with the films of GS213 and GS21l again exhibiting slightly more of the effect than did the film on 1715 glass. In this instance all three films exhibited the change from continuous rings to segmented rings corresponding to a thickness change from $\sim 0.1 \mu \mathrm{m}$ to $\sim 1.7 \mu \mathrm{m}$, whereas at $\sim 850^{\circ} \mathrm{C}$ growth temperature only the film on 1715 glass went through this transition. Generally, however, the ring patterns were much less distinct for the films grown at $950^{\circ} \mathrm{C}$ than for those at $850^{\circ} \mathrm{C}$, perhaps indicating a somewhat less ordered growth at all stages for the higher temperature.

The thickest films grown at $\sim 950^{\circ} \mathrm{C}$ (Figures 2-7c, 2-8c, 2-9c) produced RED patterns even less sharply defined than those for the $1.7 \mu \mathrm{m}$ films, although it appeared that the indistinct rings were segmented more abruptly than in the patterns produced by the intermediate-thickness films. One interpretation of this result is that the preferred orientations are relatively more sharply established in the thickest films but all other crystallites are nearly randomly oriented, with perhaps even some pseudo-amorphous regions occurring.

Whereas the RED analysis samples only a very thin region of the film near the upper (last-grown) surface, $x$-ray diffraction analysis produces patterns that are formed by contributions from diffracted beams from regions up to many micrometers in depth. X-ray diffraction analysis of the thinnest films $(0.15-0.18 \mu \mathrm{m})$ grown at $855-860^{\circ} \mathrm{C}$ indicated a highly polycrystalline structure in the three films on glass, with the $\{100\}$ planes about equally (but not strongly) preferred on all three substrates and the $\{110\}$ planes only slightly preferentially oriented on the GS211 and GS213 glasses but not on 1715 glass. These results are not inconsistent with the evidence obtained by RED analysis, although the film thicknesses are not large enough to generate strong intensities in the $\mathrm{x}$-ray spectrum. 


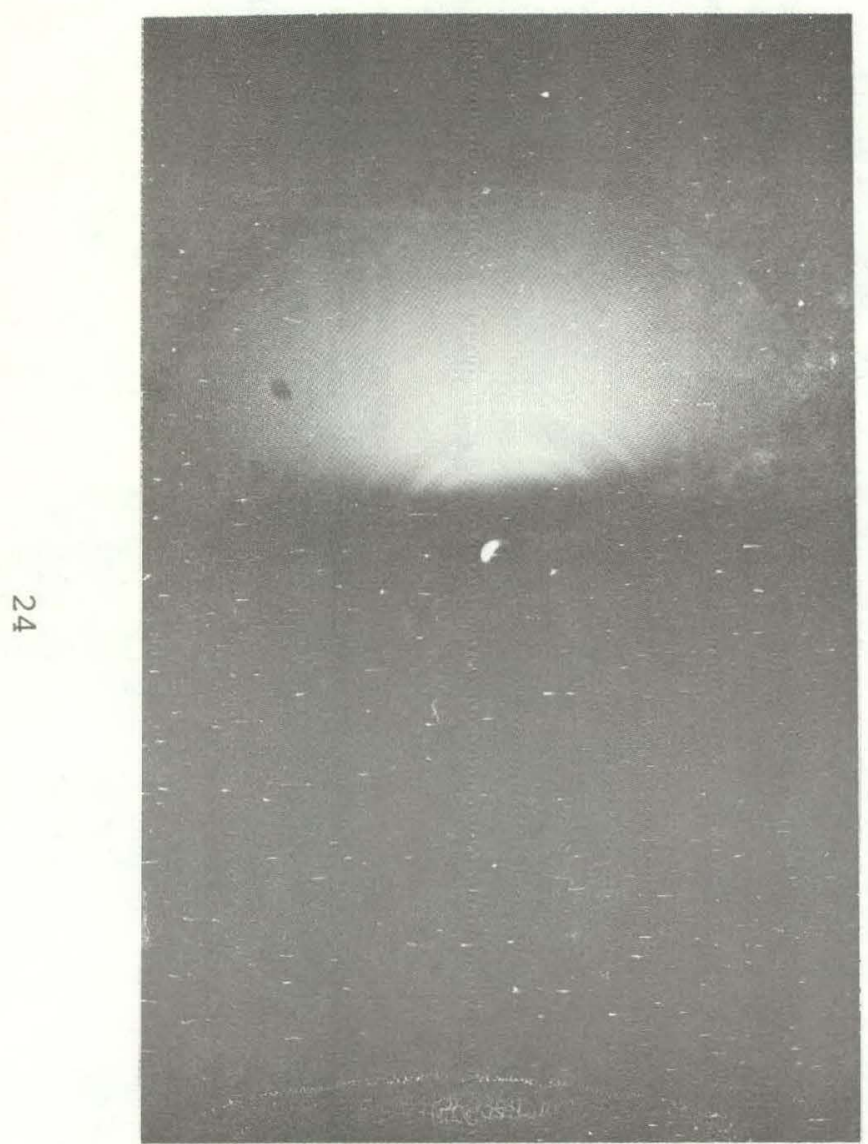

(a)

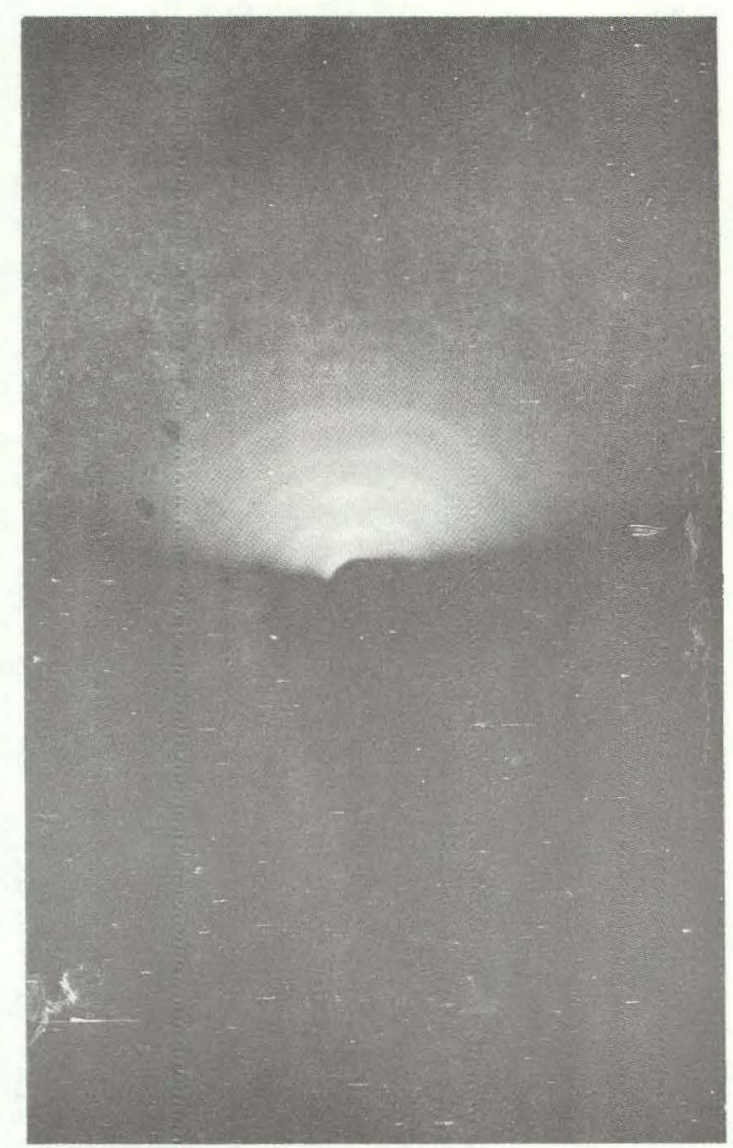

(b)

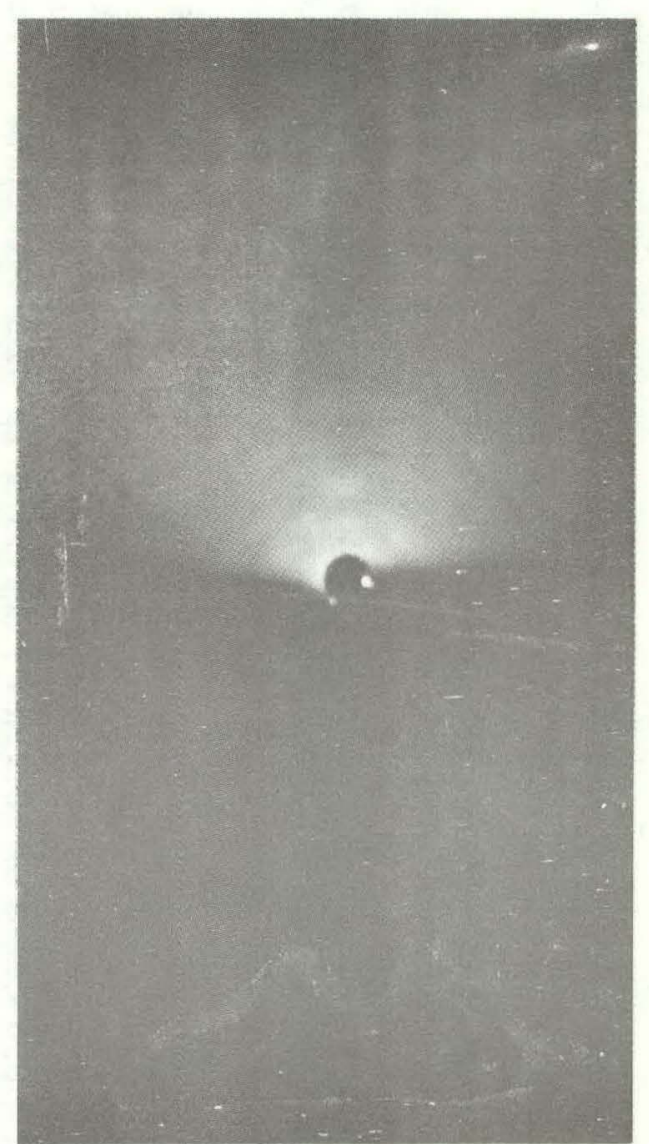

(c)

Figure 2-7. RED Patterns for CVD Si Films Grown on Corning Code 1715 Glass at $\sim 950^{\circ} \mathrm{C}$ in He, in Three Thickness Ranges. a) $\left.\left.0.3-0.4 \mu \mathrm{m}, \mathrm{b}\right) 1.7-2.3 \mu \mathrm{m}, \mathrm{c}\right) 3-6 \mu \mathrm{m}$. 


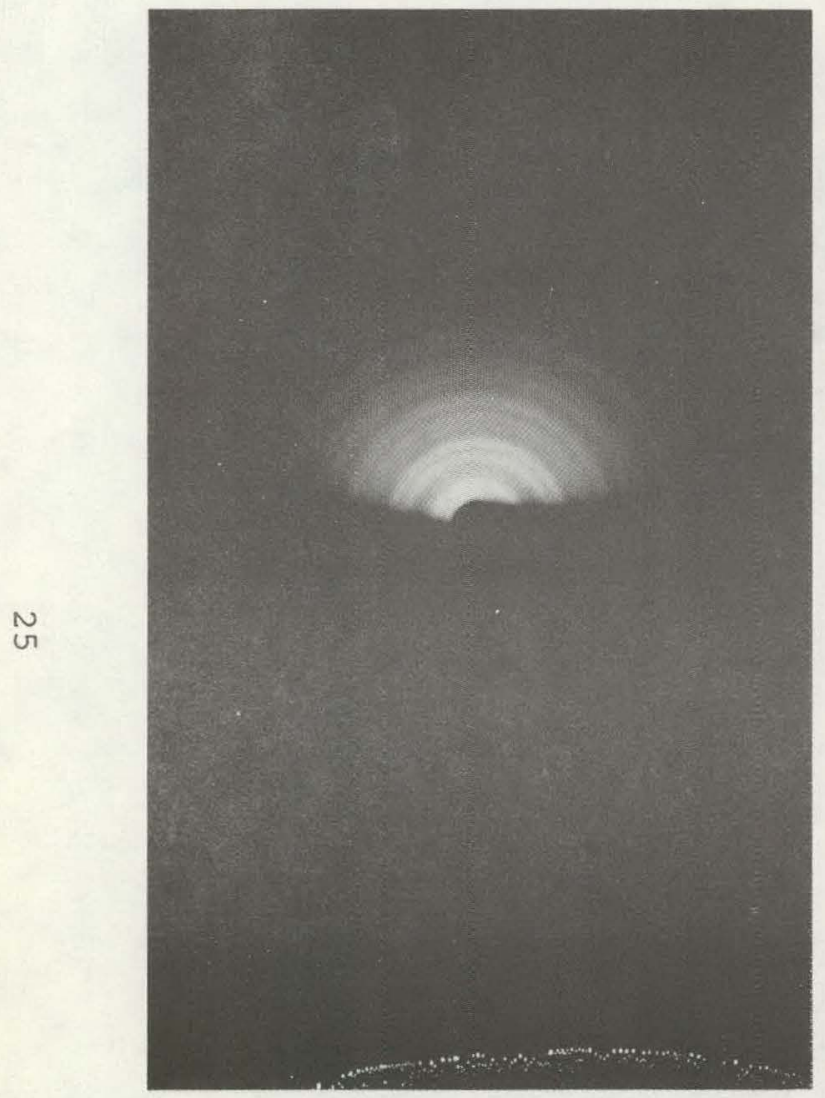

(a)

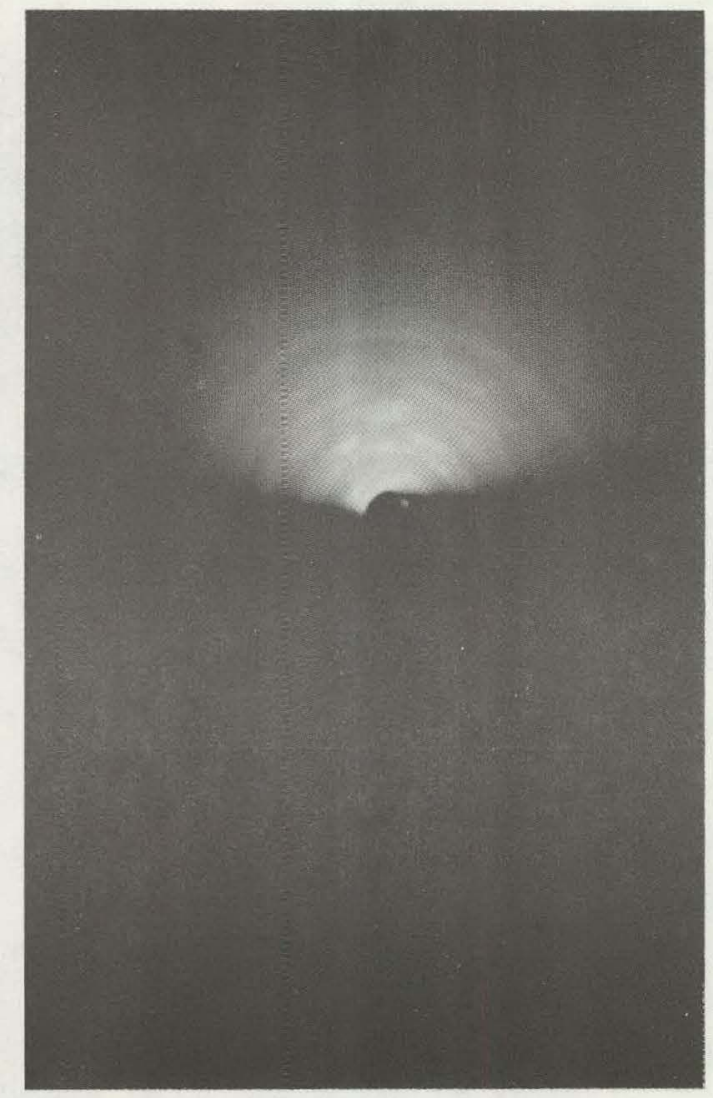

(b)

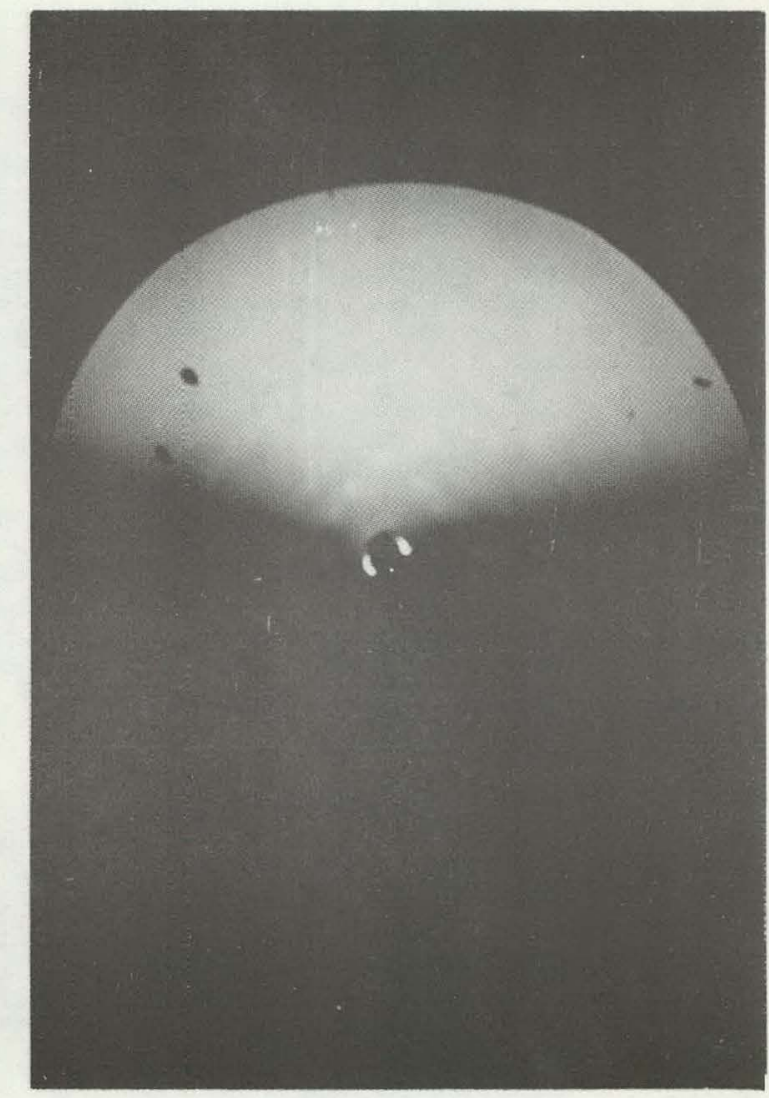

(c)

Figure 2-8. RED Patterns for CVD Si Films Grown on Owens-Illinois GS211 Glass at $\sim 950^{\circ} \mathrm{C}$ in He, in Three Thickness Ranges. a) $0.3-0.4 \mu \mathrm{m}$, b) $\left.1.7-2.3 \mu \mathrm{m}, \mathrm{c}\right) 3-6 \mu \mathrm{m}$. 


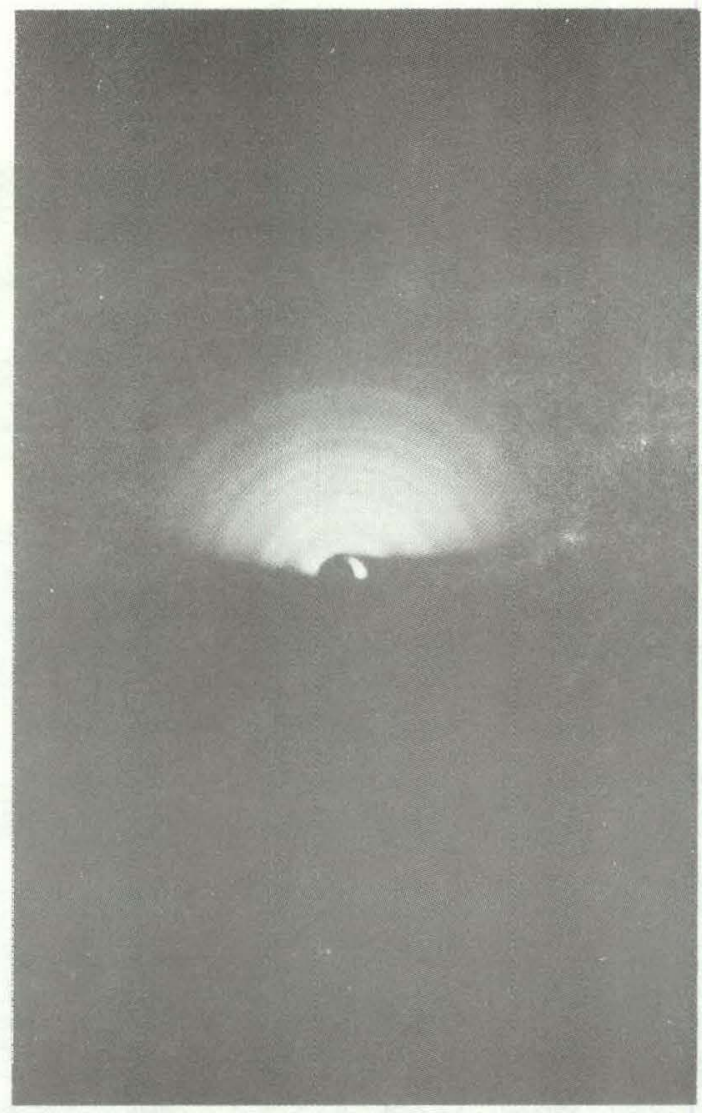

(a)

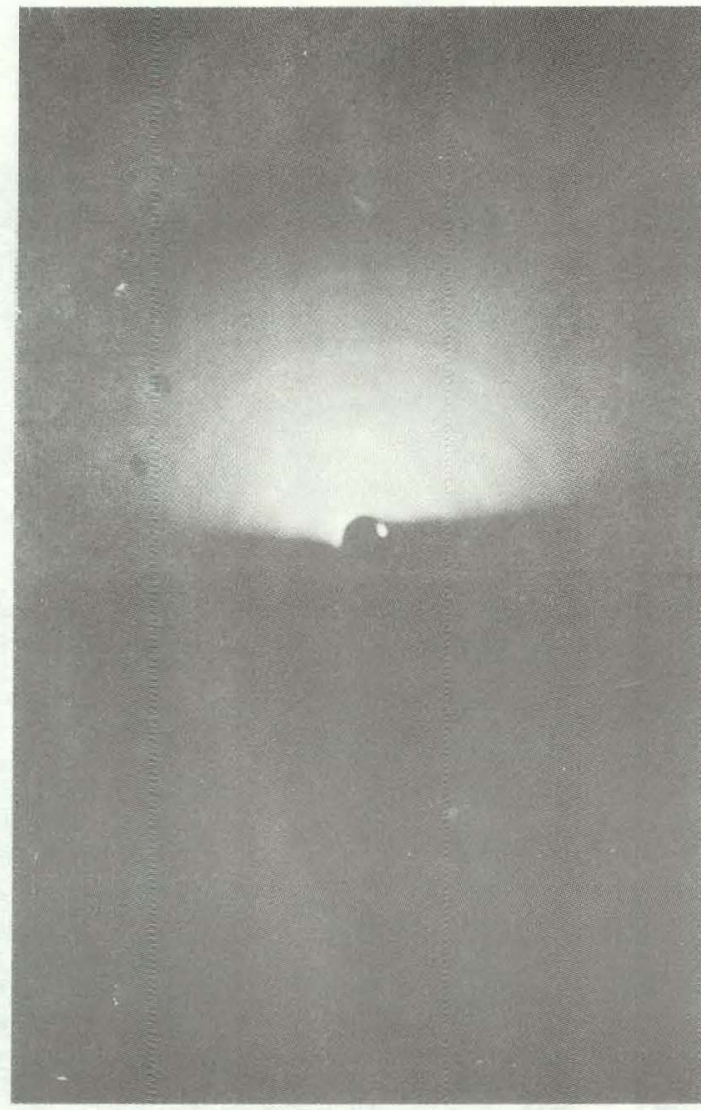

(b)

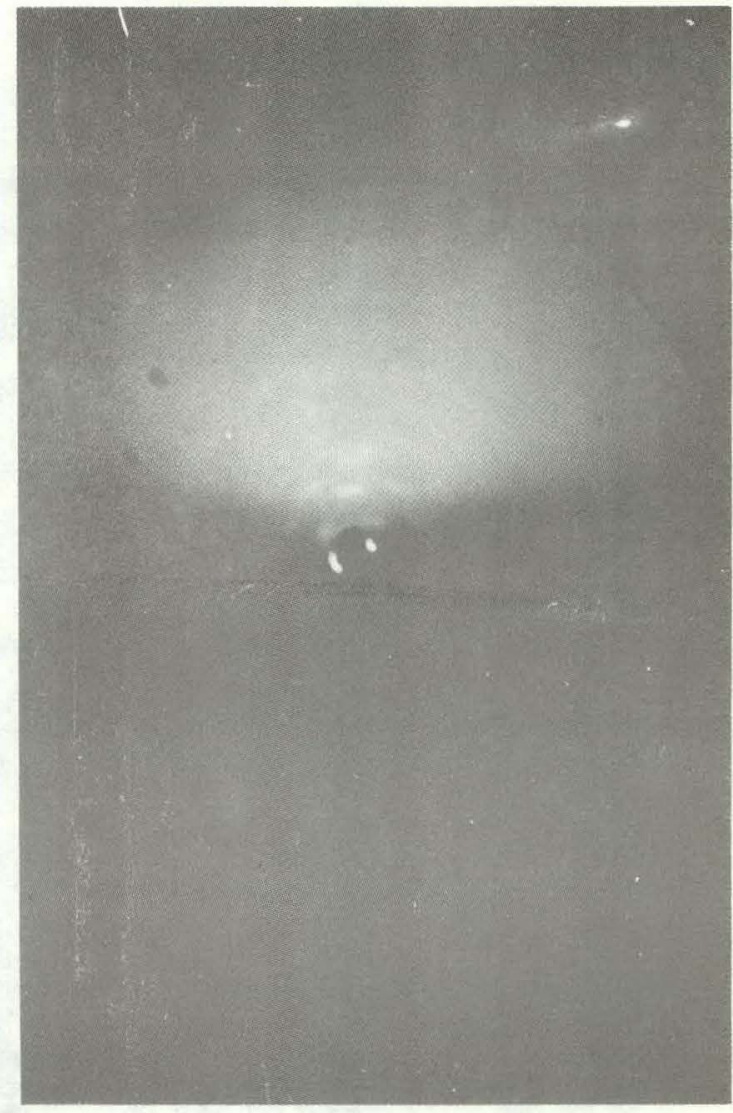

(c)

Figure 2-9. RED Patterns fCr CVD Si Films Grown on Owens-Illinois GS213 Glass at $\sim 950^{\circ} \mathrm{C}$ in $\mathrm{He}$, in Three Tr.ickness Ranges. a) $0.3-0.4 \mu \mathrm{m}$, b) $1.7-2.3 \mu \mathrm{m}$, c) $3-6 \mu \mathrm{m}$. 


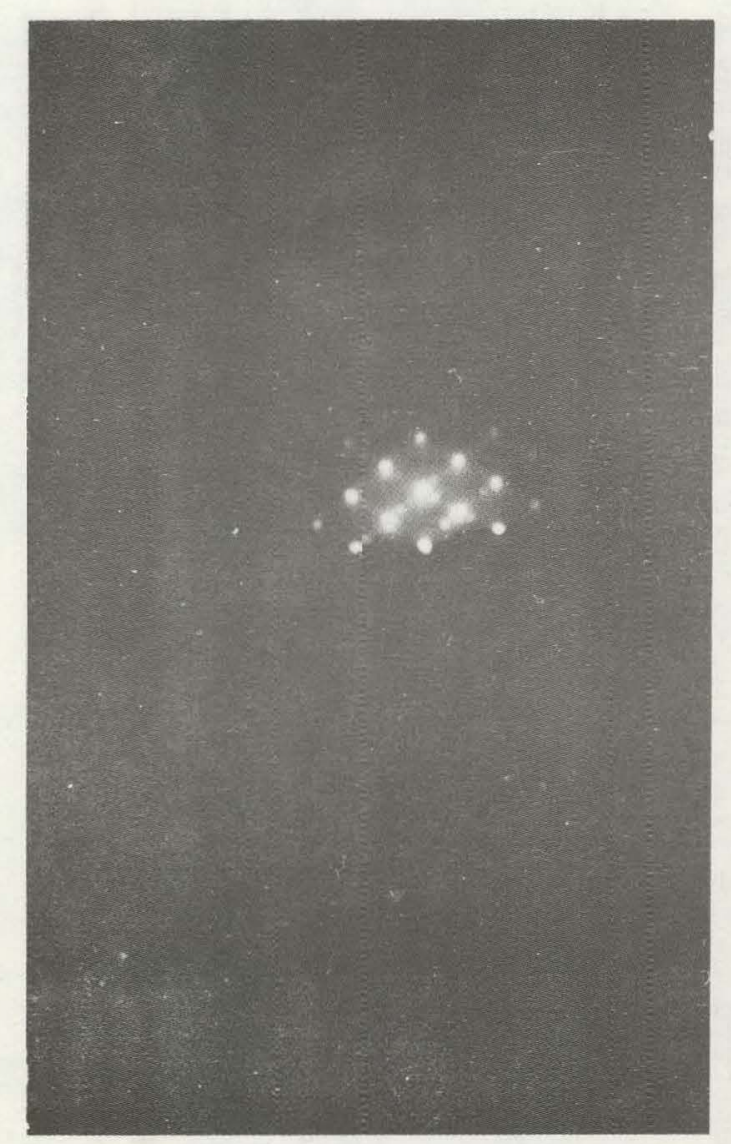

(a)

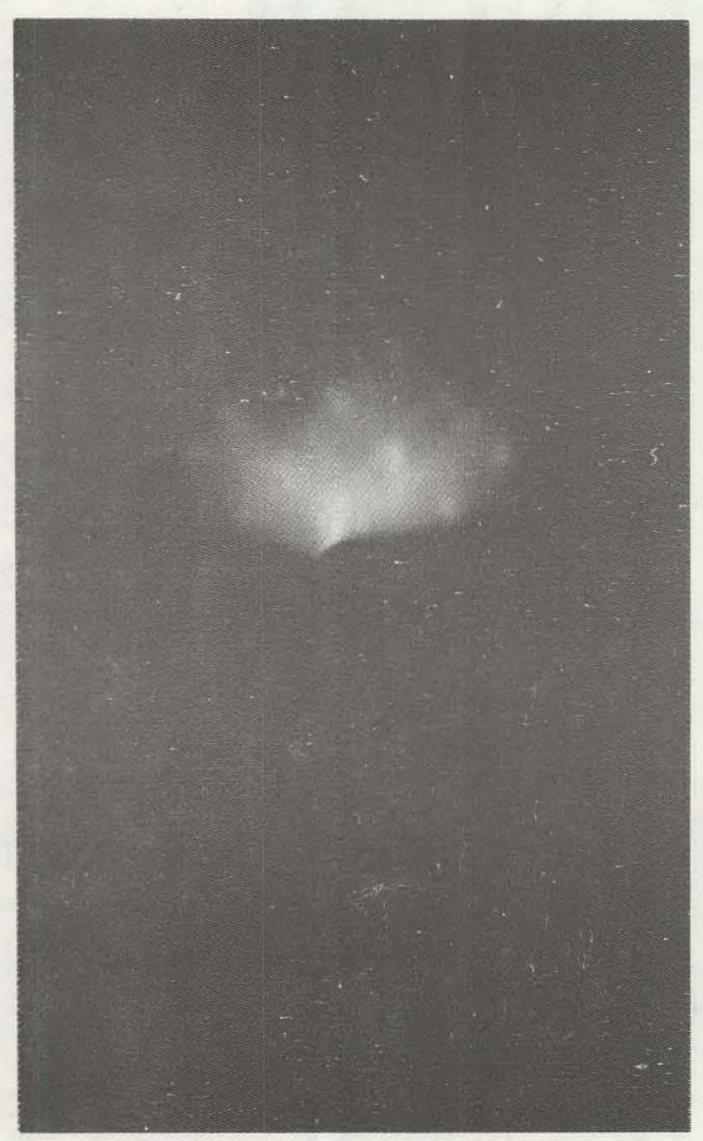

(b)

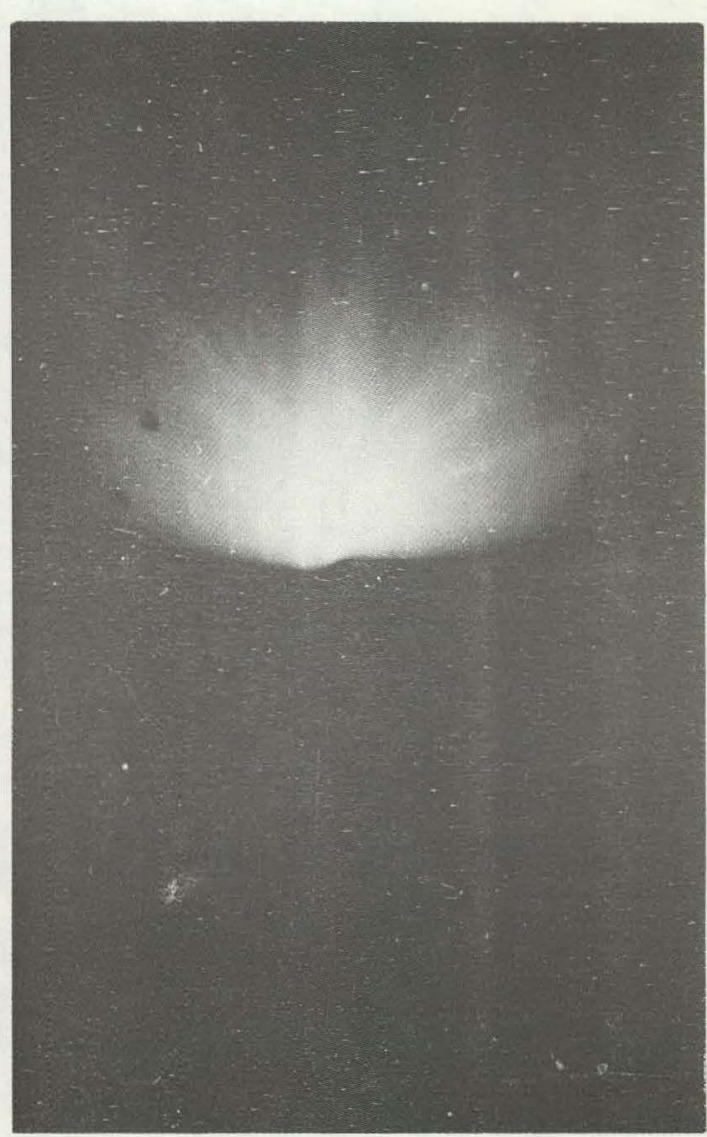

(c)

Figure 2-10. RED Patterns for CVD Si Films Grown on (011̄2)-oriented Sapphire at $\sim 950^{\circ} \mathrm{C}$ in $\mathrm{He}$, in Three Thickness Ranges. a) $0.3-0.4 \mu \mathrm{m}$, b) $\left.1.7-2.3 \mu \mathrm{m}, \mathrm{c}\right) 3-6 \mu \mathrm{m}$. 
The thicker fiims (1.7-2.5 $\mu \mathrm{m})$ on all three glasses exhibited preferred \{100\} orientation, strongest in the film on GS211 glass and weaker (but about equal) in the films on 1715 and GS213 glasses. In all three cases this preferred orientation was significantly stronger than was observed in the very thin films. The $\{110\}$ planes did not appear as preferentially oriented in these intermediate thickness films; in fact, the (220) line was nearly absent in the spectrum for the film on GS213 glass.

The thickest films (7.9-9.3 $\mu \mathrm{m})$ on all three glasses exhibited very strong $\{100\}$ preferred orientation--about the same in all three cases. In addition, the film on 1715 glass exhibited moderately strong $\{110\}$ preferred orientation, consistent with the evidence obtained by RED analysis that the thick film on 1715 glass was highly oriented (although polycrystalline).

In all three thickness ranges the films grown at $\sim 850^{\circ} \mathrm{C}$ on sapphire exhibited (111), (220), and (400) diffraction lines, but the (311) line was missing in each case. The relative intensity of the (400) line, associated with the \{100\} planes, increased with film thickness and was extremely strong, as might be expected for films that are nearly completely epitaxial but have some misoriented or polycrystalline content.

The films grown in $\mathrm{He}$ at $950-960^{\circ} \mathrm{C}$ (observed) on the same four substrate materials were similarly analyzed. The thinnest films on the glasses $(0.3-0.4 \mu m)$ generally produced very weak diffraction line intensities - only the (111) line was found in measurable intensity for the film on 1715 glass, for example. The films on GS211 and GS213 glasses produced relative line intensities quite close to what would be expected for polycrystalline films having completely random orientation. These results are very similar to the observations made by RED analysis of the same films, in nearly all respects.

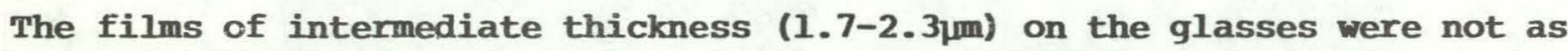
strongly $\{100\}$ oriented as those in the same thickness range grown at $855-860^{\circ} \mathrm{C}$. Further, the films grown on GS211 and GS213 at the higher temperature exhibited significant $\{110\}$ preferred orientation as well as $\{100\}$, and the film on 1715 glass was more strongly $\{110\}$ oriented than $\{100\}$, while at the lower temperature the $\{110\}$ planes were not preferred in any of the three cases.

The thickest films (3.3-6.3um) were still more strongly $\{100\}$ oriented (especially that on GS213 glass) than those of intermediate thickness, but only the film on 1715 glass still showed significant $\{110\}$ preferred orientation.

The films of all three thicknesses grown at the higher temperature on sapphire again exhibited very strong $\{100\}$ orientation which increased with film thickness, although the relative intensities of the (400) line were not as strong for each of the thicknesses as were those found in the films grown on sapphire at $855-860^{\circ} \mathrm{C}$; again the (311) line was either absent or very weak.

SEM examination of the surfaces of the films grown on GS213 glass in the two temperature ranges showed that the apparent grain sizes in the films, as 
evidenced by the dimensions of surface features, increased with increasing thickness in both cases. The average apparent grain size at the film surface was $\sim 0.1 \mu \mathrm{m}, \sim 0.3 \mu \mathrm{m}$, and $\sim 2 \mu \mathrm{m}$ for the three thicknesses grown at $855-860^{\circ} \mathrm{C}$, and $\sim 0.15 \mu \mathrm{m}, \sim 1 \mu \mathrm{m}$, and $\sim 2 \mu \mathrm{m}$ for the three thicknesses grown at $950-960^{\circ} \mathrm{C}$, thus providing an important confirmation of earlier observations of grain size increase with film thickness. It is interesting that the average apparent grain size for the thickest films is about the same for both growth temperatures in this range.

This series of experiments confirmed that $\{100\}$ preferred orientation as well as apparent grain size in the polycrystalline si films on glasses becomes more pronounced with increasing thickness. It also showed that surprisingly good crystallographic structure occurs even in very thin ( $0.1 \mu \mathrm{m})$ films deposited on the particular glasses examined. It also demonstrated that the films grown on glasses at $\sim 850^{\circ} \mathrm{C}$ are significantly better structurally than those grown at $\sim 950^{\circ} \mathrm{C}$. For thicknesses less than $\sim 2 \mu \mathrm{m}$ the films are slightly better structurally (i.e., more preferred orientation) on GS211 than on GS213, with both noticeably better than those on 1715. In thicker films the apparent structural quality is about the same for the three substrates, although both $\{100\}$ and $\{110\}$ preferred orientations are present in films grown at the higher temperature. The temperature dependence of preferred orientation in these films is obviously a complex function and requires further detailed study to define it completely.

\subsubsection{Properties of Si Sheet Grown by Two-step Process Using HCl}

As was indicated in Section 2.3.1, experiments were carried out during the quarter to evaluate the feasibility of a two-step growth process in which a first $\mathrm{Si}$ layer is grown on glass at $\sim 850^{\circ} \mathrm{C}$ in He using $\mathrm{SiH}_{4}$ alone and then a second layer is grown from a $\mathrm{SiH}_{4}-\mathrm{HCl}$ mixture. The parameters used in those investigations are described in that section. The experiments described above, in which $\mathrm{Si}$ layers in three different thickness ranges were prepared by $\mathrm{SiH}_{4}$ pyrolysis in $\mathrm{He}$ at $\sim 850^{\circ} \mathrm{C}$, provided reference characteristics for the layers prepared by the two-step HCl process. The latter were grown to total thicknesses that were approximately equal to the thicknesses of the single-layer samples described in the preceding section so that structural comparisons would be meaningful.

One set of double layers consisted of a bottom layer nominally 1-2 $\mu \mathrm{m}$ thick and a thicker top layer (nominally 6-10 $\mathrm{m}$ thick) grown in the presence of HCl flowing through the deposition chamber at $\sim 13$ and $\sim 50 \mathrm{ccpm}$. Substrates of GS211, GS213, and 1715 glasses and single-crystal sapphire were used. X-ray diffraction analysis of the composite layers on GS211 and 1715 glass indicated essentially random orientation of the polycrystalline Si on both substrates for the low HCl flow rate and slightly preferred $\{100\}$ orientation for the higher HCl flow rate, the preferred orientation being more prominent in the film on GS2ll glass. However, the extent of preferred orientation did not even approach that observed in films grown to about the same thickness on the same glasses at $\sim 850^{\circ} \mathrm{C}$ in the absence of $\mathrm{HCl}$, as described in the preceding section. The companion double layers grown on sapphire in these same experi- 
ments exhibited about the same relative $x$-ray diffraction line intensities as did the film of comparable total thickness $(\sim 7.9 \mu \mathrm{m})$ grown without HCl, although the (400) line was relatively less intense for both of the doublelayer samples.

A second set of double-layer samples, with the bottom layer 0.1-0.3um thick and a top layer $1-2 \mu \mathrm{m}$ thick, the latter again grown with HCl flows of 13 and $50 \mathrm{ccpm}$, was also prepared. X-ray diffraction analysis of these samples again showed that essentially random polycrystalline Si was formed on both GS 211 and 1715 glass substrates for the low HCl flow rate and on 1715 glass for the higher HCl flow rate. The double layer grown on GS21l glass with the higher HCl flow rate exhibited a slight tendency for preferred orlentation of both \{100\} and $\{110\}$ planes; single layers of about the same thickness grown on this same glass at $\sim 850^{\circ} \mathrm{C}$ without $\mathrm{HCl}$ had significantly more $\{100\}$ preferred orientation and essentially no evidence of $\{110\}$ preferred orientation. The companion double layers grown on sapphire substrates were somewhat different from the film of similar thickness $(\sim 1.7 \mu \mathrm{m})$ grown without the HCl. Both of the double layers exhibited considerably more $x$-ray evidence of $\{110\}$ planes than did the single layer, and the double layer grown with $50 \mathrm{ccpm}$ of HCl flowing during the second step was also much more strongly $\{100\}$ oriented than was the one with $13 \mathrm{ccpm}$ of HCl flowing during growth of the upper portion. These differences have not yet been explained.

Only the films grown on GS213 glass and sapphire substrates in the presence of HCl had surfaces sufficiently smooth, as grown, for RED analysis. Whisker growth was evident on the surface of the film grown on 1715 glass, and the surface of the top layer on the GS21l glass substrate was quite irregular. Comparison of the RED patterns obtained for the four double-layer films on GS213 glass and the single-crystal sapphire substrates with the rorrfannniing patterns for single layers produced without $\mathrm{HCl}$ (Figure 2-5b and $\mathrm{c}$ and Figure 2-6b and $c$, respectively) clearly showed major differences in film quality near the surface for both substrates. Highly twinned growth was indicated on the sapphire substrates for the HCl two-step process, for example.

SEM examination of fracture cross-sections of the four double layers on the companion sapphire substrates permitted confirming measurements of the total thickness of the composite layers, and also revealed the boundary between the

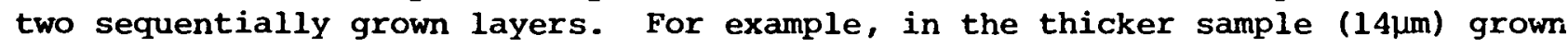
with an HCl flow rate of $50 \mathrm{ccpm}$ for the upper layer the first-grown layer was $\sim 4 \mu \mathrm{m}$ thick and the second layer $\sim 10 \mu \mathrm{m}$. SEM examination of the surface of this sample indicated strongly faceted, highly crystallographic surface features averaging $2 \mu \mathrm{m}$ across, essentially the same as the dimensions of the surface features on the single layer of comparable thickness grown without HCl on the GS213 glass substrate (see Section 2.5.1).

The thinner sample $(\sim 1.3 \mu \mathrm{m})$ grown on sapphire with $13 \mathrm{ccpm}$ of HCl flowing through the chamber during deposition of the top layer consisted of a bottom layer $0.2-0.3 \mu \mathrm{m}$ thick and a top layer $\sim 1.0 \mu \mathrm{m}$ thick. SEM examination of the surface of this sample revealed much less well-defined surface facets and an average dimension for the surface features of about $0.5 \mu \mathrm{m}$, only slightly 
different from the dimensions of surface features on the single layer grown to comparable thickness on GS213 glass at $\sim 850^{\circ} \mathrm{C}$ without HCl.

The apparent stability of the three glasses to the HCl two-step process, based on general observations during these experiments and on the observed structure of the upper layers formed with HCl present, is greatest for GS 213 and least for Code 1715 glass. However, the overall conclusion is that the two-step process involving $\mathrm{HCl}$ at $\sim 850^{\circ} \mathrm{C}$ in He clearly produces films of poorer structural quality than those grown directly from $\mathrm{siH}_{4}$ in a single step without $\mathrm{HCl}$, under otherwise similar conditions.

\subsubsection{Properties of Single and Double Layers Prepared for Solar Cell Fabrication}

In Section 2.3.3 experiments carried out during the quarter to prepare various single- and double-layer $\mathrm{si}$ sheet samples for subsequent fabrication of experimental solar cells at OCLI were described. The sample structures prepared include the following: (1) upiformly doped p-type epitaxial si films with carrier concentrations in the $10^{17}-10^{18} \mathrm{~cm}^{-3}$ range, on both p-type single-crystal $\mathrm{Si}$ substrate wafers of solar cell quality (i.e., 2-3 ohm-cm resistivity and carrier diffusion lengths of $\sim 100 \mu \mathrm{m})$ and higher resistivity ( $\geq 10 \mathrm{ohm}-\mathrm{cm}$ ) p-type single-crystal si wafers of good device quality; (2) epitaxial double-layer $\mathrm{p} / \mathrm{p}^{+} \mathrm{Si}$ sheet samples on sapphire substrates, with carrier concentrations in the $10^{18}$ and $10^{19} \mathrm{~cm}^{-3}$ ranges, respectively, and thickness ratios $t_{p} / t_{p}$ of $1: 3,1: 1$, and $3: 1$ (to evaluate the effect of proximity of the $\mathrm{p}^{+}$region to the junction on the photovoltaic performance of the cells subsequently formed by diffusion); (3) similar double-layer $\mathrm{p} / \mathrm{p}^{+}$ structures on single-crystal si wafers of the two types used in (1); and (4) uniformly doped p-type polycrystalline Si films with carrier concentrations in the $10^{17}-10^{18} \mathrm{~cm}^{-3}$ range on several different glasses. Some of these structures were prepared for fabrication of diagnostic experimental cells intended to clarify some of the questions raised by the results obtained with the last group of cells processed (see Section 2.6.2).

The single-layer $\mathrm{p}$-type $\mathrm{Si}$ sheet samples grown on substrates of single-crystal $\mathrm{Si}$ of two different resistivities at $\sim 1025^{\circ} \mathrm{C}$ in $\mathrm{H}_{2}(1.5 \mathrm{lpm})$ with a $\mathrm{SiH}$ flow rate of $\sim 10 \mathrm{ccpm}$ were epitaxial, as expected. The problems encountered in cleaning the p-type $2 \mathrm{ohm}-\mathrm{cm}$ solar cell blanks prior to deposition, as described in section 2.3.3, resulted in some of the epitaxial layers having noticeable macroscopic as well as microscopic irregularities in surface characteristics and, presumably, in interior structural perfection.

$\mathrm{X}$-ray topographic examination of these defects is being undertaken, and results of the analyses will be given in subsequent reports. Some attempts will also be made to correlate these structural irregularities with any variations that may be observed in the photovoltaic performance of individual mesa solar cells fabricated in the sheet material, after completion of the photovoltaic response measurements (see section 2.6.2). The mesa surface as well as the interior of the layer structure will be examined by optical and scanning electron microscope techniques for this purpose. 
The electrical properties of these single-layer samples were determined by van der Pauw measurements of the Hall effect and, in several instances, also by spreading resistance (SR) probe measurements. The latter method indicated somewhat ( $\sim 50$ percent) higher average resistivity values for a given film than was obtained by the van der Pauw method. Conversion of the SR resistivity values to carrier concentrations, using the standard correction for (100)oriented bulk single-crystal $\mathrm{Si}$, resulted in values less than those measured by the van der Pauw method by a factor of about 3. The SR scans through the thickness of the films indicated good uniformity of doping on both Si substrate materials, throughout the $10^{17}-10^{19} \mathrm{~cm}^{-3}$ concentration range.

The epitaxial double-layex $\mathrm{p} / \mathrm{p}^{+}$samples grown on the two types of singlecrystal Si and on (01/12)-oriented sapphire substrates were also deposited at $\sim 1025^{\circ} \mathrm{C}$ in $\mathrm{H}_{2}(1.5 \mathrm{lpm})$ with $\mathrm{SiH}$ flow rates of $\sim 10 \mathrm{ccpm}$. The $\mathrm{p}^{+}$regions were $\mathrm{B}$-doped by means of diborane $\left(46 \mathrm{ppm} \mathrm{B}_{2} \mathrm{H}_{6}\right.$ in He) flow rates of 150 ccpm, which resulted typically in measured carrier concentrations of $4-6 \times 10^{19} \mathrm{~cm}^{-3}$, irrespective of the substrate involved. The p-type upper regions of these double-layer samples were doped by diborane flow rates of $6 \mathrm{ccpm}$, resulting in measured carrier concentrations of $3-5 \times 10^{18} \mathrm{~cm}^{-3}$. As indicated earlier (Section 2.3.3), it had originally been intended that the upper regions of these composite samples be doped to concentrations in the $10^{17} \mathrm{~cm}^{-3}$ range for use in solar cell fabrication.

The transition between the $\mathrm{p}^{+}$and the $\mathrm{p}$ regions in these samples was shown by SR probe scans to be very abrupt. Figure 2-11 shows the results of SR probe scans ${ }^{*}$ on bevels through the full thickness of the $p$ and $p^{+}$regions of three double-layer Si films grown on sapphire substrates with the above deposition parameters. Although the SR probe measures spreading resistance, which is converted to resistivity for plotting purposes, the data shown are in terms of the automatically calculated carrier concentrations (based on the standard correction for bulk (100)-oriented si) plotted as functions of depth into the composite samples.

Each of the three different nominal values of the thickness ratio $t_{p}: t_{+}-$ $1: 3,1: 1$, and $3: 1$ - is represented in Figure 2-11. The data excursions to lower carrier concentration values at the lower side of the transition in each of the three plots are artifacts introduced by the automatic plotting equipment and are related to the correction for the finite sampling volume of the probe; the transition is too abrupt for the equipment to "follow" accurately. The procedure followed in growing the p-type layer on the conpleted $\mathrm{p}^{+}$layer involved simply a $2 \mathrm{~min}$. carrier gas purge - without $\mathrm{SiH}_{4}-$ between the two depositions.

Similar SR probe scans through three double layers grown on single-crystal Si substrates are shown in Figure 2-12. The three thickness ratios are again represented. Figure $2-12 \mathrm{a}$ is the data for a double layer with $t_{\mathrm{p}}: t_{\mathrm{p}^{+}} \approx 1: 3$, grown on $2 \mathrm{ohm}-\mathrm{cm} \mathrm{Si}$. Figure $2-12 \mathrm{~b}$ is the data for a double layer grown on $10 \mathrm{ohm}-\mathrm{cm} \mathrm{Si}$ with the two regions about equal in thickness, while Figure 2-12c

*Measurements made by Solecon Laboratories, Costa Mesa, CA. 


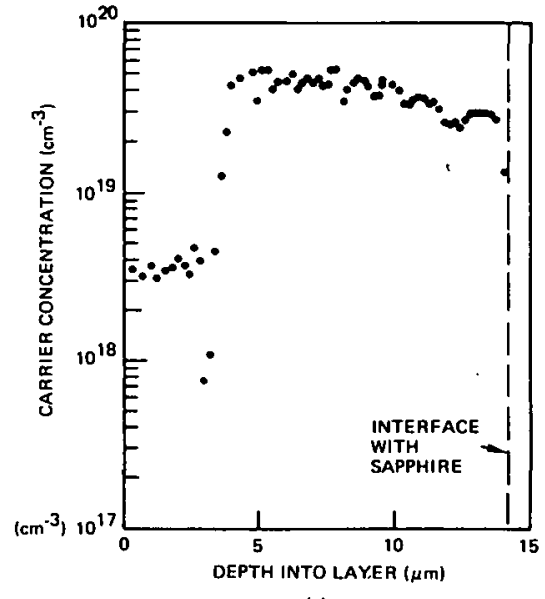

(a)

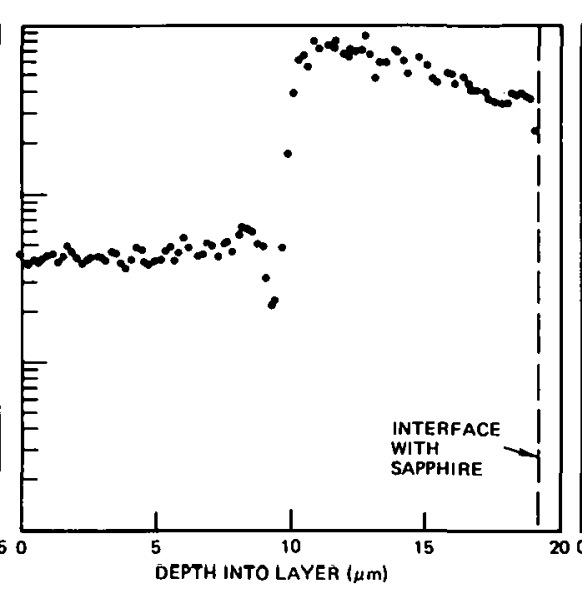

(b)

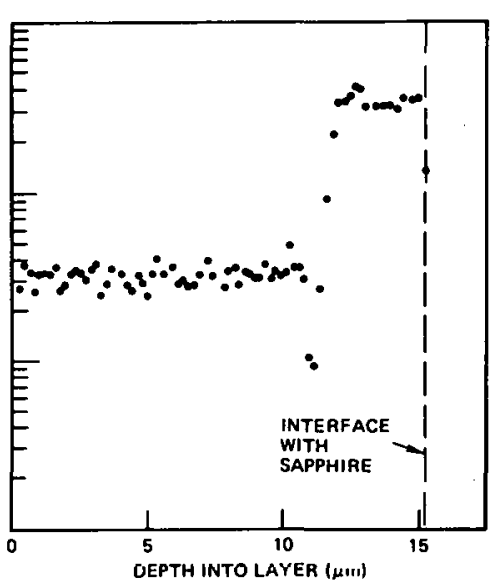

(c)

Figure 2-11. Spreading Resistance Probe Scans Showing Calculated Carrier Concentration versus Depth in Three $\mathrm{p} / \mathrm{p}^{+} \mathrm{Si}$ Films Grown on Sapphire Substrates at $\sim 1025^{\circ} \mathrm{C}$ in $\mathrm{H}_{2}$. a) $t_{p}: t_{p^{+}} \approx 1: 3$, b) $\left.t_{p}: t_{p^{+}} \approx 1: 1, c\right) t_{p}: t_{p^{+}} \approx 3: 1$.

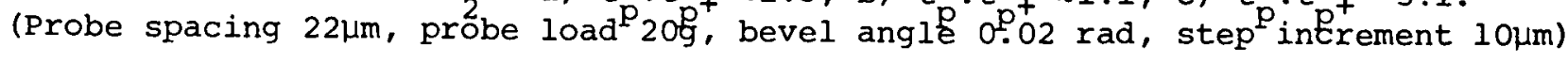

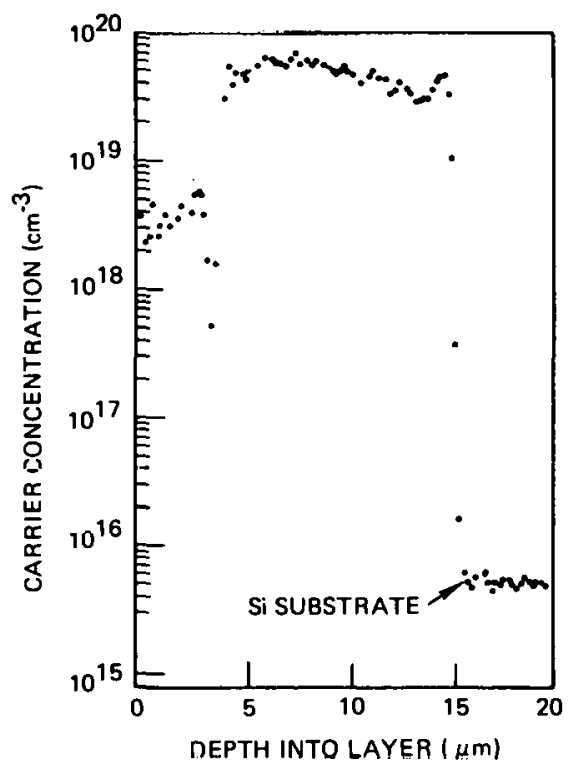

(a)

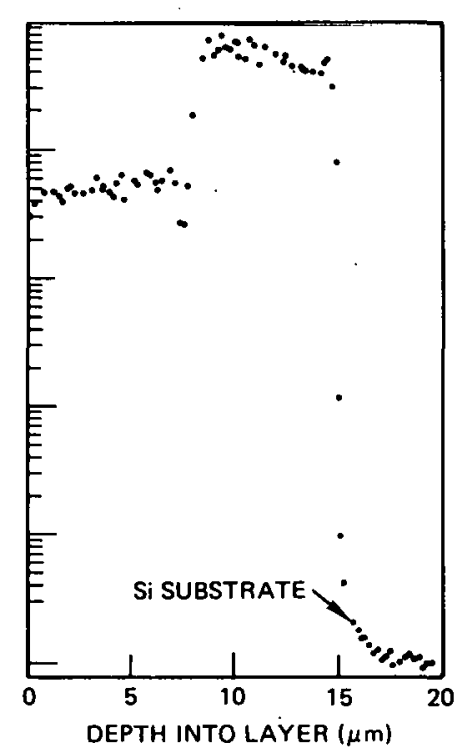

(b)

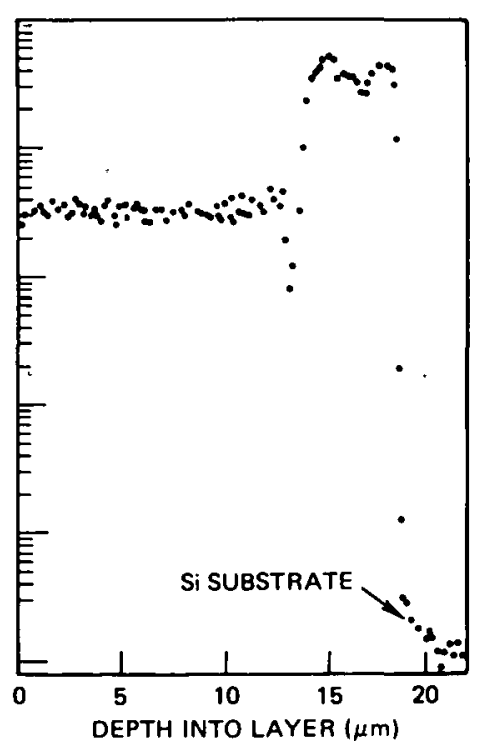

(c)

Figure 2-12. Spreading Resistance Probe Scans Showing Calculated Carrier Concentration versus Depth in Three $\mathrm{p} / \mathrm{p}^{+} \mathrm{Si}$ Films Grown on Single-crystal

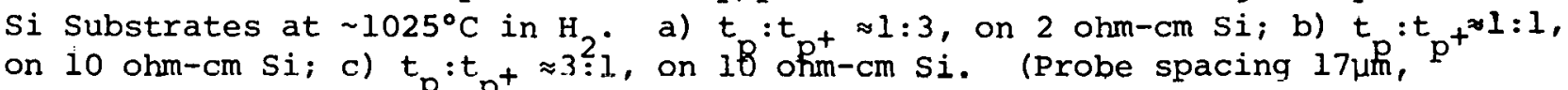
probe load $20 \mathrm{~g}$, bevel ${ }^{\mathrm{p}}$ angle $0.02 \mathrm{rad}$, step increment $10 \mathrm{\mu m}$ ) 
is for a sample on the same type of substrate but with $t_{p}: t_{p^{+}} \approx 3: 1$. The artifacts on the low side of the concentration step are agaih plesent. The abruptness of the $\mathrm{p}^{-\mathrm{p}^{+}}$transition in these samples does not appear to be influenced by the nature of the substrate - whether sapphire, $10 \mathrm{ohm}-\mathrm{cm} \mathrm{Si}$, or $2 \mathrm{ohm}-\mathrm{cm}$ Si.

A series of $\mathrm{B}$-doped $\mathrm{Si}$ films was grown on sapphire substrates in $\mathrm{He}$ at $\sim 850^{\circ} \mathrm{C}$, as described in Section 2.3.3, to provide additional data on the maximum doping concentrations to be expected in films deposited on various glasses under these same experimental conditions. As indicated earlier, $x$-ray diffraction analysis showed that these films on sapphire were largely epitaxial, with surprisingly good crystal structure considering the low growth temperature. This implies that the measured electrical properties should closely approach the maximum Si sheet quality that could be achieved on any other substrate material (exclusive of single-crystal si) under these same growth conditions.

The electrical properties of these Si layers as determined by Hall-effect measurements (van der Pauw method) and by SR probe scans are in relatively good agreement. The SR scans show uniform doping throughout the Iayer thickness except for the layers grown with lower doping concentrations in two runs in which the SiH mass-flow controller was beginning to malfunction, presumably because of a buildup of $\mathrm{SiO}_{2}$ powder in its interior. After the controller was removed from the $\mathrm{SiH}_{4}$ line (the flow rate then being determined by means of the glass rotameter) 4 uniform doping was again achieved.

p-type B-doped polycrystalline Si layers were then grown on several glasses at $\sim 850^{\circ} \mathrm{C}$ in $\mathrm{He}(1.5 \mathrm{lpm})$, with $\mathrm{SiH}_{4}$ flow rates of $11.5 \mathrm{ccpm}$ and diborane flow rates ranging from 5 to $1000 \mathrm{ccpm}$. The substrates used were Corning Code 1715 , Owens-Illinois GS213, Owens-Illinois GS211, and the customary (01) 2 )-oriented sapphire monitor wafer. As indicated in Section 2.3.3, the observed growth rates on sapphire were lower in these experiments $(0.3-0.4 \mathrm{~lm} / \mathrm{min})$ with glasses present than in the precedinq experiments (see above) involving the same deposition conditions but no glass substrates. The growth rates ohserven nn the sapphire substrates were also less than those occurring for the films grown simultaneously on the glasses--typically half to two-thirds of the rate for the glasses, although variations were considerable.

The tendency for somewhat higher carrier concentrations to be measured in B-doped polycrystalline films grown on glasses in He at $\sim 850^{\circ} \mathrm{C}$ than in the simultaneously grown films on sapphire substrates, an effect observed earlier in the program (Ref 4), was again seen in this group of samples. Since very good crystal structure (i.e., essentially epitaxial growth) was found in the films on sapphire it would be expected that the available carrier concentration associated with added $B$ impurity in any polycrystalline film grown at the same time would be less than that measured in the epitaxial film. Since this was not found to be the case, it appears that other electrically active centers of some kind may also have been present. 
Both van der Pauw and SR determinations of layer resistivities showed that the polycrystalline films on the glasses consistently had higher resistivities than did the simultaneously grown films on sapphire, also as observed in the earlier results (Ref 4), except for one case. in which a low B doping concentration was involved (diborane flow rate $5 \mathrm{ccpm}$ ) and the films had very similar resistivity profiles throughout their thicknesses. The SR scans obtained on patrs of films simultaneously grown on substrates of Owens-Illinois GS2ll glass and sapphire at three different B doping levels (diborane flow rates of 5, 150, and $1000 \mathrm{ccpm}$ ) are shown in Figure 2-13.

The SR scans in Figure 2-13a show the similarity in the resistivity profiles for the polycrystalline film and that grown on sapphire for the low doping case mentioned above. Figure 2-13b shows the large difference in resistivity for the two films obtained with a diborane flow rate of $150 \mathrm{ccpm}$. This large difference is believed to be associated primarily with a major difference in the effective carrier mobilities in the two films; separate van der Pauw measurements indicated significantly larger carrier concentration in the polycrystalline film on glass than in the film on sapphire. The large difference in thickness of the two films is also seen in this figure. Figure 2-13c shows the SR scans for the two films obtained with a very large diborane flow rate $(1000 \mathrm{ccpm})$. Again the resistivity of the film on glass exceeds that of the film on sapphire, especially near the interface. The scans indicate fairly uniform resistivity with depth in the film on sapphire, but a steady trend toward higher resistivity as the interface is approached in the film on glass (with several localized fluctuations).

There appears to be some indication in the three films on Gs211 glass for a resistivity variation with depth that could be associated with the presence of a donor impurity occurring in increasing concentration nearer the interface, but the effect is not nearly as pronounced as in films grown under similar conditions on Corning Code 1715 glass (Ref 4). The entire question of effects of impurities in the glass substrates being used in this program is still under investigation. As was mentioned earlier (Section 2.3.3), composition analyses are being carried out on several of the glasses now in use to attempt to identify major electrically active impurity species that might be responsible for some of the observed properties of the CVD Si material on these glasses. Electrical and structural analyses of additional Si films on various glasses are also in progress, and the further results to be obtained may help to clarify this question.

\subsubsection{Properties of Very Thick Si Layers}

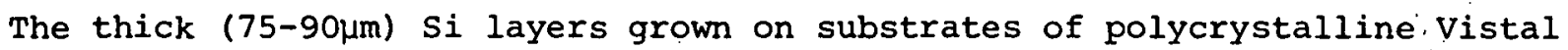
alumina (commercial process, but polished) and single-crystal sapphire, as described in section 2.3.4, exhibited interesting properties. The growth rate previously observed for the parameters used (but for much shorter deposition times) was also maintained throughout the 100 min duration of this experiment. spreading resistance scans through the entire thickness of both sheet samples did indicate, however, a perturbation in the otherwise uniform resistivity profile centered at a distance of $14-17 \mu \mathrm{m}$ from the growth interface. This 


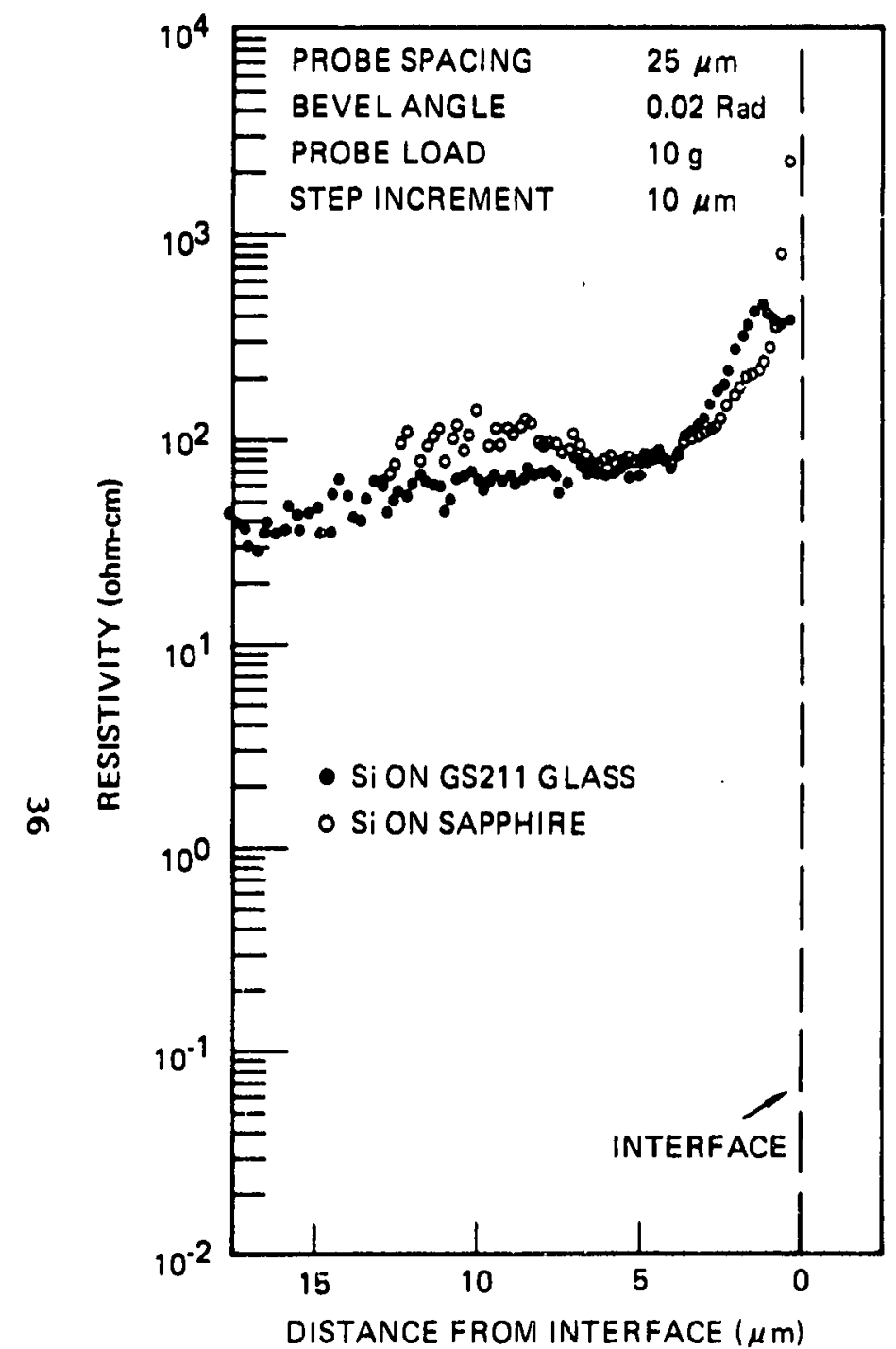

(a)

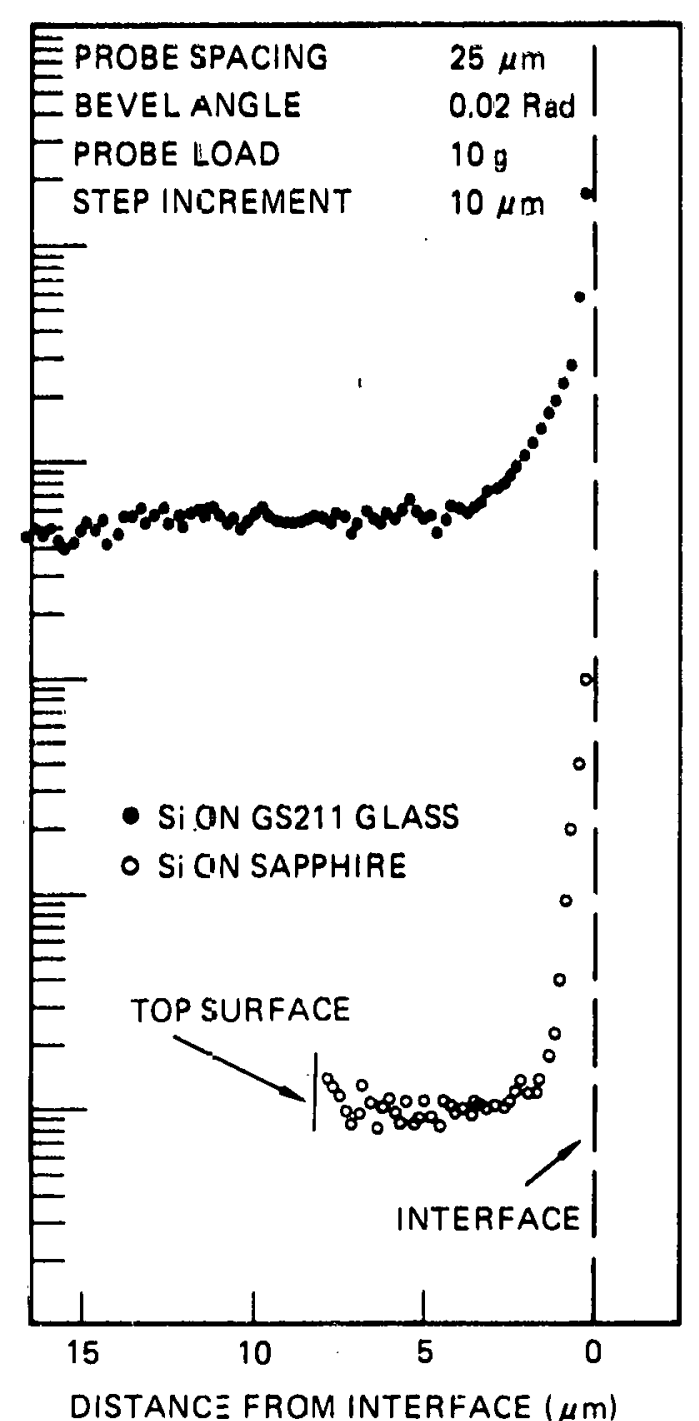

(b)

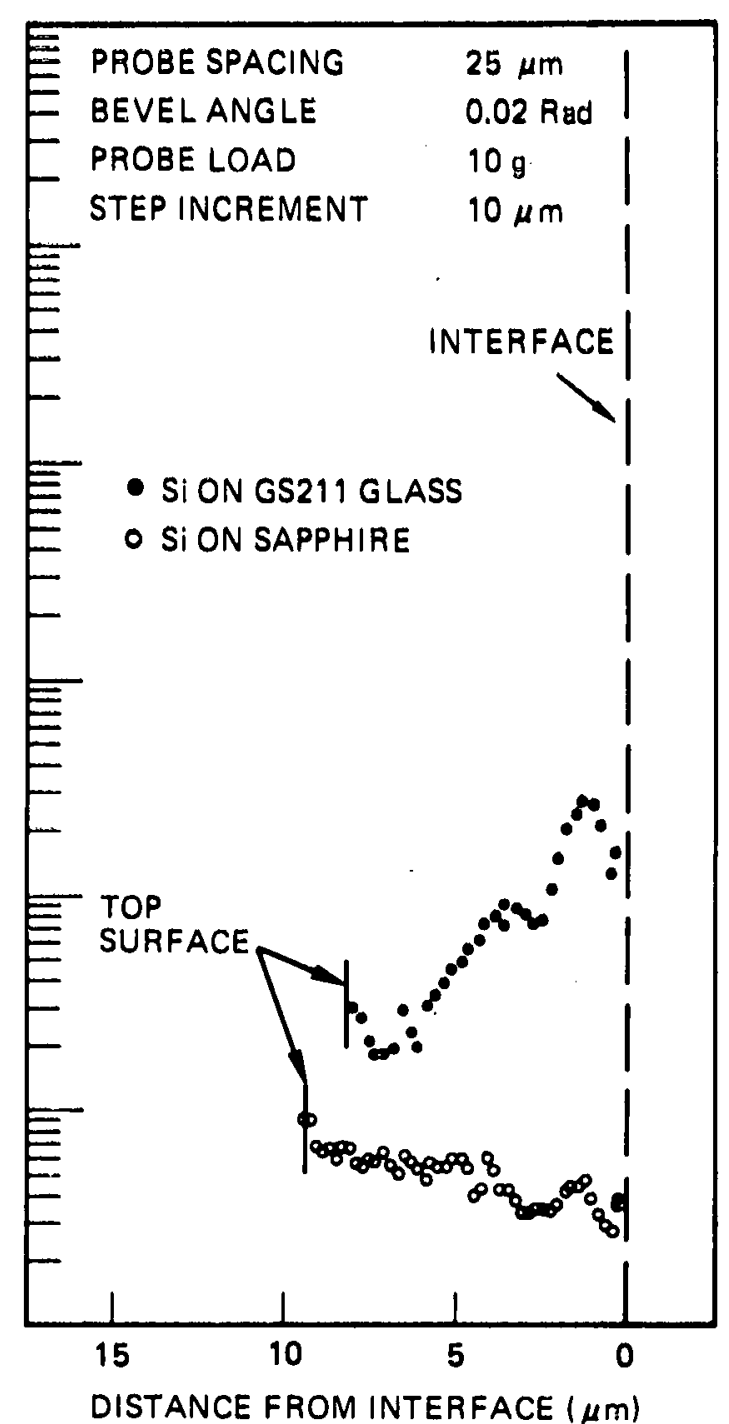

(c)

Figure 2-13. Spreading Resistance Probe Scans Showing Resistivity as Function of Distance from Interface for Three Pairs of CVD Si Films Grown Simultaneously on GS211 Glass and (01I2) Sapphire at $\sim 850^{\circ} \mathrm{C}$ ir. He, for Diborane Flow Rates of a) $5 \mathrm{ccpm}$, b) $150 \mathrm{ccpm}$, c) $1000 \mathrm{ccpm}$. 
perturbation appeared as an increase in resistivity over the uniform average for the rest of the layer and extended over a region about $10 \mu \mathrm{m}$ thick in both films. It is not known what caused this fluctuation, but it is assumed that it was associated with some unidentified transient condition in the reactor gas flow control system.

The resistivity measured by $\mathrm{SR}$ in the layer on polycrystalline alumina was slightly higher than that in the epitaxial layer on sapphire (the latter layer was found by $x$-ray examination to be highly perfect structurally), as expected. The measured carrier concentration in the epitaxial layer was about $1 \times 10^{18} \mathrm{~cm}^{-3}$, a value consistent with B doping data obtained earlier for growth of Si layers in $\mathrm{H}_{2}$ at $\sim 1025^{\circ} \mathrm{C}$ (Ref 1 and Section 2.3.3, this report).

SEM examination of the surface of the layer grown on Vistal alumina produced the photographs shown in Figure $2-14 \mathrm{a}$ and $\mathrm{b}$. The two views--taken at the same magnification but at an angle of $45 \mathrm{deg}$ and normal to the surface, respectively-clearly show the variety of surface features occurring as well as the high incidence of features with transverse dimensions exceeding $25 \mu \mathrm{m}$. The extremely rough texture of the surface is further emphasized by the SEM photographs in Figure 2-15, which show unpolished fracture cross sections of the layer and the polycrystalline substrate in two different regions. In the center of Figure $2-15$ a a region in which the Si layer filled a sizeable void in the initial surface of the alumina substrate can be clearly seen. Figure 2-15b, showing a region near the edge of the small piece being examined, further emphasizes the rough but faceted texture of the layer and also shows a major crack in the layer itself. It is not known if this crack resulted from fracturing the small piece of the sample used for examination in the SEM or if it had occurred previously, as a result of the thermally induced stresses near the interface.

The presence of defects of some kind near the interface (i.e., within about $10 \mu \mathrm{m})$ in the Si layer on the Vistal alumina had been indicated by the SR scan through the full thickness of the layer. This was more clearly demonstrated however, by two SR scans at constant depths in the layer--one $\sim 10 \mathrm{~m}$ below the top surface and one $\sim 15 \mu \mathrm{m}$ from the interface (Figure 2-16); both scans extended for distances of several millimeters parallel to the layer-substrate interface.

The scan at $10 \mu \mathrm{m}$ depth shows a very uniform resistivity of $\sim 0.04$ ohm-cm across the sample, consistent with the SK scan of resistivity versus depth which had indicated a nearly constant value of $0.4-0.5 \mathrm{ohm}-\mathrm{cm}$ for the upper $50 \mu \mathrm{m}$ of the polycrystalline layer. The excursions to higher resistivity values at five different locations in the $5 \mathrm{~mm}$-long scan are associated with grain boundaries in the Si layer that probably correlate with grain boundaries in the initial polycrystalline substrate surface. The data shown in Figure 2-16 should be compared with that obtained in a similar scan on a Si layer grown on refired Vistal (containing larger individual grains), described in the Annual Report (Ref 1, pp. 109-112).

The scan made at a distance of $\sim 15 \mu \mathrm{m}$ from the interface indicates an average resistivity of $\sim 0.2 \mathrm{ohm}-\mathrm{cm}$ - again consistent with the resistivity found at this depth (in the perturbed region mentioned earlier) in the SR scan through 


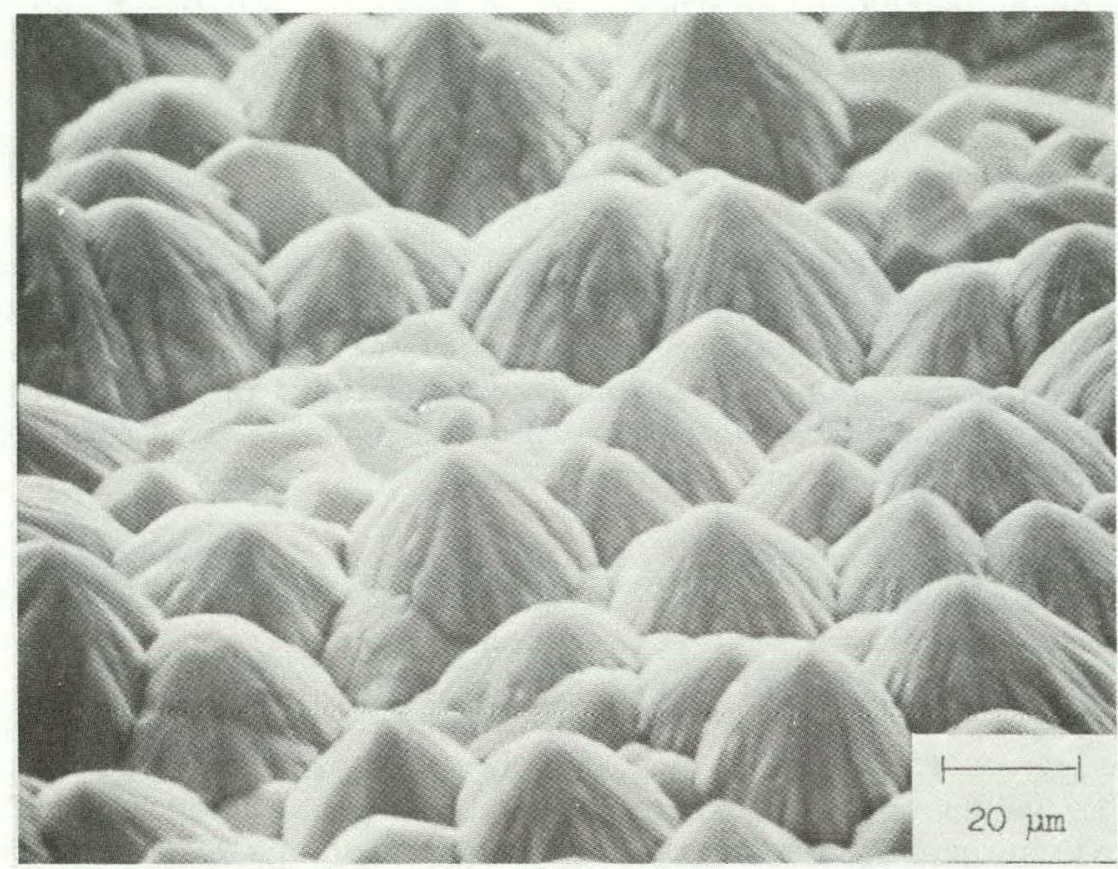

(a)

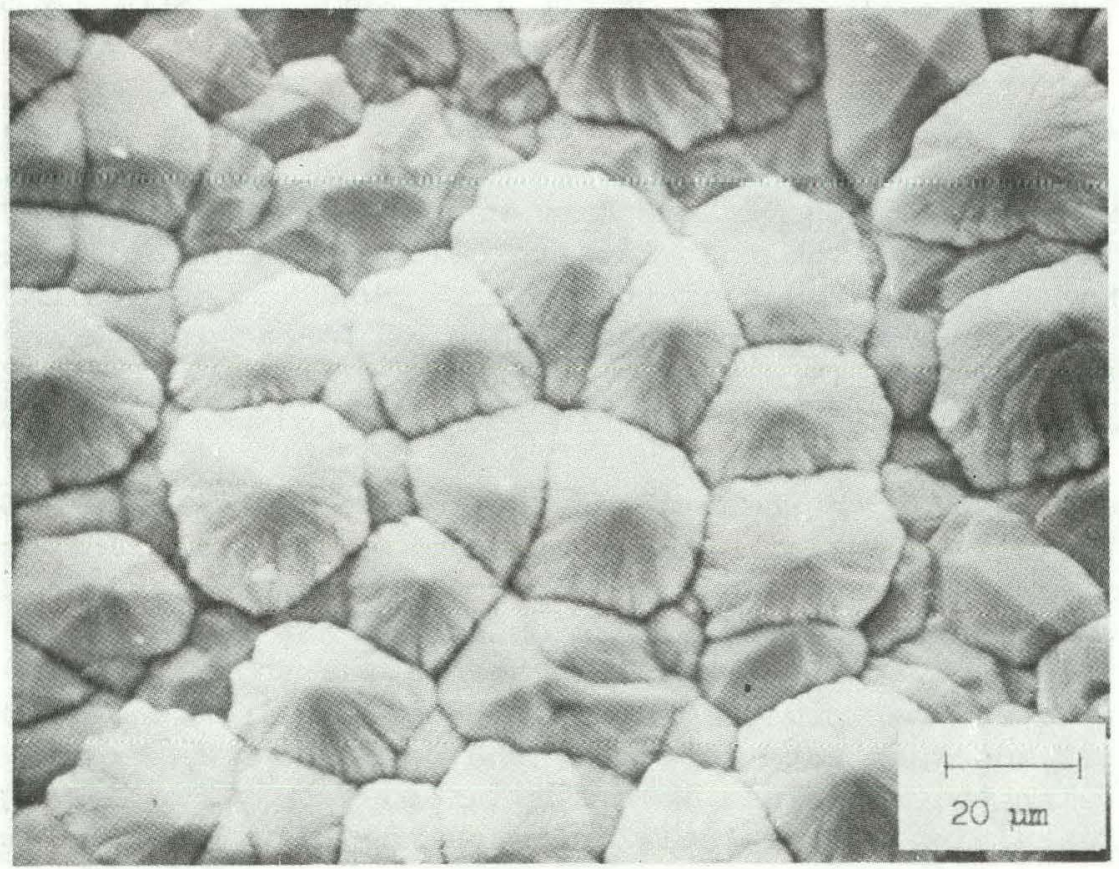

(b)

Figure 2-14. SEM Photographs of Surface of 85-90um Thick Doped CVD Si Layer Grown on Polycrystalline Alumina (Vistal) Substrate at $\sim 1030^{\circ} \mathrm{C}$ in $\mathrm{H}_{2}$. a) View at 45 deg Angle with Surface, b) Perpendicular View. 


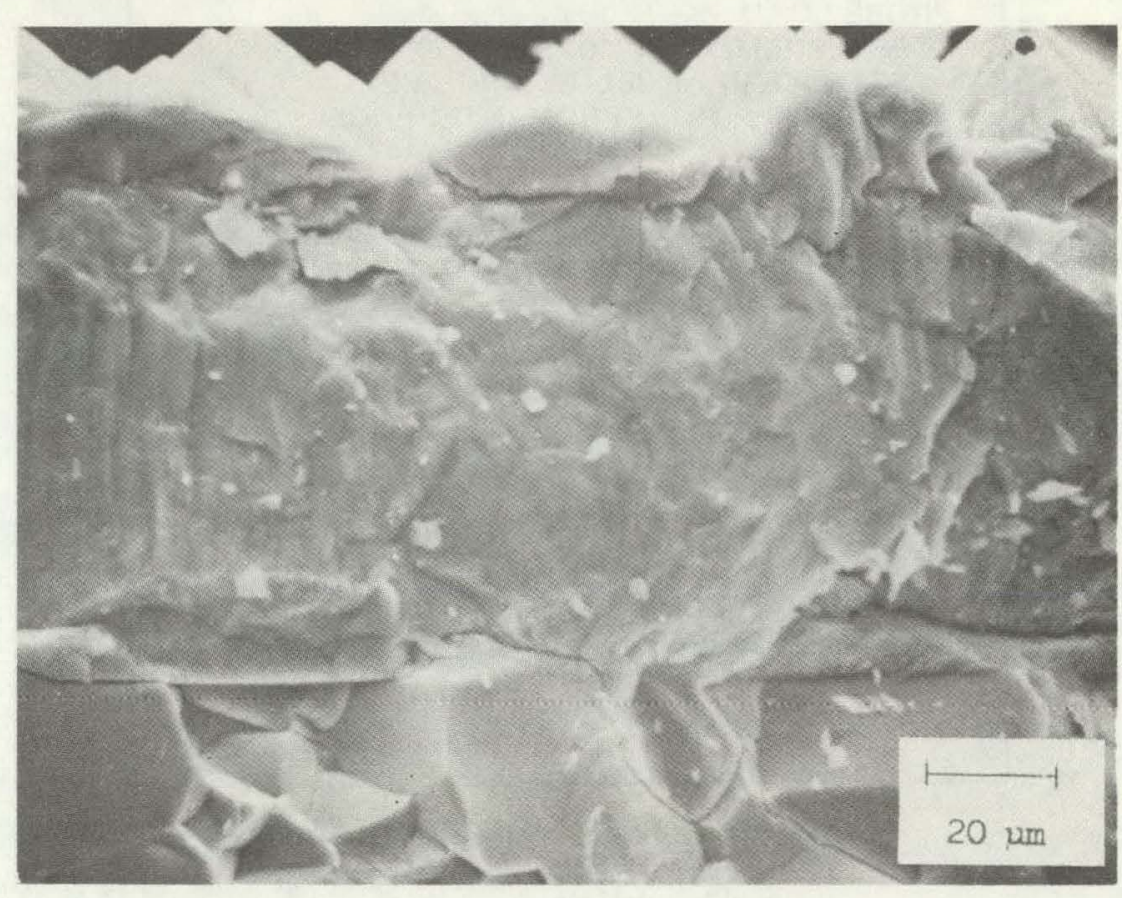

(a)

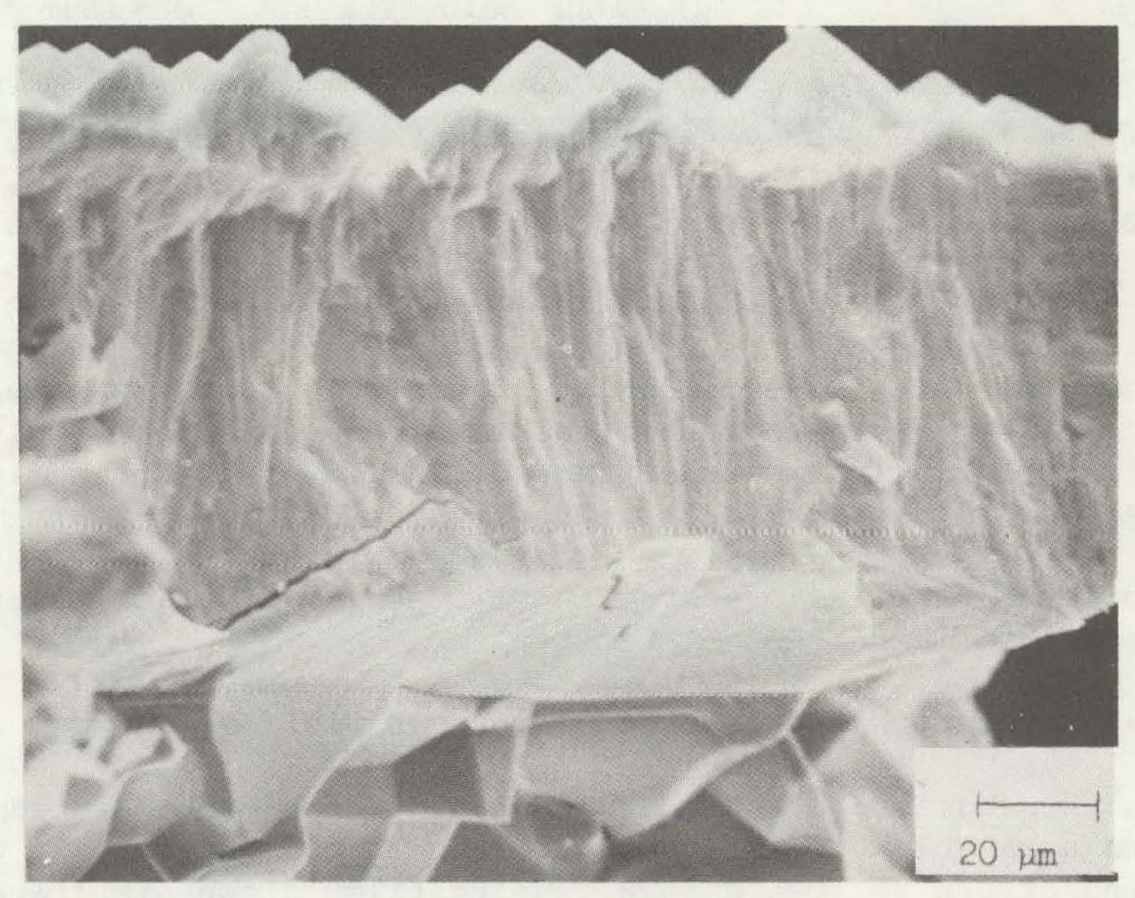

(b)

Figure 2-15. SEM Photographs of Unpolished Fracture Cross Sections of Sample of Figure 2-14, Showing Rough Surface Texture and a) Si Growth into Voids in Suhstrate Surface and b) Crack in Layer near Interface. 


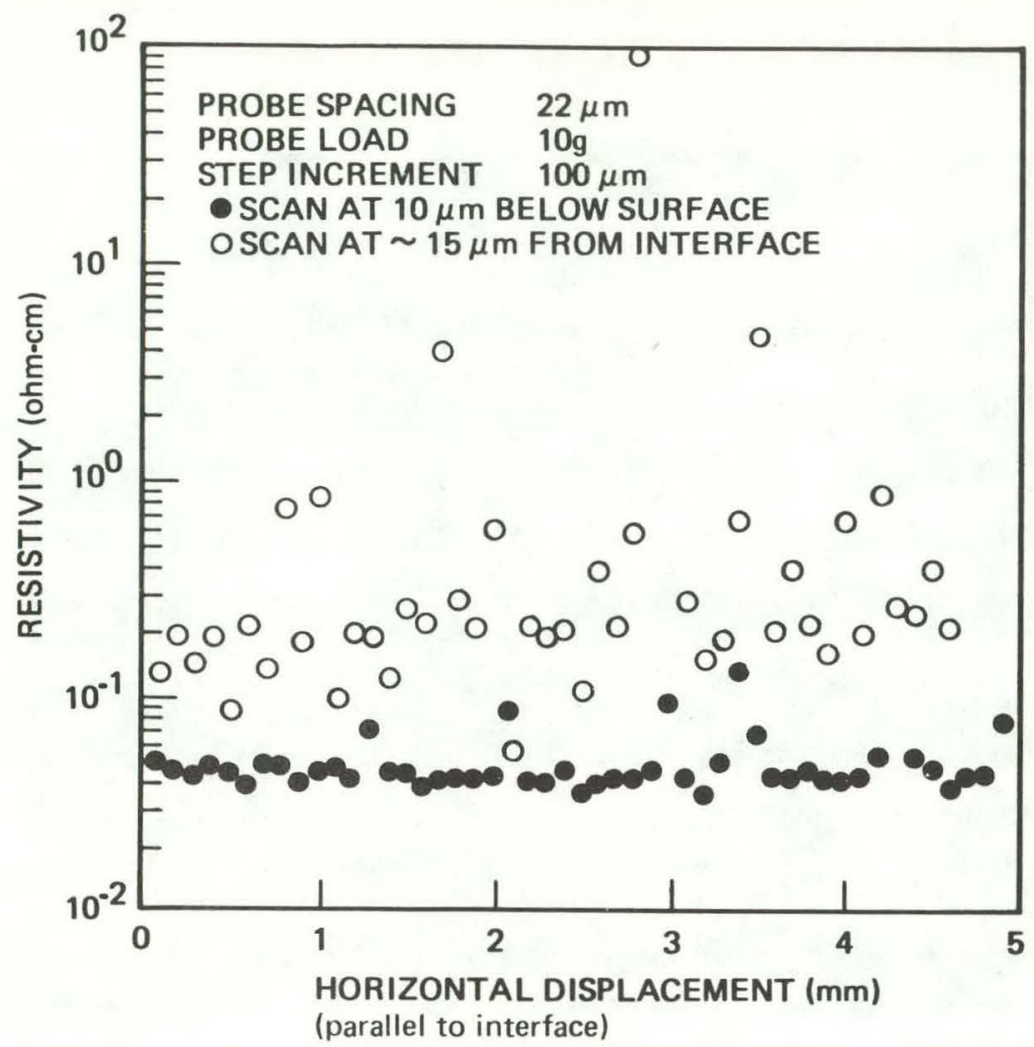

Figure 2-16. Spreading Resistance Probe Scans Showing Resistivity as Function of Horizontal Displacement Parallel to Interface, at Two Constant Depths in Layer of Figure 2-14. a) $10 \mu \mathrm{m}$ below Surface, b) $\sim 15 \mu \mathrm{m}$ from Interface.

the thickness of the layer. However, at this depth there are extreme excursions in resistivity that are associated with numerous voids, cracks, and other defects, some of which were visible in the optical microscope along the beveled surface near the interface.

In contrast, the surface of the thick epitaxial layer grown on the sapphire substrate is shown in the SEM photograph in Figure 2-17a, a view normal to the layer surface. The crystallographic facets are seen to be largely overgrown, and the relatively smooth surface of the layer is shown clearly in the SEM photograph of an unpolished fracture cross section in Figure 2-17b.

The properties of other samples prepared in this series of thick-layer depositions will be described in subsequent reports.

\subsubsection{Electrical Properties of Polycrystalline CVD Si Films}

A study has been in progress to establish the relationship between added B concentration and available carrier concentration in polycrystalline CVD Si films doped during growth at $1025^{\circ} \mathrm{C}$ in $\mathrm{H}_{2}$, using films grown simultaneously on various alumina and single-crystal sapphire substrates. It has been established that a large and rapid decrease in available (measured) carrier concentration occurs in the polycrystalline films as the added doping impurity is decreased in the range from $10^{18}$ to $10^{16} \mathrm{~cm}^{-3}$ (Ref 4, pp. 34-37). The exact nature of the functional dependence in this range is still not known, 


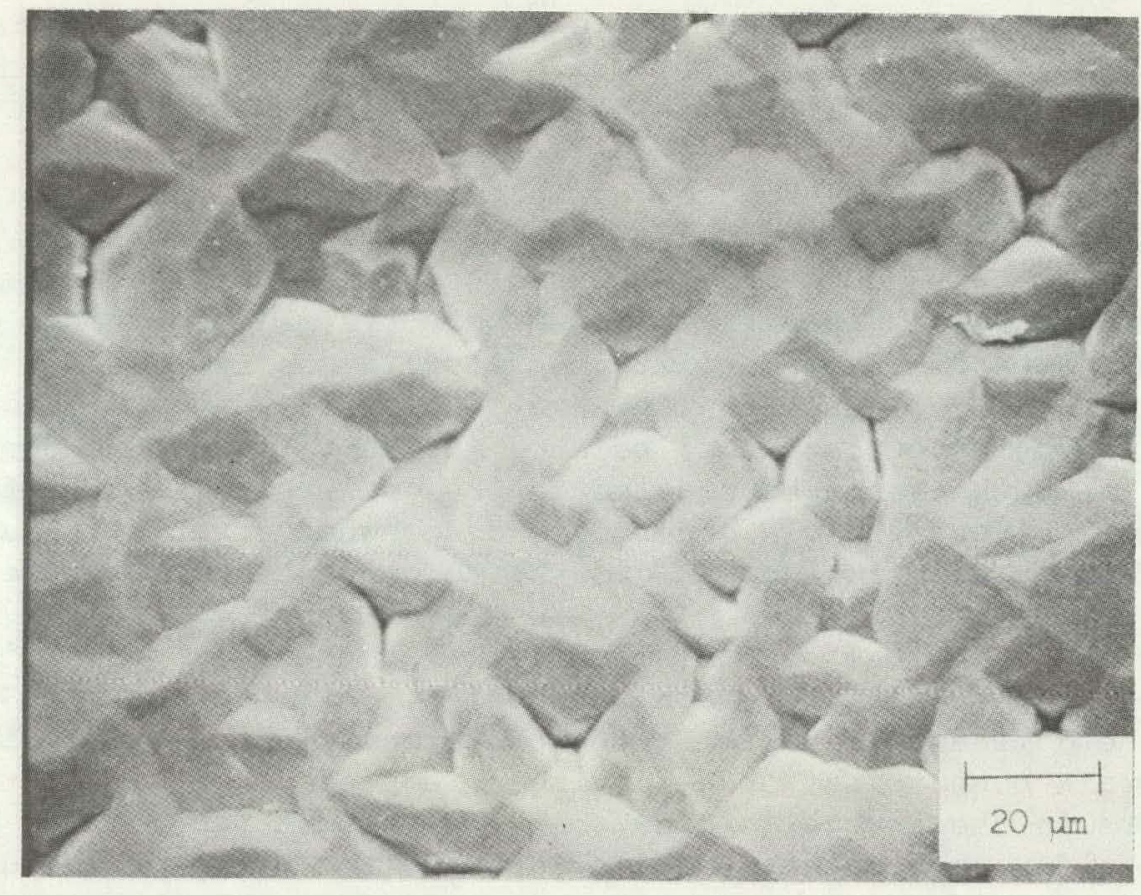

(a)

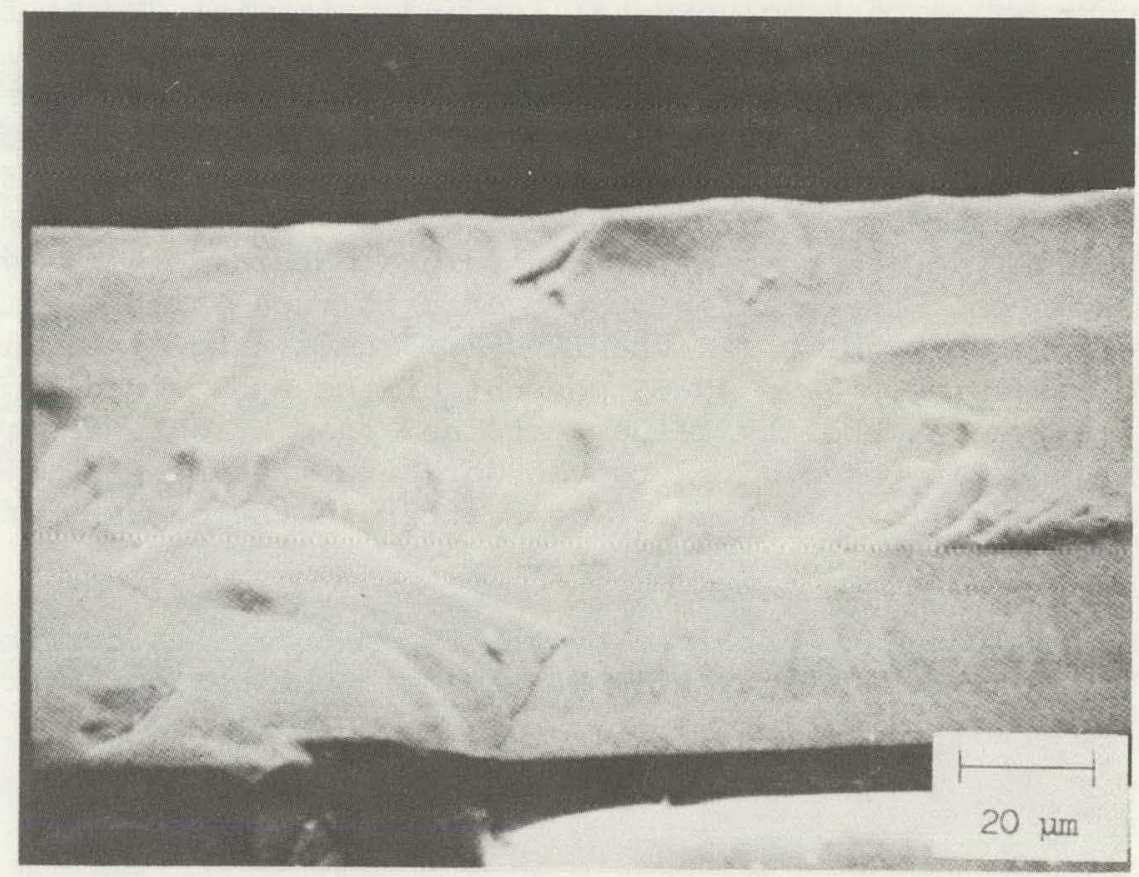

(b)

Figure 2-17. SEM Photographs of 75-8qum Thick Doped CVD Si Layer Grown on (0112) Sapphire Simultaneously with Sample of Figure 2-14, a) View Normal to Surface, b) Unpolished Fracture Cross Section. 
but the general shape of the curve is clear. The result appears to be consistent with Seto's model (Ref 7 ), which is based on the observed behavior of B-ion-implanted polycrystalline Si.

However, additional room-temperature carrier mobility data in the critical dopant concentration range are required to determine if the mobility behavior observed by Seto or that found by Cowher and Sedgwick (Ref 8), or yet a third type of behavior, characterizes these doped polycrystalline films. The principal difference in the observed mobility behavior in the two cases is that there is a strong minimum (i.e., essentially zero) in mobility at a doping concentration ( $10^{18} \mathrm{~cm}^{-3}$ in Seto's films) related to the ratio of the density of trapping centers in the grain boundaries to the grain size, in the former case; Cowher and Sedgwick found only a general (and somewhat erratic) reduction in mobility for films doped (during CVD growth) to concentrations above $10^{17} \mathrm{~cm}^{-3}$.

Seto considers the principal mechanism controlling the film properties to be that of carrier trapping at the grain boundaries, while Cowher and Sedgwick subscribe to the dominant mechanism being preferential deposition of impurity atoms at the grain boundaries, thus leaving a reduced density of active impurity centers in the crystal grains. At the present time either mechansim appears feasible for the polycrystalline CVD Si films being produced in this program.

Throughout the contract work to date, measurements have been made of the electrical properties of both polycrystalline and epitaxial CVD Si films on various substrates by van der Pauw and--where possible--conventional Hallbridge methods. Carrier concentrations from $\sim 10^{12}$ to $>10^{19} \mathrm{~cm}^{-3}$ have been measured, and the results obtained by the two methods have been compared to show the empirical relationships. Generally, the two methods give fairly predictable carrier concentration results above $\sim 10^{15} \mathrm{~cm}^{-3}$, with the bridge method results usually 60-75 percent of the values obtained by the van der Pauw method. BElow $10^{15} \mathrm{~cm}^{-3}$ the scatter of the data is much larger, although the same general relationship holds; in the $10^{13}-10^{14} \mathrm{~cm}^{-3}$ range the bridge method appears to give values more like 40-60 percent of those obtained by the van der Pauw technique. Mobility values obtained from bridge measurements are consistently higher than those given by van der Pauw measurements, throughout the concentration range investigated. The scatter in the data is larger in this case than for the carrier concentrations.

Plots of the accumulated data obtained by the two methods for carrier concentration, mobility, and resistivity will be given in the next quarterly report. 


\subsection{TASK 6. FABRICATION AND EVALUATION OF SOLAR CELL STRUCTURES}

The contract provides for the fabrication and evaluation of experimental solar cells in CVD Si sheet on various substrates. This part of the work is done by the Photoelectronics Group of Optical Coating Laboratory, Inc., in City of Industry, $C A$, on a purchased-services basis.

The contract Statement of Work stipulates that the contractor shall "fabricate and evaluate solar cells with a minimum of $1 \mathrm{~cm}^{2}$ area" and that "techniques for producing solar cells from these films shall be, to the maximum extent possible, previously developed procedures." It is further stipulated that "one solar cell, on the average, shall be made per week during this program."

With the approval of the JPL Contract Technical Manager at the start of the program an arrangement was developed with OCLI that provides the necessary solar cell processing and evaluation work, thus allowing Rockwell personnel to concentrate on the S1 CVD investigations.

Preliminary results on the photovoltaic properties of a group of experimental solar cell structures fabricated at OCLI in Si sheet samples involving substrates of several glasses, polycrystalline alumina, and single-crystal sapphire (as baseline reference material) were given in Quarterly Report No. 3 (Ref 4). Characterization of these experimental cells was completed early in this quarter, and the results are summarized below.

Based on these results, another group of experimental cells was fabricated later in the quarter using Si sheet samples already described (șee Sections 2.3.3 and 2.5.3). These samples were prepared on substrates of single-crystal Si, sapphire, and several glasses, with a variety of $B$ doping levels and relative thicknesses of the $\mathrm{p}$ and $\mathrm{p}^{+}$regions. Although characterization was not complete by the end of the quarter, it appears that performance of these CVD cells is critically dependent on base region doping density (more so than in single-crystal Si cells), and low photogenerated currents again indicate seriously reduced charge collection efficiencies--even in epitaxial material.

\subsubsection{Solar Cell Processing Procedures}

Details of the handling, processing, and measurement techniques applied to any one sample at OCLI are varied to accommodate the characteristics and/or limitations of the sample. There is a standard sequence of procedures that is generally followed to whatever extent possible. Standard solar cell processing methods are used, to allow correlation of results with those obtained with conventional bulk single-crystal $\mathrm{Si}$ cells that are always processed along with the $\mathrm{Si}$ sheet samples to serve as controls.

The Si sheet samples received by OCLI are first routinely checked for surface characteristics, thickness, conductivity type, and resistivity by standard methods. In some cases a preferential etch is applied to delineate individual crystallites in selected areas; various surface treatments are used, if necessary, to prepare the sample for $p-n$ junction formation. 
A junction is formed by diffusion of phosphorus into the p-type sheet material. The temperature and time used for the diffusion (which employs a POCl $_{3}$ source) are modified slightly from time to time, depending upon the samples being processed, but are usually adjusted to produce junctions 0.3-0.6 $\mathrm{m}$ deep into the p-type sheet material. Diffusion oxides are removed and open-structure ohmic contacts are applied, using conventional deposition methods. The junctions are then isolated to reduce edge-leakage, and in some cases antireflection coatings are applied to permit more accurate measurement of photovoltaic conversion efficiency.

With illumination from a defined light source, such as the AMO or the AMl spectrum from a solar simulator, the conventional photovoltaic parameters I sc $^{\prime}$ $v_{\text {oc' }}$ Pax $_{\text {max }}$ CFF, and power conversion efficiency are determined. The diffusión lengths of minority carriers in the completed cell structure is estimated or determined, when possible, by a photovoltaic method using a monochromatic light source. For samples in which the uniformity of photoresponse is of interest (for example, to examine effects of grain boundaries) a photocurrent scan of the surface of the sheet can be made using a small-diameter light spot to compare the output of various regions of the sample.

In most instances an array of small-diameter mesa diodes is formed on the junction structure by etching techniques. These diodes are evaluated separately to indicate the degree of homogeneity in the sample and to correlate the electrical properties with any visible structural features (e.g., grain boundaries). Diode measurements include the photovoltaic parameters $I$ and $\mathrm{v}_{\mathrm{f}}$ and dark and light forward diode characteristic. Other measurements are made as required, depending upon the particular samples involved.

Reports of all data and related observations concerning the sheet samples are supplied to Rockwell by OCLI. Technical consulation on the correlations between observed sheet properties and the details of the CVD sheet growth process takes place regularly as part of the working arrangement.

\subsubsection{Characteristics of Experimental Solar Cells in CVD Si Sheet Material}

The evaluation of samples OCLI-25 through OCLI-35 was completed at OCLI early in the quarter. These samples had been processed in two separate batches; processing details for the first batch (A) were given in Quarterly Report No. 3 (Ref 4, p. 45). Only slightly different procedure was used for the second batch (B). In each case single-crystal 1-2 ohm-cm high-lifetime Si control wafers were processed along with the $\mathrm{Si}$ sheet samples. Also, each batch contained one piece of sample OCLI-35, a $\mathrm{p} / \mathrm{p}^{+}$double-layer epitaxial $\mathrm{S} \mathrm{I}_{7} \mathrm{film}$

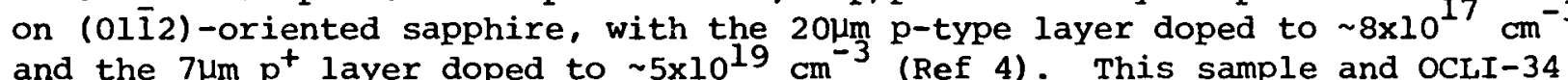
were the first sheet samples in which the $\mathrm{p} / \mathrm{p}^{+}$structure had been used for fabrication of experimental cell structures in this program.

Samples included in batch A were OCLI-25,26, 28,29,32,33,35-1, and controls Al and A2. Batch B included samples OCLI-27,30,31,34,35-2, and controls B1 and B2. The principal properties of samples OCLI-25 through 35, as prepared 
for delivery to OCLI, are given in Table 2-1 together with the relevant deposition parameters. This information was first given in Table 2-5 of Quarterly Report No. 3 (Ref 4), but it is repeated here for reference.

Diffusion of $\mathrm{P}$ (from POCl ${ }_{3}$ ) was done on both batches (separately) at $840^{\circ} \mathrm{C}$ for $20 \mathrm{~min}$; no pre-diffusion etch was used. Batch $\mathrm{A}$ samples were etched into $1 \mathrm{~mm}$ dia circular mesas by wax masking through apertures, while batch $B$ samples were photoresist-masked and etched into rectangular $2 \mathrm{~mm} \times 1 \mathrm{~mm}$ mesas; mesa heights were $\sim 5 \mu \mathrm{m}$. A coarse contact grid pattern of narrow Ti-Ag lines (not sintered) had been deposited onto the batch $A$ samples before the mesa etching, and some mesas were crossed by a grid line and some were not; only those free of the grid line were evaluated. An annular contact of Ti-Ag (not sintered) was deposited (using masking techniques) around the edges of the batch $A$ samples, and a similar line contact along one edge only was applied to each of the batch B samples; the contacts on three samples of batch B (including one control wafer) were sintered to determine if a significant change in measured properties resulted, but it ald not.

Measurements were made with several different kinds of illumination: 1) moderateintensity ( AMO, i.e., 1 sun) tungsten lamp; 2) high-intensity tungsten lamp; 3) LED, with $\sim 0.9 \mu \mathrm{m}$ wavelength radiation; 4) tungsten lamp with filter wheel (for spectral response); 5) AMO solar simulator, using both xenon and tungsten lamps; 6) xenon lamp of simulator; and 7) tungsten lamp of simulator. During illumination, mechanical probe contact was made to the mesa top and to the Ti-Ag ohmic base contact.

Open-circuit photovoltages $\mathrm{v}_{\text {oc }}$ were first obtained with the moderate-intensity ( 1 sun) tungsten lamp. Initial results for the samples of batch $A$ were reported in Quarterly Report No. 3 (Ref 4, Table 2-6). Results for both batches are summarized in Table 2-2; several mesa devices on each sample in batch $A$ were measured, but only one device on each sample of batch $B$ was measured.

These preliminary results indicated that fairly good uniformity of response from mesa to mesa on a given sample occurred for the samples of batch $A$, but that major differences in response were obtained from sample to sample in both batches, depending upon the properties of the CVD Si sheet material. In particular, the epitaxial sheet material on single-crystal sapphire substrates exhibited relatively high $v_{\text {og }}$ values, although not as high as the $v$ for the single-crystal Si control wafers. The polycrystalline samples showed much lower photovoltages, as might be expected.

Additional measurements were then made on both groups of samples using a highintensity tungsten lamp, with an output roughly equivalent to 2 suns. The open-circuit voltage $\mathrm{V}_{\mathrm{c}}$ and the photogenerated increase in reverse current at $-1 V$ were measured under illumination, the latter taken as an indication of the short-circuit current $I_{\text {. }}$. The results are given in Table 2-3 for three (or two) different mesascievices on each sample in both groups. Short-circuit current densities $J_{S C}$ have been calculated in each cąse by using the nominal area of the individual mesas in batch $A\left(7.0 \times 10^{-3} \mathrm{~cm}^{2}\right)$ and in batch $B$ 
Table 2-1. Properties of B-doped CVD SI Sheet Samples Submitted to OCLI in Fourth Quarter for Solar Cell Processing and Measurement

\begin{tabular}{|c|c|c|c|c|c|c|c|c|c|c|c|c|}
\hline $\begin{array}{c}\text { SAMPLE } \\
\text { NO. }\end{array}$ & $\begin{array}{l}\text { SUBSTRATE } \\
\text { MATERIAL } \\
\text { AND } \\
\text { THICKNESS }(\mu \mathrm{m})\end{array}$ & $\begin{array}{c}\text { OBSERV. } \\
\text { DEPOS. } \\
\text { TEMP. } \\
\left({ }^{\circ} \mathrm{C}\right)\end{array}$ & $\begin{array}{c}\text { CARR\|ER } \\
\text { GAS AND } \\
\text { FLOW RATE } \\
(\ell \mathrm{pm})\end{array}$ & $\begin{array}{l}\mathrm{SiH}_{4} \\
\text { FLOW } \\
\text { RATE } \\
\text { (ccpm) }\end{array}$ & $\begin{array}{c}\text { DOPANT } \\
\text { GAS } \\
\text { FLOW RATE } \\
\text { (ccpm) }\end{array}$ & $\begin{array}{c}\text { FILM } \\
\text { THICK. } \\
\text { NESS } \\
\text { (um) }\end{array}$ & $\begin{array}{c}\text { AVE. } \\
\text { GROWTH } \\
\text { RATE } \\
\left(\mu_{\mathrm{m} / \mathrm{min})}\right.\end{array}$ & $\begin{array}{l}\text { FILM } \\
\text { RESIS. } \\
\text { TIVITY } \\
\text { (ohm-cm) }\end{array}$ & $\begin{array}{l}\text { HOLE } \\
\text { CONCEN. } \\
\text { TRATION } \\
\left(\mathrm{cm}^{-3}\right)\end{array}$ & $\begin{array}{c}\text { HALL } \\
\text { MOBILITY } \\
(\mathrm{cm} 2 / V \cdot s \theta c)\end{array}$ & $\begin{array}{l}\text { SAMPLE } \\
\text { DIMENSIONS } \\
\text { (cm) AND } \\
\text { APPROX } \\
\text { AREA }\left(\mathrm{cm}^{2} \text { ) }\right.\end{array}$ & $\begin{array}{l}\text { FILM } \\
\text { STRUCTURE } \\
\text { AND/OR } \\
\text { SURFACE } \\
\text { TEXTURE }\end{array}$ \\
\hline OCLI.25 & $\begin{array}{l}\text { Corning Code } \\
1715 \text { glass } \\
800\end{array}$ & 850 & $\begin{array}{l}\mathrm{He} \\
1.5\end{array}$ & 10 & 50 & 30 & $\sim 0.6$ & $8+$ & $3.0 \times 10^{17} t$ & $2.6 t$ & $\begin{array}{l}1.1 \times 0.9 \\
0.99\end{array}$ & $\begin{array}{l}\text { Poly: }\{100\} \\
\text { prefarred } \\
\text { oriantation }\end{array}$ \\
\hline OCLI.26 & $\begin{array}{l}\text { Corning Code } \\
1715 \text { glass } \\
800\end{array}$ & 885 & $\begin{array}{l}\mathrm{He} \\
1.5\end{array}$ & 10 & 500 & $\sim 11$ & 0.24 & 0.20 ** & $2.8 \times 10^{18 *}$ & $12^{* * *}$ & $\begin{array}{l}1.5 \times 1.0 \\
1.5\end{array}$ & $\begin{array}{l}\text { Poly: }\{100\} \\
\text { proferred } \\
\text { orientation }\end{array}$ \\
\hline OCLI-27 & $\begin{array}{l}\text { Owens-Illinois } \\
\text { GS211 gless } \\
1050\end{array}$ & 851 & $\begin{array}{l}\mathrm{He} \\
1.5\end{array}$ & 10 & 50 & $\sim 18$ & 0.38 & $.0 .37^{* *}$ & $1.2 \times 10^{18^{* *}}$ & $14 *$ & $\begin{array}{l}1.2 \times 1.3 \\
1.6\end{array}$ & $\begin{array}{l}\text { Poly: }\{100\} \\
\text { preferred } \\
\text { orientation }\end{array}$ \\
\hline OCLI.28 & $\begin{array}{l}\text { Owens-Illinois } \\
\text { GS213 glass } \\
1025\end{array}$ & 858 & $\begin{array}{l}\mathrm{He}_{\theta} \\
1.5\end{array}$ & 10 & 500 & -16 & 0.36 & $0.37^{* *}$ & $1.6 \times 10^{18^{* *}}$ & $10 * *$ & $\begin{array}{l}1.2 \times 1.2 \\
1.4\end{array}$ & $\begin{array}{l}\text { Poly: (100) } \\
\text { preferred } \\
\text { orientation }\end{array}$ \\
\hline OCLI.29 & $\begin{array}{l}\text { Owans-Illinois } \\
\text { GS213 glass } \\
1025\end{array}$ & 856 & $\begin{array}{l}H_{8} \\
1.5\end{array}$ & 10 & 50 & 28 & 0.32 & $8.3^{\text {** }}$ & $2.5 \times 10^{16^{*}}$ & $40 * *$ & $1.3 \times 1.1$ & $\begin{array}{l}\text { Poly: }\{100\} \\
\text { preferred } \\
\text { orientation }\end{array}$ \\
\hline OCLI.30 & $\begin{array}{l}\text { Owens-Illinois } \\
\text { GS185 glass } \\
1025\end{array}$ & 839 & $\begin{array}{l}\mathrm{He}_{8} \\
1.5\end{array}$ & 10 & 60 & 38 & 0.42 & $14 * *$ & $1.2 \times 10^{17^{* *}}$ & $3.8^{* *}$ & $\begin{array}{l}1.2 \times 1.2 \\
1.4\end{array}$ & $\begin{array}{l}\text { Poly: }\{100\} \\
\text { preferred } \\
\text { orientation }\end{array}$ \\
\hline OCLI.31 & $\begin{array}{l}\text { Owens-Illinois } \\
\text { GS211 glass } \\
1050\end{array}$ & 861 & $\begin{array}{l}\mathrm{He}_{\theta} \\
1.5\end{array}$ & 10 & 300 & 27 ** & $0.3^{* * *}$ & $0.5^{* * * *}$ & $10^{18^{* * *}}$ & $10^{\text {*n* }}$ & $\begin{array}{l}1.2 \times 1.1 \\
1.3\end{array}$ & $\begin{array}{l}\text { Poly: }\{100\} \\
\text { preferred } \\
\text { orientation }\end{array}$ \\
\hline OCLI.32 & $\begin{array}{l}\text { (01T̄2) } A l_{2} \mathrm{O}_{3} \\
\text { (Polishod) } \\
750\end{array}$ & 1025 & $\begin{array}{l}\mathrm{H}_{2} \\
1.5\end{array}$ & 10 & 5 & 25 & 1.4 & $0.12^{* * *}$ & $6 \times 10^{17^{* *}}$ & $88 * *$ & $\begin{array}{l}1.2 \times 0.8 \\
0.96\end{array}$ & Epitaxial \\
\hline OCLI.33 & $\begin{array}{l}\text { MRC Superstrace } \\
\text { Alumine (as mfd) } \\
875\end{array}$ & 1025 & $\begin{array}{l}\mathrm{H}_{2} \\
1.5\end{array}$ & 10 & 5 & 25 & 1.4 & $2.3 t$ & $2.6 \times 10^{17 \dagger}$ & $11 t$ & $\begin{array}{l}1.2 \times 0.8 \\
0.86\end{array}$ & $\begin{array}{l}\text { Polv: }\{110\} \\
\text { preferred } \\
\text { orientation }\end{array}$ \\
\hline OCLI.34 & $\begin{array}{l}(01 \overline{12}) \mathrm{Al}_{2} \mathrm{O}_{3} \\
\text { (Polished) } \\
750\end{array}$ & 1025 & $\begin{array}{l}\mathrm{H}_{2} \\
1.5\end{array}$ & 10 & $\begin{array}{l}\text { 1) } 300+t t \\
\text { 2) } 8+t\end{array}$ & $\begin{array}{l}114^{* * * *} \\
2117^{* * *}\end{array}$ & $\begin{array}{l}\text { 1)1.3*** } \\
\text { 2)1.3*** }\end{array}$ & $\begin{array}{l}110.005^{* *} \\
210.1^{* * *} \mid\end{array}$ & $\begin{array}{l}* \text { 1) } 10^{19^{* * *}} \\
\text { 2) } 5 \times 10^{* 17^{* * *}}\end{array}$ & $\begin{array}{l}\text { 1) } 35^{* * *} \\
\text { 2) } 90^{* * *}\end{array}$ & $\begin{array}{l}2.3 \times 1.2 \\
2.8\end{array}$ & $\begin{array}{l}\text { Epitaxial (both } \\
\text { layers) }\end{array}$ \\
\hline OCLI.35 & $\begin{array}{c}(01 \overline{12}) \mathrm{Al}_{2} \mathrm{O}_{3} \\
\text { (Polishod) } \\
750\end{array}$ & 1031 & $\begin{array}{l}\mathrm{H}_{2} \\
1.5\end{array}$ & 10 & $\begin{array}{l}\text { 1) } 295+t \\
\text { 2) } 6+t\end{array}$ & $\begin{array}{l}116^{* * * *} \\
2121 * * *\end{array}$ & $\begin{array}{l}\text { 1)1.1*w* } \\
\text { 2)1.5*w* }\end{array}$ & $\begin{array}{l}110.005^{* * 1} \\
210.1^{* * 1}\end{array}$ & $\begin{array}{l}1 / 2 \times 10^{19} \\
2 / 5 \times 10^{*}\end{array}$ & $\begin{array}{l}* \text { 1) } 35^{* * * *} \\
\text { (2) } 90^{* * * *}\end{array}$ & $\begin{array}{l}2.3 \times 1.3 \\
3.0\end{array}$ & $\begin{array}{l}\text { Epitaxial (both } \\
\text { layers) }\end{array}$ \\
\hline
\end{tabular}

"Films B-doped from $\mathrm{B}_{2} \mathrm{H}_{6}$-in-He (46 ppm)

tMessured by Hall bridge method

* Measured by van der Pauw mathod

t+Double layer: No. 1 deposited first, then No. 2

** Estimate, based on CVD parameters and other factors. 
Table 2-2. Photovoltage Response* of P-diffused n/p Mesa-type Solar Cells Fabricated in B-doped CVD Si Sheet Material on Various Substrates

\begin{tabular}{|c|c|c|c|c|c|c|c|}
\hline \multicolumn{4}{|c|}{ SAMPLE } & \multirow{2}{*}{\multicolumn{4}{|c|}{$\begin{array}{l}\text { OPEN-CIRCUIT PHOTOVOLTAGE** } \\
\qquad V_{\text {oc }}(\mathrm{mV})\end{array}$}} \\
\hline Number & $\begin{array}{l}\text { Substrate } \\
\text { Material }\end{array}$ & $\begin{array}{c}\text { Film } \\
\text { Structure }\end{array}$ & $\begin{array}{c}\text { Carrier } \\
\text { Concentr. }\left(\mathrm{cm}^{-3}\right)\end{array}$ & & & & \\
\hline \multicolumn{8}{|l|}{ Batch A } \\
\hline OCLI-25 & 1715 glass & Poly. & $3 \times 10^{17}$ & 126 & 114 & 106 & 99 \\
\hline OCLI-26 & 1715 glass & Poly. & $3 \times 10^{18}$ & 7 & 5 & 4 & \\
\hline OCLI-28 & GS213 glass & Poly. & $2 \times 10^{18}$ & 29 & 27 & 21 & 16 \\
\hline OCLI.29 & G8213 glass & Poly. & $2 \times 10^{16}$ & $167^{\prime}$ & 165 & 157 & 156 \\
\hline 0CLI-32 & Sapphire & S.c. & $6 \times 10^{17}$ & 310 & 307 & 304 & \\
\hline OCLI-33 & $\begin{array}{l}\text { Superstrate } \\
\text { alumina } \\
\text { (as fired) }\end{array}$ & Poly. & $3 \times 10^{17}$ & 57 & 53 & 52 & \\
\hline OCLI-35-1 & Sapphire & S.c. & $8 \times 10^{17} / 5 \times 10^{19}$ & 446 & 442 & 429 & 426 \\
\hline Control A1 & S.c. Si & - & $\sim 5 \times 10^{15}$ & 556 & 552 & 536 & \\
\hline Control A2 & S.c. Si & - & $\sim 5 \times 10^{15}$ & 398 & 397 & 394 & 375 \\
\hline Batch B & & & & & & & \\
\hline OCLI-27 & GS211 glass & Poly. & $1 \times 10^{18}$ & 90 & & & \\
\hline OCLI-30 & GS185 glass & Poly. & $1 \times 10^{17}$ & 30 & & & \\
\hline 0CLI-31 & GS211 glass & Poly. & $1 \times 10^{18}$ & 35 & & & \\
\hline OCLI-34 & Sapphire & S.c. & $8 \times 10^{17} / 2 \times 10^{19}$ & 400 & & & \\
\hline OCLI-35-2 & Sapphire & S.c. & $8 \times 10^{17} / 5 \times 10^{19}$ & 400 & & & \\
\hline Control B1 & S.c. Si & - & $\sim 5 \times 10^{15}$ & 550 & & & \\
\hline Control B2 & S.c. Si & - & $\sim 5 \times 10^{15}$ & 500 & & & \\
\hline
\end{tabular}

* Muderate intensity ( $* 1$ sun) tungsten lamp source.

**Measured on one or more individual mesa devices, as indicated. 
Table 2-3. Photovoltaic Response* of P-diffused n/p Mesa-type Solar Cells Fabricated in B-doped CVD $\leqslant i$ Sheet Material on Various Substrates

\begin{tabular}{|c|c|c|c|c|c|c|c|c|c|}
\hline \multicolumn{4}{|c|}{ SAMPLE } & \multicolumn{3}{|c|}{$\begin{array}{l}\text { OPEN-CIRCUIT PHOTOVOLTAGE } \\
\qquad V_{\text {OC }}(\mathrm{mV})\end{array}$} & \multicolumn{3}{|c|}{$\begin{array}{l}\text { SHORT-CIRCUIT CURRENT DENSITY** } \\
\qquad J_{\mathrm{sc}}\left(\mathrm{mA} / \mathrm{cm}^{2}\right)\end{array}$} \\
\hline Number & $\begin{array}{l}\text { Substrate } \\
\text { Material }\end{array}$ & $\underset{\text { Structure }}{\text { Film }}$ & $\begin{array}{c}\text { Carrier } \\
\text { Concentr. }(\mathrm{cm}-3)\end{array}$ & Mesa 1 & Mesa 2 & Mesa 3 & Mesa 1 & Mesa 2 & Mesa 3 \\
\hline Batch A & & & & & & & & & \\
\hline OCLII-25 & 1715 glass & Poly. & $3 \times 10^{17}$ & 125 & 110 & 105 & 7.9 & 8.6 & 7.1 \\
\hline OCLI-26 & 1715 glass & Poly. & $3 \times 10^{18}$ & $\overline{11}$ & 12 & 12 & 2.9 & $\overline{2.9}$ & 2.9 \\
\hline OCLI.28 & GS213 glass & Poly. & $2 \times 10^{18}$ & 36 & $\overline{27}$ & 26 & 4.3 & $\overline{3.6}$ & 3.6 \\
\hline OCLI-29 & GS213 glass & Poly. & $2 \times 10^{16}$ & $\overline{190}$ & 195 & 190 & $\overline{13 .}$ & 11. & 14. \\
\hline OCLI-32 & Sapphire & S.c. & $6 \times 10^{17}$ & 315. & $\overline{330}$ & 320 & 12. & 10. & 10. \\
\hline OCLI.33 & $\begin{array}{l}\text { Superstrate } \\
\text { alumina } \\
\text { (as fired) }\end{array}$ & Poly. & $3 \times 10^{17}$ & 55 & $\overline{68}$ & 50 & 26. & 21. & 14. \\
\hline OCLI-35-1 & Sapphire & S.c. & $8 \times 10^{17} / 5 \times 10^{-9}$ & 453 & 465 & 475. & 10. & 10. & 11. \\
\hline Control A1 & S.c. Si & - & $\sim 5 \times 10^{15}$ & 562 & 530 & - & 50. & 51. & 51. \\
\hline Control A2 & S.c. Si & - & $\sim 5 \times 10^{15}$ & $\mathrm{NM}^{\dagger}$ & $\mathrm{NM}^{\dagger}$ & $\mathrm{NM}^{\dagger}$ & $\mathrm{NM}^{\dagger}$ & $\mathrm{NM}^{\dagger}$ & $\mathrm{NM}^{\dagger}$ \\
\hline$\overline{B a t c h} B$ & -- & - - & ---- & - & - & -- & - & 一 & - \\
\hline$\overline{O C L I} \cdot 27$ & GS211 glass & Poly. & $1 \times 10^{18}$ & 170 & 175 & 170 & 6.5 & 7.0 & 7.8 \\
\hline OCLI-30 & GS185 glass & Poly. & $1 \times 10^{17}$ & 85 & $\overline{75}$ & 80 & 4.5 & 5.5 & 4.0 \\
\hline OCLI-39 & GS211 glass & Poly. & $1 \times 10^{18}$ & 45 & 50 & 30 & 2.0 & 2.2 & 1.5 \\
\hline OCLI.34 & Sapphire & S.c. & $8 \times 10^{17} / 2 \times 10^{19}$ & 300 & $\overline{455}$ & 480 & 7.8 & $\overline{9.2}$ & 9.5 \\
\hline OCLI-35-2 & Sapphire & S.c. & $8 \times 10^{17 / 5} \times 10^{19}$ & 435 & 460 & $\overline{455}$ & 8.6 & 8.8 & $\overline{6.8}$ \\
\hline Control B1 & S.c. Si & - & $\sim 5 \times 10^{15}$ & 585 & $\overline{590}$ & - & 50. & 52. & - \\
\hline Control B2 & S.c. Si & - & $\sim 5 \times 10^{15}$ & 585 & $\overline{585}$ & - & 45. & 45. & - \\
\hline
\end{tabular}

*High-intensity tungsten lamp source equivalent to $\sim 2$ sun intensity.

${ }^{\dagger} \mathrm{NM}=$ not measured.

** Current densities calculated using batch A mesa area as $7.0 \times 10^{-3} \mathrm{~cm}^{2}$ and batch B mesa area as $2.0 \times 10^{-2} \mathrm{~cm}^{2}$. 
(2.0 $\times 10^{-2} \mathrm{~cm}^{2}$ ) without taking account of minor variations in actual area from mesa to mesa, differences in surface reflectivities for the various si sheet materials, or shadowing by the measuring probe. The highest values of $\mathrm{V}$ and $J$ for each sheet sample and for the control samples as a group are under Sined.

These results again illustrate the general uniformity of response among mesas on a given sample. The wide variation in $v$ values is evident, as in the

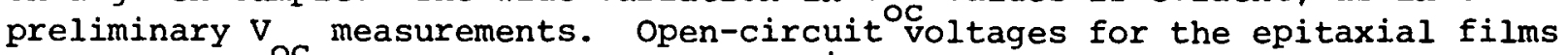
on sapphire, especially those with a $\mathrm{p} / \mathrm{p}^{+}$deposited region, compare favorably with $V$ for the control wafers; the highest $V$ for an epitaxial film sample (OCLI-35-1) is $\sim 80$ percent of the highest $v$ for a control sample, and exceeds considerably that of the poorest control sample (A2, Table 2-2) under comparable illumination conditions. $V$ values for the polycrystalline films are much lower, ranging from $\sim 1$ percent ${ }^{c}$ to $\sim 45$ percent of the $V$ for the poorest control sample, under comparable conditions; the $V$ values for some of the films on glass are significantly larger than that for the polycrystalline film on alumina (OCLI-33).

Photogenerated currents for the thin-film samples (including the epitaxial films on sapphire) are quite low, however. For comparable illumination (including some data not shown in these tables), generated short-circuit current densities for the cells in epitaxial films (irrespective of $\mathrm{p} / \mathrm{p}^{+}$or single-layer-p base region) are from 13 to 23 percent of those in control cells. The cells in polycrystalline films on glasses produced current densities from $\sim 3$ to 29 percent of those in the control cells, while the cells in the polycrystalline film on alumina gave current densities ranging from 6 to 45 percent of those obtained with the control cells, under comparable illumination.

The best cells were those fabricated in an epitaxial film on sapphire, with a deposited $\mathrm{p} / \mathrm{p}^{+}$base region (OCLI-35-2). There was very good uniformity among the properties of individual mesas on most of the samples, but this sample was especially good in this respect. For 10 mesas measured at random under given illumination $V$ values averaged $\sim 455 \mathrm{mV}$, with a minimum of $430 \mathrm{mv}$ and a maximum of $475 \mathrm{mv}$. The same 10 mesa devices produced an average generated short-circuit photocurrent of $184 \mu \mathrm{A}$, with a minimum of $160 \mu \mathrm{A}$ and a maximum of $210 \mu \mathrm{A}$.

The same consistency was demonstrated by forward and reverse I-V characteristics obtained for several mesa devices on the same sample. Figure 2-18 shows the I-V curves for OCLI-35-2 and Control B2, which were processed simultaneously in batch B. Figure 2-18a gives the dark and illuminated (t.ungsten lamp source) characteristics for four mesas on the single-crystal Si control B2, and Figure 2-18b gives the corresponding characterlsticis for four mesas on OCLI-35-2. 


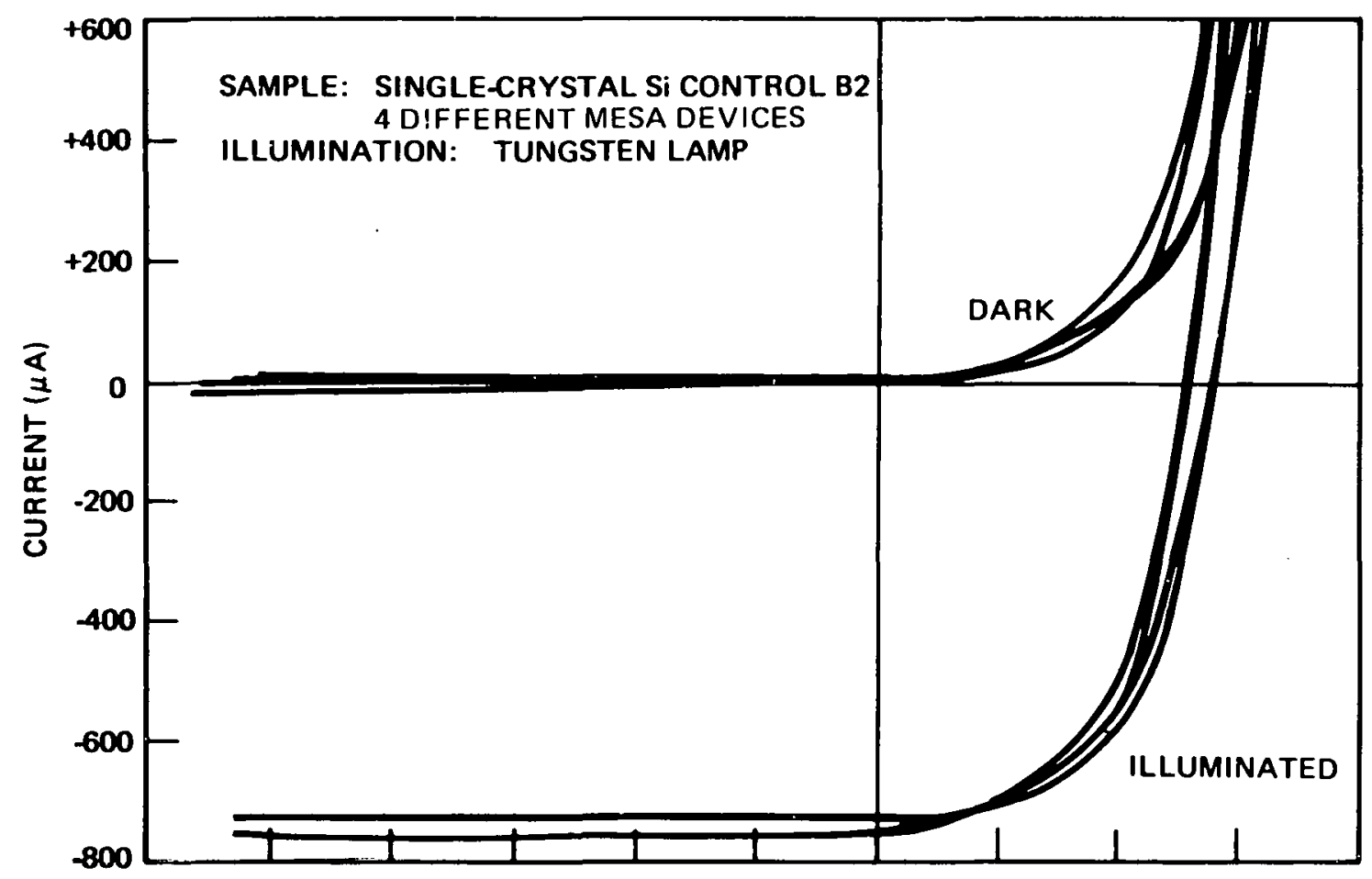

(a)

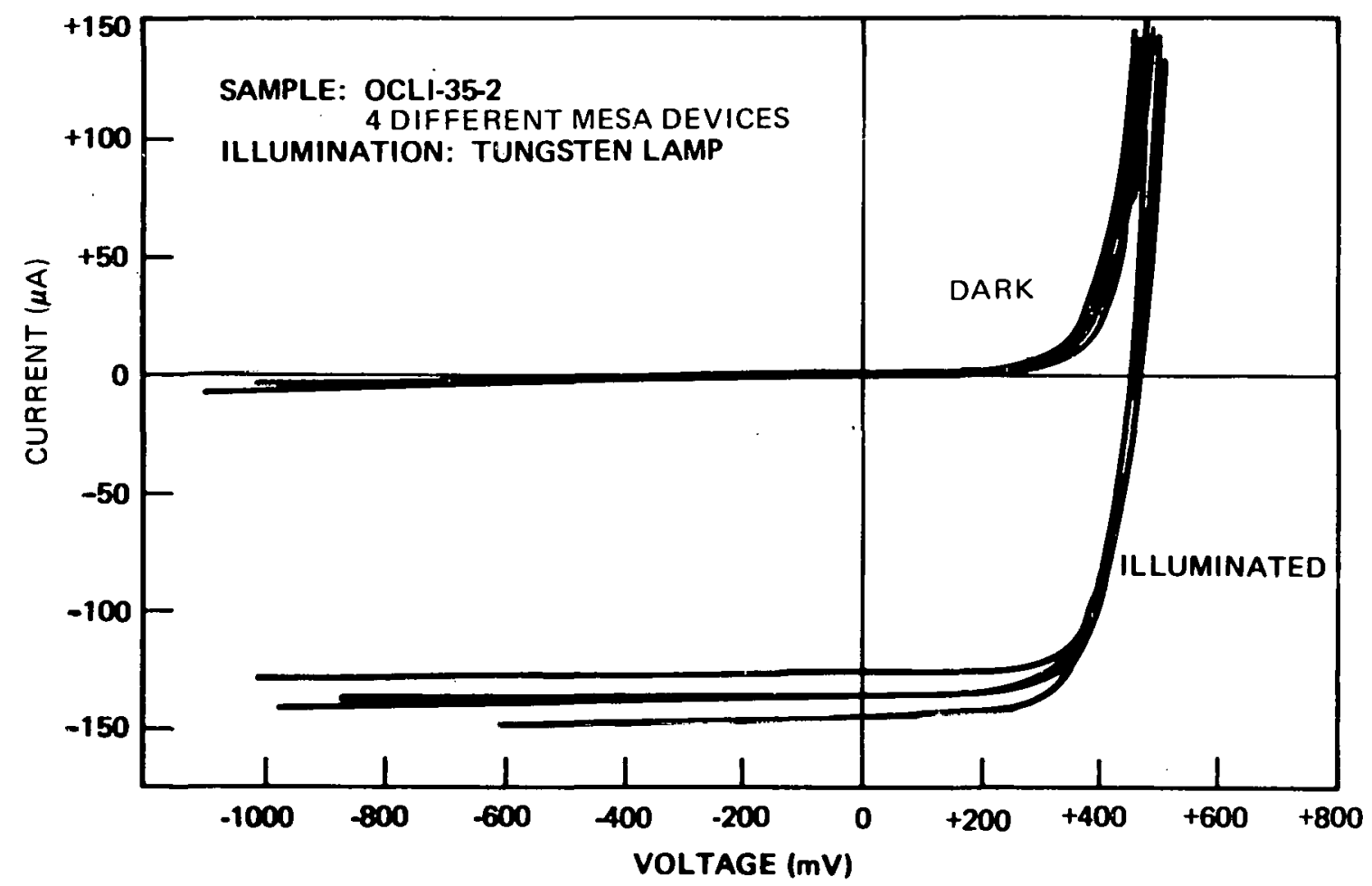

(b)

Figure 2-18. Dark and Light Forward and Reverse I-V Characteristics for 4 Separate Mesa Devices on Samples Processed Simultaneously in Batch B. a) Single-crystal Si Control Wafer B2, b) Si on Sapphire Sample OCLI-35-2. 
Photoresponse measurements were also made on most of the samples using the $0.94 \mu \mathrm{m}$ wavelength radiation from a light-emitting diode (LED) as the illumination. Based on the assumption that the control samples had minority-carrier diffusion lengths. $\mathrm{L}$ of $\sim 100 \mu \mathrm{m}$ it was possible to deduce approximate values for. $L$ for the $\mathrm{Si}$ sheet samples. Values calculated in that manner are listed in Table 2-4; these have not been corrected for surface reflectivity effects or for variations in the LED intensity incident on the different mesas. The approximate values obtained, however, are indicative of the photovoltaic quality of the $\mathrm{Si}$ sheet samples relative to that of the single-crystal Si solar cell blanks. The epitaxial samples on sapphire (OCLI-32, 35-1, and 35-2) are seen to have $I_{n}$ values from 3.5 to $4.3 \mu \mathrm{m}$. The polycrystalline sheet samples on glasses ${ }^{n}$ have $L$ values in the $0.5-5.5 \mu \mathrm{m}$ range, while the polycrystalline sample on as-fired MRC superstrate alumina (OCLI-33) has $I_{n}=5.5 \mu \mathrm{m}$ by this method.

Approximate spectral photoresponse measurements were made on samples OCLI-27, 30 , and 35-2, as well as a control sample, using a tungsten lamp source with a filter wheel for illumination. The relative spectral response data are plotted in Figure 2-19 for two different mesa devices on each of the four samples. No corrections were made for reflectivity differences in presenting the data. The severe loss of long-wavelength response (i.e., for $\lambda>0.7 \mu \mathrm{m}$ ) for the three sheet samples is evident and is consistent with the low shortcircuit photocurrent values obtained (Table 2-3) and the small values deduced for $L_{n}$ (Table 2-4).

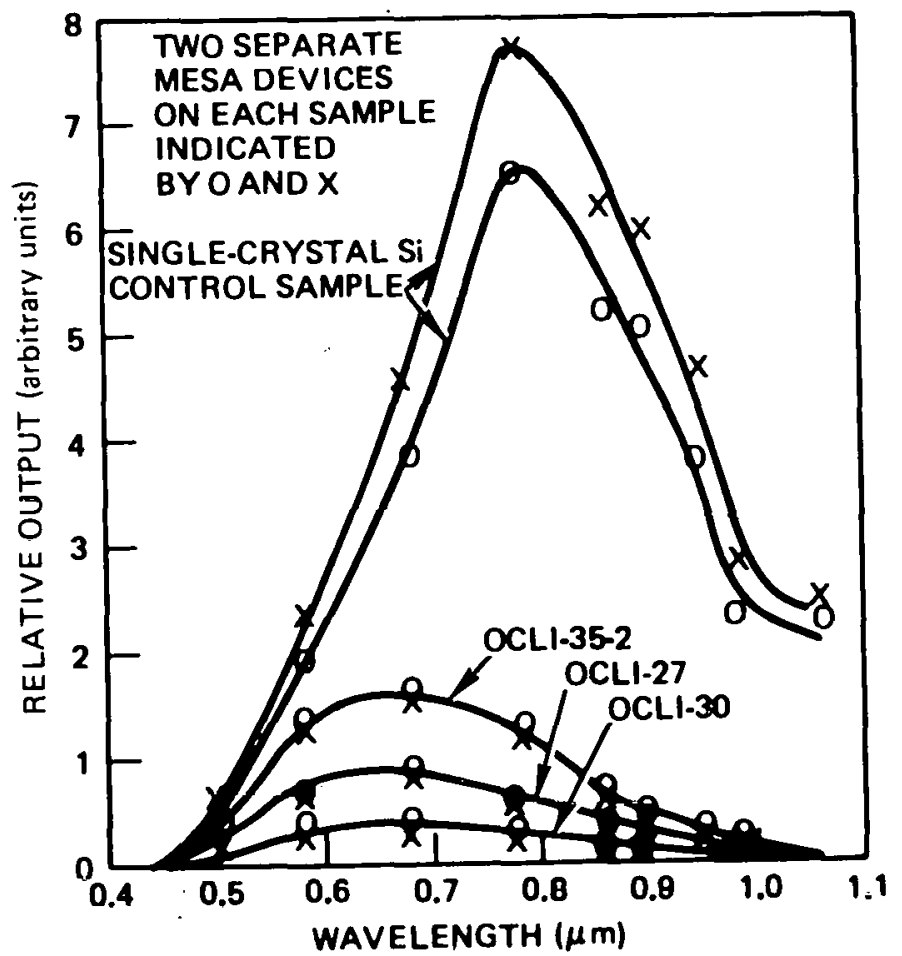

Figure 2-19. Relative Photovoltaic spectral Response for 2 Separate Mesa Devices on Samples OCLI-35-2, OCLI-27, OCLI-30, and Single-crystal si Control Cell. 
Table 2-4. Minority-carrier Diffusion Lengths $L_{n}$ for P-diffused $n / p$ Mesa-type Solar Cell Structures in B-doped CVD Si Sheet Material on Various Substrates

\begin{tabular}{|c|c|c|c|c|c|c|}
\hline \multicolumn{4}{|c|}{ SAMPLE } & \multicolumn{3}{|c|}{$\begin{array}{l}\text { MINORITY-CARRIER DIFFUSION LENGTH } \\
\qquad L_{n}(\mu \mathrm{m})\end{array}$} \\
\hline Number & $\begin{array}{l}\text { Substrate } \\
\text { Material }\end{array}$ & $\begin{array}{c}\text { Film } \\
\text { Structure }\end{array}$ & $\begin{array}{c}\text { Carrier } \\
\text { Concentr. }\left(\mathrm{cm}^{-3}\right)\end{array}$ & $\begin{array}{c}\text { LED* }^{*} \\
(\lambda=0.94 \mu \mathrm{m})\end{array}$ & $\begin{array}{c}\text { Spectral } \\
\text { Response*** } \\
(\lambda=0.8 \mu \mathrm{m})\end{array}$ & $\begin{array}{c}\text { Spectral } \\
\text { Response** } \\
(\lambda=0.9 \mu \mathrm{m})\end{array}$ \\
\hline Batch A & & & & & & \\
\hline DCLI-25 & 1715 glass & Poly. & $3 \times 10^{17}$ & 4.5 & - & - \\
\hline OCLI-26 & 1715 glass & Poly. & $3 \times 10^{18}$ & 0.5 & - & - \\
\hline OCLI-28 & GS213 glass & Poly. & $2 \times 10^{18}$ & 0.9 & - & - \\
\hline OCLI-29 & GS213 glass & Poly. & $2 \times 10^{16}$ & 5.5 & - & - \\
\hline OCLI-32 & Sapphire & S.c. & $6 \times 10^{17}$ & 4.3 & - & - \\
\hline OCLI-33 & $\begin{array}{l}\text { Superstrate } \\
\text { alumina } \\
\text { (as fired) }\end{array}$ & Poly. & $3 \times 10^{17}$ & 5.5 & - & - \\
\hline OCLI-35-1 & Sapphire & S.c. & $8 \times 10^{17} / 5 \times 10^{19}$ & 3.5 & - & - \\
\hline Control A1 & S.c. Si & - & $\sim 5 \times 10^{15}$ & - & - & - \\
\hline Control A2 & S.c. Si & - & $\sim 5 \times 10^{15}$ & $\begin{array}{c}100 \\
\text { (assumed) }\end{array}$ & - & - \\
\hline Batch B & & & & & & \\
\hline OCLI-27 & GS211 glass & Poly. & $1 \times 10^{18}$ & 1.2 & 1.5 & 0.8 \\
\hline OCLI-30 & GS185 glass & Poly. & $1 \times 10^{17}$ & 1.1 & 0.4 & 0.3 \\
\hline OCLI-31 & GS211 glass & Poly. & $1 \times 10^{18}$ & - & - & - \\
\hline OCLI-34 & Sapphire & S.c. & $8 \times 10^{17} / 2 \times 10^{19}$ & - & - & - \\
\hline OCLI-35-2 & Sapphire & S.c. & $8 \times 10^{17} / 5 \times 10^{19}$ & 3.6 & 2.2 & 1.8 \\
\hline Control B1 & S.c. Si & - & $\sim 5 \times 10^{15}$ & - & - & - \\
\hline Control B2 & S.c. Si & - & $\sim 5 \times 10^{15}$ & $\begin{array}{c}100 \\
\text { (assumed) }\end{array}$ & $\begin{array}{c}100 \\
\text { (assumed) }\end{array}$ & $\begin{array}{c}100 \\
\text { (assumed) }\end{array}$ \\
\hline
\end{tabular}

* $L_{n}$ estimated from $I_{S c}$ values for sheet samples relative to those for control samples for illumination by LED $(\lambda=0.94 \mu \mathrm{m})$.

${ }^{*} \mathrm{~L}_{\mathrm{n}}$ calculated from relative spectral responses at $\lambda=0.8 \mu \mathrm{m}$ and $\lambda=0.9 \mu \mathrm{m}$ for sheet samples relative to that for control sample, using tungsten lamp and filter wheel as illumination source. Si absorption coefficlents used in calculation: $\alpha_{0.8 \mu \mathrm{m}}=950 \mathrm{~cm}^{-1}$ and $\alpha_{0.9 \mu \mathrm{m}}=350 \mathrm{~cm}^{-1}$. 
The relative spectral responses for these three samples at $\lambda=0.8$ and $0.9 \mu \mathrm{m}$ were used to calculate approximate values for $L_{n^{\prime}}$ again based on the assumed value of $100 \mathrm{~m}$ for the minority-carrier diffusion length in the control sample. These values are also given in Table 2-4 and are seen to be in close agreement with the approximate values for these three samples as deduced from the photoresponse measurements with the LED.

Finally, the same four samples were characterized using the AMO solar simulator, which employs a xenon arc lamp for the short wavelength radiation and a tungsten lamp for the long wavelength portion of the simulated solar spectrum. The outputs of several mesa devices on each sample were measured. The fourth quadrant of the I-V characteristic under AMO illumination for the best mesa device tested on each of the four samples is displayed in Figure 2-20. The curves for the control and for OCLI-35-2 have good shape. Those for polycrystalline sheet samples OCLI-27 (on GS211 glass) and OCLI-30 (on GS185 glass) are very poor, indicating severe carrier collection and/or junction shunting problems.

The measured values of $\mathrm{V}_{\mathrm{OC}^{\prime}} \mathrm{J}_{\mathrm{Sc}}$, and curve fill-factor (CFF) for the four

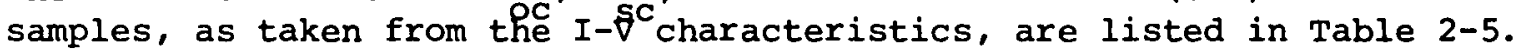
As indicated therein, the epitaxial sample (OCLI-35-2) has a larger CFF (0.66) than does the single-crystal control sample $(0.60)$, consistent with the better loaded I-V characteristic displayed by the sheet sample (Figure 2-20). The CFF values for the polycrystalline sheet samples, on the other hand, are extremely low.

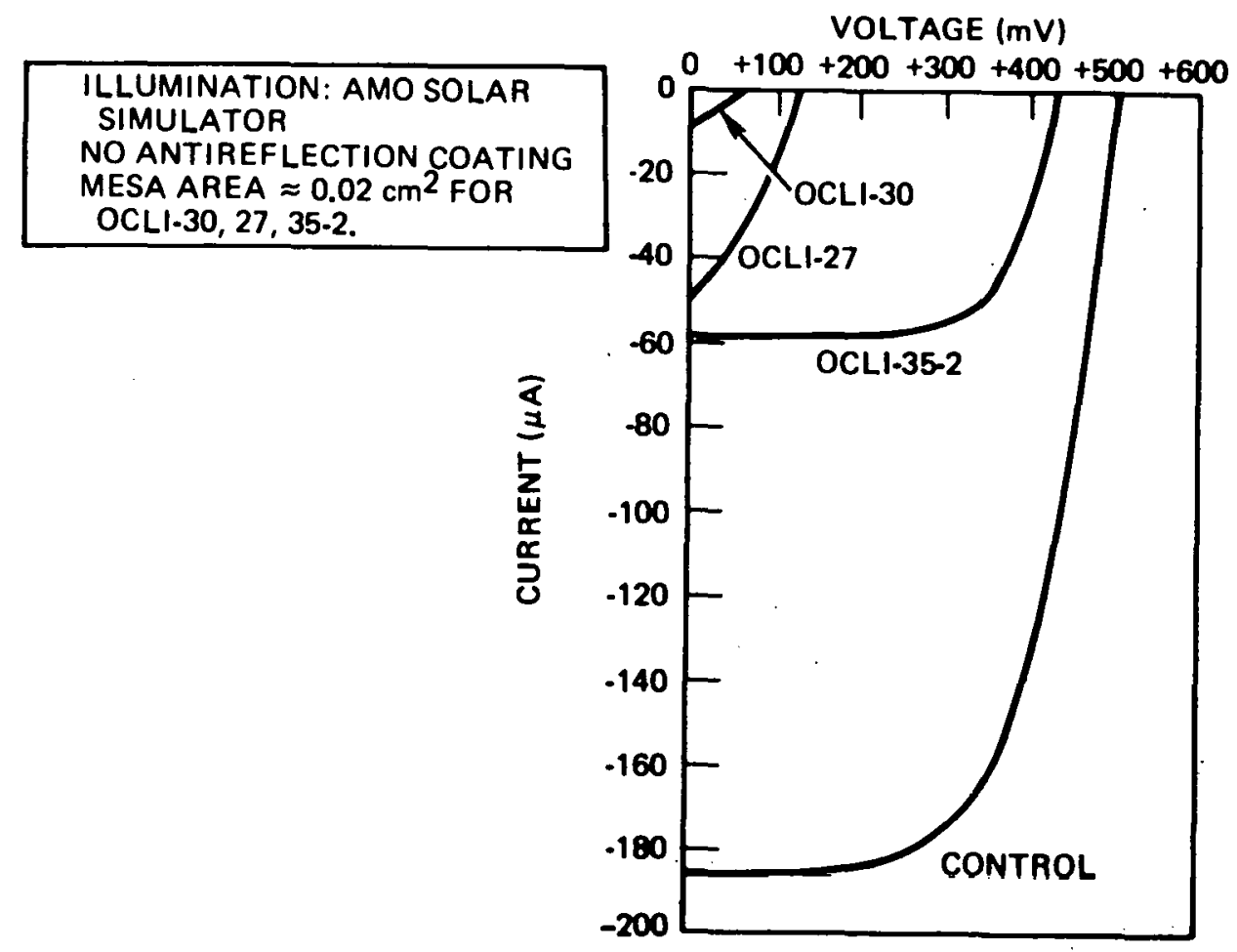

Figure 2-20. Fourth Quadrant of I-V Characteristic for Individual Mesa Devices on Samples OCLI-30, OCLI-27, OCLI-35-2, and single-Crystal Si Control, for AMO Solar Simulator Illumination. 
Table 2-5. Photovoltaic Properties for Individual Mesa Sclar Cells* in Three CVD Si Sheet Samples and Single-crystal Si Control Sample, from I-V Characteristics of Figure 2-20 (AMO Solar Simulator Illumination)

\begin{tabular}{|l|c|c|c|c|}
\hline SAMPLE & $\begin{array}{c}V_{\text {oc }} \\
(\mathrm{mV})\end{array}$ & $\begin{array}{c}\mathrm{I}_{\mathrm{sc}} \\
(\mu \mathrm{A})\end{array}$ & $\begin{array}{c}\mathrm{P}_{\max } \\
(\mu \mathrm{w})\end{array}$ & CFF \\
\hline OCLI-27 & 130 & 48.5 & 2.0 & 0.32 \\
OCLI-30 & 65 & 8.8 & 0.16 & 0.28 \\
OCLI-35-2 & 430 & 58. & 16.4 & 0.66 \\
Control & 510 & 185. & 57.0 & 0.60 \\
\hline
\end{tabular}

*Mesa area approximately $0.02 \mathrm{~cm}^{2}$, except Control sample.

The power delivered to the load by the mesa devices on the epitaxial sample was about 30 percent of that delivered by the control sample under AMO illumination; thus, if the control cell efficiency is assumed to be $\sim 12$ percent, the cells in the epitaxial sample have efficiencies of about 3.5 percent. The efficiencies in the two polycrystalline samples, on the same basis, are well bolow 1 percent.

These results tend to indicate that improved photovoltaic performance occurs when $\mathrm{p} / \mathrm{p}^{+}$, rather than just $\mathrm{p}$, base regions are used in the CVD si films. The low generated photocurrents, especially when examined as a function of wavelength, indicate poor diffusion lengths in the films. The high opencircuit voltages, on the other hand, are somewhat surprising in view of the poor current responses. The relatively large $v$ values obtained in several of the polycrystalline sheet samples on glass suffstrates indicate a fairly good $\mathrm{p}-\mathrm{n}$ junction has been formed in this small-grain material. The data collected do not appear to indicate that high series resistance (that is, poor contacts) alone is responsible for the low measured photocurrents, but additional samples will be prepared for fabrication with a fine-grid contact pattern to contact more of the individual grains in polycrystalline material.

Additional experimental solar cells were fabricated at OCLI during the quarter in both single-layer $\mathrm{p}$-type and double-layer $\mathrm{p} / \mathrm{p}^{+}$si sheet samples prepared on substrates of single-crystal $\mathrm{Si}$ and single-crystal sapphire. The preparation and properies of these samples were described in sections 2.3.3 and 2.5.3, respectively. 
In total, 22 new $\mathrm{Si}$ sheet samples were delivered to OCLI during the quarter for cell fabrication; of these, 15 were processed into solar cell structures during this report period. The others will be used for experimental cell fabrication early in the next quarter. The samples delivered, OCII-36 through OCLI-57, are listed in Table 2-6 together with their measured properties and the pertinent deposition parameters. In addition, remaining pieces of each of the earlier $\mathrm{p} / \mathrm{p}^{+} \mathrm{Si}$ sheet samples OCLI-34 and 35 (see Table 2-1) were submitted to provide an opportunity to check on the reproducibility of cell processing and photovoltaic performance on two separate occasions with essentially identical material. These samples are designated OCII-34A and 35A and are also listed in Table 2-6.

Other sheet samples that were prepared during the quarter, including polycrystalline films on several glasses and additional reference films on sapphire, are ready for delivery to ocLI for processing early in the coming quarter. These samples will be described in subsequent reports.

The 15 samples processed into experimental cells to date are designated by underline in Table 2-6. These include 13 sheet samples on single-crystal Si and two on single-crystal sapphire. Si wafers from two different sources were used as substrates in the preparation of the Si/Si samples. A group of (100)-oriented p-type $2 \mathrm{ohm}-\mathrm{cm}$ single-crystal $\mathrm{Si}$ wafers $(2 \mathrm{~cm} \times 2 \mathrm{~cm})$ was obtained from OCLI; these are long-diffusion-length ( $L_{n} \sim 100 \mu \mathrm{m}$ ) Czochralskigrown blanks used for the fabrication of high-efficiency diffused-junction single-crystal solar cells. Some of the blanks had been chemically-mechanically polished and some had been chemically polished (i.e., etched) only, in both cases at OCLI. In addition, $10 \mathrm{ohm}-\mathrm{cm}$ p-type (100)-oriented singlecrystal $\mathrm{Si}$ wafers ( $5 \mathrm{~cm}$ dia) obtained from (and polished by) Monsanto for MOS/LSI device use at Rockwell were available for use as comparison substrates.

Three different nominal B doping levels are represented in the p-type epitaxial sheet samples OCLI-46 and 47, OCLI- 36 and 39, and OCLI-42, 44, and 45. Each of the three groups involves optically polished single-crystal Si substrates from both of the above sources.

Three different thickness ratios $(1: 3,1: 1,3: 1)$ of the two regions in the $\mathrm{p} / \mathrm{p}^{+}$double-layer $\mathrm{B}$-doped structure are represented in the epitaxial sheet samples OCLI-50 and 51, OCLI-52 and 53, and OCLI-55 and 56. Each of the three pairs involves one sheet sample on an OCLI solar cell blank and one on a $10 \mathrm{ohm}-\mathrm{cm}$ Monsanto wafer.

Finally, OCLI-48 and 49 are double-layer $\mathrm{p} / \mathrm{p}^{+}$samples grown on sapphire substrates, the first with a layer thickness ratio $t_{p}: t_{p+}=1: 3$ and the second with the ratio $1: 1$. As with the sheet samples ihvolving single-crystal Si substrates, these also are epitaxial samples.

The above samples were processed at OCLI according to the general procedure outlined in Section 2.6.1. After an initial thorough degreasing (trichloroethane, with $\mathrm{N}_{2}$ blow-dry) the samples were P-diffused simultaneously with 4 control wafers ${ }^{2}$ (p-type $2 \mathrm{ohm}-\mathrm{cm}$ single-crystal $2 \mathrm{~cm} \times 2 \mathrm{~cm}$ blanks) at $875^{\circ} \mathrm{C}$ for 
Table 2-6. B-Doped CVD Si Sheet Samples Submitted to OCLI During

Fifth Quarter for Solar Cell Processing and Measurement (See Note)

\begin{tabular}{|c|c|c|c|c|c|c|c|c|c|c|c|c|}
\hline $\begin{array}{l}\text { SAMPLE } \\
\text { NO. }\end{array}$ & $\begin{array}{c}\text { SUBSTRATE } \\
\text { MATERIAL }\end{array}$ & $\begin{array}{l}\text { O\&SERV. } \\
\text { DEPOS. } \\
\text { TEMP } \\
\text { (OC) }\end{array}$ & $\begin{array}{c}\text { CARRIER } \\
\text { GAS AND } \\
\text { FLOW RATE } \\
(\ell p m)\end{array}$ & $\begin{array}{l}\mathrm{SiH}_{4} \\
\text { FLOW } \\
\text { RATE } \\
\text { (ccpm) }\end{array}$ & $\begin{array}{l}\text { DOPANT } \\
\text { GAS* } \\
\text { FLOW RATE } \\
\text { (ccpm) }\end{array}$ & $\begin{array}{c}\text { FILM } \\
\text { THICK. } \\
\text { NESS } \\
(\mu \mathrm{m})\end{array}$ & $\begin{array}{l}\text { AVE. } \\
\text { GROWTH } \\
\text { RATE } \\
(\mu \mathrm{m} / \mathrm{min})\end{array}$ & $\begin{array}{l}\text { FILM } \\
\text { RESIS- } \\
\text { TIVITY } \\
\text { (ohnI-cm) }\end{array}$ & $\begin{array}{c}\text { HOLE } \\
\text { CONCEN. } \\
\text { TRATION } \\
(\mathrm{cm}-3)\end{array}$ & $\begin{array}{c}\text { HALL } \\
\text { MOBILITY } \\
\text { (cm²/V-sec) }\end{array}$ & \begin{tabular}{|c|} 
SAMPLE \\
DIMENSIONS \\
(cm) AND \\
APPROX \\
AREA (cm 2)
\end{tabular} & $\begin{array}{l}\text { FILM } \\
\text { STRUCTURE } \\
\text { AND/OR } \\
\text { SURFACE } \\
\text { TEXTURE }\end{array}$ \\
\hline OCLI.36 & $\begin{array}{l}\text { (100) S.C. Si } \\
2 \text { chm-cm p-type } \\
\text { (Mech. Polished) }\end{array}$ & 1025 & $\begin{array}{l}\mathrm{H}_{2} \\
1.5\end{array}$ & 10 & 6 & 16.5 & 0.75 & $0.05^{\dagger}$ & $\sim 9 \times 10^{17 t t}$ & NM & $\begin{array}{c}2.0 \times 1.2 \\
2.4\end{array}$ & Epitaxial \\
\hline OCLI-37 & $\begin{array}{l}\text { (100) S.C. Si } \\
2 \text { ohm-cm p-type } \\
\text { (Mech. Polished) }\end{array}$ & 1028 & $\begin{array}{l}\mathrm{H}_{2} \\
1.5\end{array}$ & 10 & 6 & $19^{* * *}$ & $0.9 *$ *** & $0.03^{* * *}$ & $2 \times 10^{18 * * *}$ & $\sim 90^{* * *}$ & $\begin{array}{c}2.0 \times 0.9 \\
1.8\end{array}$ & Epitaxia|**** \\
\hline OCLI.38 & $\begin{array}{l}\text { (100) S.C. Si } \\
2 \text { ohm-cm p-type } \\
\text { (Mech. Polished) }\end{array}$ & 1028 & $\begin{array}{l}\mathrm{H}_{2} \\
1.5\end{array}$ & 10 & 6 & $19 * * *$ & $0.9 * * *$ & $0.03^{* * *}$ & $2 \times 10^{18^{* * *}}$ & $-90 * * *$ & $\begin{array}{c}2.0 \times 1.0 \\
2.0\end{array}$ & Epitaxial*** \\
\hline OCLI.39 & $\begin{array}{l}\text { (100) S.C. Si } \\
10 \text { ohm-cm p-typo } \\
\text { (Moch. Polished) }\end{array}$ & 1032 & $\begin{array}{l}\mathrm{H}_{2} \\
1.5\end{array}$ & 10 & 6 & $17^{* * *}$ & 0.8 *** & $0.02^{* * *}$ & $4 \times 10^{18 * * \#}$ & $\sim 75^{* * *}$ & $\begin{array}{c}2.1 \times 1.8 \\
3.8\end{array}$ & Epitaxial*** \\
\hline OCLI-40 & $\begin{array}{l}\text { (100) S.C. Si } \\
2 \text { ohm-cm p-type } \\
\text { (Mech. Polished) }\end{array}$ & 1029 & $\begin{array}{l}\mathrm{H}_{2} \\
1.5\end{array}$ & 10 & 6 & 19 19** & $0.9^{* * *}$ & $0.05^{* * *}$ & $-2 \times 10^{18^{* * *}}$ & $\sim 75^{* * *}$ & $\begin{array}{c}2.0 \times 1.3 \\
2.6\end{array}$ & Epitaxial*** \\
\hline OCLI41 & $\begin{array}{l}\text { (100) S.C. Si } \\
2 \text { ohm-cm p-type } \\
\text { (Chem. Polished) }\end{array}$ & 1029 & $\begin{array}{l}\mathrm{H}_{2} \\
1.5\end{array}$ & 10 & 6 & $19^{* * *}$ & $0.9^{* * *}$ & $0.05^{* * * *}$ & $\sim 2 \times 10^{18^{* * *}}$ & $-75^{* * *}$ & $\begin{array}{c}2.0 \times 1.2 \\
2.4\end{array}$ & Epitaxial*** \\
\hline OCLLI-42 & $\begin{array}{l}\text { (100) S.C. Si } \\
2 \text { ohm-cm p-type } \\
\text { (Mech. Polished) }\end{array}$ & 1026 & $\begin{array}{l}\mathrm{H}_{2} \\
1.5\end{array}$ & 10 & 18 & $15^{* * *}$ & $0.7^{* * *}$ & $\sim 0.01^{* * *}$ & $\sim 1 \times 10^{19 * * *}$ & $\sim 40^{* * *}$ & $\begin{array}{c}2.0 \times 1.1 \\
2.2\end{array}$ & Epitaxial*** \\
\hline OCLI-43 & $\begin{array}{l}\text { (100) S.C. Si } \\
2 \text { ohm-cm p-type } \\
\text { (Chem. Polished) }\end{array}$ & 1026 & $\begin{array}{l}\mathrm{H}_{2} \\
1.5\end{array}$ & 10 & 18 & $15^{* * *}$ & $0.7^{* * *}$ & $\sim 0.01 * * *$ & $-1 \times 10^{19 * * *}$ & $\sim 40^{* * *}$ & $\begin{array}{c}2.0 \times 1.3 \\
2.6\end{array}$ & Epitaxial*** \\
\hline OCLIA4 & $\begin{array}{l}\text { (100) S.C. Si } \\
2 \text { ohm-cm p-type } \\
\text { (Mech. Polished) }\end{array}$ & 1031 & $\begin{array}{l}\mathrm{H}_{2} \\
1.5\end{array}$ & 8.8 & 18 & $16 * * *$ & $0.7^{* * *}$ & $\sim 0.01^{* * *}$ & $-5 \times 10^{18 * * *}$ & $\sim 50 * * *$ & $\begin{array}{c}2.0 \times 1.4 \\
2.8\end{array}$ & Epitaxial*** \\
\hline OCLI-45 & $\begin{array}{l}\text { (100) S.C. Si } \\
10 \text { ohm-cm p-type } \\
\text { (Mech. Polished) }\end{array}$ & 1031 & $\begin{array}{l}\mathrm{H}_{2} \\
1.5\end{array}$ & 8.8 & 18 & 16 & 0.7 & $0.02^{\dagger}$ & $3 \times 10^{18+t}$ & $\sim 50^{* * *}$ & $\begin{array}{c}2.0 \times 1.2 \\
2.4\end{array}$ & Epitaxial*** \\
\hline OCLI-46 & $\begin{array}{l}\text { (100) S.C. Si } \\
2 \text { ohm-cm p-type } \\
\text { (Mech. Polished) }\end{array}$ & 1027 & $\begin{array}{l}\mathrm{H}_{2} \\
1.5\end{array}$ & 8.8 & 1.9 & 19 & 0.9 & $0.09 * *$ & $4 \times 10^{17^{* *}}$ & $190^{* *}$ & $\begin{array}{c}2.0 \times 1.3 \\
2.6\end{array}$ & Epitaxial*** \\
\hline OCLIIA7 & $\begin{array}{l}\text { (100) S.C. Si } \\
10 \text { ohm-cm p-type } \\
\text { (Mech. Polished) }\end{array}$ & 1027 & $\begin{array}{l}\mathrm{H}_{2} \\
1.5\end{array}$ & 8.8 & 1.9 & $17^{* * *}$ & $0.8^{* * *}$ & 0.20 *** & $2 \times 10^{17^{* * *}}$ & $170 * * *$ & $\begin{array}{c}1.9 \times 1.3 \\
2.5\end{array}$ & Epitaxial*** \\
\hline$\frac{0 C L I-48}{(D L)}$ & $\begin{array}{l}\text { (0112) Sapphire } \\
\text { (Polished) }\end{array}$ & 1030 & $\begin{array}{l}\mathrm{H}_{2} \\
1.5\end{array}$ & 8.5 & $\begin{array}{l}\text { 1) } 150 \\
\text { 2) } 6\end{array}$ & $\begin{array}{l}\text { 1) } 10.5 \\
\text { 2) } 4\end{array}$ & 1) 0.7 & $\begin{array}{l}1 / 0.0025^{\dagger} \\
2) 0.015^{\dagger}\end{array}$ & $\begin{array}{l}\text { 1) } 4 \times 10^{19+t} \\
\text { 2) } 3.5 \times 10^{18 t t}\end{array}$ & $\begin{array}{l}\text { 1) } N M \\
\text { 2) } N M\end{array}$ & $\begin{array}{c}2.0 \times 1.4 \\
2.8\end{array}$ & $\begin{array}{l}\text { Epitaxial*** } \\
\text { (Both Layers) }\end{array}$ \\
\hline
\end{tabular}

structures during quarter have n

*Films B-doped from $\mathrm{B}_{2} \mathrm{H}_{6}$-in-He (46 ppm)

**Measured by van der Pauw method

*** Estimate, based on deposition parameters and/or measurement on companion film grown simultaneously

tMeasured by spreading resistance probe.

t† Calculated from spreading resistance measurement.

$\mathrm{NM}=$ not measured.

$D L$ = dauble layer; 1) deposited first, 2) deposited second 
Table 2-6. (Cont)

\begin{tabular}{|c|c|c|c|c|c|c|c|c|c|c|c|c|}
\hline $\begin{array}{l}\text { SAMPLE } \\
\text { NO. }\end{array}$ & $\begin{array}{l}\text { SUBSTRATE } \\
\text { MATERIAL }\end{array}$ & $\begin{array}{l}\text { OBSERV } \\
\text { DEPOS. } \\
\text { TEMP. } \\
\text { (OC) }\end{array}$ & $\begin{array}{c}\text { CARAIER } \\
\text { GAS AND } \\
\text { FLOW RATE } \\
(\ell p m)\end{array}$ & $\begin{array}{l}\mathrm{SiH}_{4} \\
\text { FLOW } \\
\text { RATE } \\
\text { (ccpm) }\end{array}$ & $\begin{array}{c}\text { DOPANT } \\
\text { GAS* } \\
\text { FLOW RATE } \\
\text { (ccpm) }\end{array}$ & $\begin{array}{c}\text { FILM } \\
\text { THICK- } \\
\text { NESS } \\
(\mu \mathrm{m})\end{array}$ & $\begin{array}{c}\text { AVE. } \\
\text { GROWTH } \\
\text { RATE } \\
(\mathrm{um} / \mathrm{min})\end{array}$ & $\begin{array}{l}\text { FILM } \\
\text { RESIS- } \\
\text { RIVITY } \\
\text { (ohm-cm) }\end{array}$ & $\begin{array}{l}\text { HOLE } \\
\text { CONCEN- } \\
\text { TRATION } \\
\left(\mathrm{cm}^{-3}\right)\end{array}$ & $\mid \begin{array}{c}\text { HALL } \\
\text { HOBILITY } \\
\left(\mathrm{cm}^{2} / \mathrm{V} \text {-sec }\right)\end{array}$ & $\begin{array}{c}\text { SAMPLE } \\
\text { DIMENSIONS } \\
\text { (cm) AND } \\
\text { APPROX } \\
\text { AREA (cm }\end{array}$ & $\begin{array}{c}\text { FILM } \\
\text { STRUCTURE } \\
\text { AND/OR } \\
\text { SURFACE } \\
\text { TEXTURE }\end{array}$ \\
\hline$\frac{0 C L I-49}{(D L)}$ & $\begin{array}{l}\text { (0112) Sapphire } \\
\text { (Polished) }\end{array}$ & 1031 & $\begin{array}{l}\mathrm{H}_{2} \\
1.5\end{array}$ & 11.4 & $\begin{array}{l}\text { 1) } 150 \\
\text { 2) } 6\end{array}$ & 1) 9.0 & $\begin{array}{l}\text { 1) } 0.9 \\
\text { 2) } 1.0\end{array}$ & $\begin{array}{l}\text { 1) } 0.002^{\dagger} \\
\text { 2) } 0.015^{\dagger}\end{array}$ & $\begin{array}{l}\text { 1)5.5x1019tt } \\
\text { 2) } 4.5 \times 10^{18 \mathrm{tt}}\end{array}$ & $\begin{array}{l}\text { 1) NM } \\
\text { 2) NM }\end{array}$ & $\begin{array}{c}2.0 \times 1.5 \\
3.0\end{array}$ & $\begin{array}{l}\text { Epitaxial }{ }^{* * *} \\
\text { (Both Layers) }\end{array}$ \\
\hline$\frac{0 C L I .50}{(D L)}$ & $\begin{array}{l}\text { (100) S.C. Si } \\
2 \text { ohm-cm p-type } \\
\text { (Mech. Polished) }\end{array}$ & 1025 & $\begin{array}{l}\mathrm{H}_{2} \\
1 . \mathrm{E}\end{array}$ & 11.4 & $\begin{array}{l}\text { 1) } 150 \\
\text { 2) } 6\end{array}$ & $\begin{array}{l}\text { 1) } 11.3 \\
\text { 2) } 4.2\end{array}$ & $\begin{array}{l}\text { 1) } 0.75 \\
\text { 2) } 0.8\end{array}$ & $\begin{array}{l}\text { 1) } 0.002^{\dagger} \\
\text { 2) } 0.015 \dagger\end{array}$ & $\begin{array}{l}\text { 1) } 5 \times 1019 \mathrm{tt} \\
\text { 2) } 4 \times 10^{18 \mathrm{tt}}\end{array}$ & 1) $\mathrm{NM}$ & $\begin{array}{c}2.0 \times 0.9 \\
1.8\end{array}$ & $\begin{array}{l}\text { Epitaxial }{ }^{* * *} \\
\text { (Both Layers) }\end{array}$ \\
\hline$\frac{0 C L I .51}{(D L)}$ & $\begin{array}{l}\text { (100) S.C. Si } \\
10 \text { ohm-cm p-type } \\
\text { (Mech. Polished) }\end{array}$ & 1025 & $\begin{array}{l}\mathrm{H}_{2} \\
1.5\end{array}$ & 11.4 & $\begin{array}{l}\text { 1) } 150 \\
\text { 2) } 6\end{array}$ & $\begin{array}{l}\text { 1) } 13.3 \\
\text { 2) } 4.7\end{array}$ & 1) 0.9 & $\begin{array}{l}\text { 1) } 0.002 t \\
\text { 2) } 0.016 \dagger\end{array}$ & $\begin{array}{l}\text { 1) } 5 \times 10^{19 t t} \\
\text { 2) } 3.5 \times 10^{18 \mathrm{tt}}\end{array}$ & $\begin{array}{l}\text { 1) NM } \\
\text { 2) NM }\end{array}$ & $\begin{array}{c}1.3 \times 1.2 \\
1.5\end{array}$ & $\begin{array}{l}\text { Epitaxial }{ }^{* * *} \\
\text { (Both Layers) }\end{array}$ \\
\hline$\frac{0 C L I .52}{(D L)}$ & $\begin{array}{l}\text { (100) S.C. Si } \\
2 \text { ohm-cm p-type } \\
\text { (Mech. Polished) }\end{array}$ & 1023 & $\begin{array}{l}\mathrm{H}_{2} \\
1.5\end{array}$ & 11.3 & $\begin{array}{l}\text { 1) } 150 \\
\text { 2) } 6\end{array}$ & $\begin{array}{l}\text { 1) } 7.3 \\
\text { 2) } 8.7\end{array}$ & $\begin{array}{l}\text { 1) } 0.7 \\
\text { 2) } 0.9\end{array}$ & $\begin{array}{l}\text { 1) } 0.0015 t \\
\text { 2) } 0.012 t\end{array}$ & $\begin{array}{l}\text { 1) } 7 \times 10^{19} \mathrm{tt} \\
\text { 2) } 5.5 \times 10^{18+t}\end{array}$ & $\begin{array}{l}\text { 1) NM } \\
\text { 2) NM }\end{array}$ & $\begin{array}{c}2.0 \times 1.5 \\
3.0\end{array}$ & $\begin{array}{l}\text { Epitaxial*** } \\
\text { (Both Layers) }\end{array}$ \\
\hline$\frac{\text { OCLI-53 }}{(D L)}$ & $\begin{array}{l}\text { (100) S.C. Si } \\
10 \text { ohm-cm p-type } \\
\text { (Mech. Polished) }\end{array}$ & 1023 & $\begin{array}{l}\mathrm{H}_{2} \\
1.5\end{array}$ & 11.3 & $\begin{array}{l}\text { 1) } 150 \\
\text { 2) } 6\end{array}$ & $\begin{array}{l}\text { 1) } 7 . \\
\text { 2) } 8 .\end{array}$ & $\begin{array}{l}\text { 1) } 0.7 \\
\text { 2) } 0.8\end{array}$ & $\begin{array}{l}\text { 1) } \cdot 0.002 t \\
\text { 2) } 0.014 t\end{array}$ & $\begin{array}{l}\text { 1) } 5.5 \times 10^{19+t \dagger} \\
\text { 2) } 5 \times 10^{18+t}\end{array}$ & $\begin{array}{l}\text { 1) } N M \\
\text { 2) NM }\end{array}$ & $\begin{array}{c}1.6 \times 1.1 \\
1.8\end{array}$ & $\begin{array}{l}\text { Epitaxial**** } \\
\text { (Both Layers) }\end{array}$ \\
\hline$\frac{0 C L(-54}{(D L)}$ & $\begin{array}{l}\text { (011̄2) Sapphire } \\
\text { (Polished) }\end{array}$ & 1026 & $\begin{array}{l}\mathrm{H}_{2} \\
1.5\end{array}$ & 10.3 & $\begin{array}{l}\text { 1) } 150 \\
\text { 2) } 6\end{array}$ & $\begin{array}{l}\text { 1) } 3.6 \\
\text { 2) } 11.7\end{array}$ & $\begin{array}{l}\text { 1) } 0.7 \\
\text { 2) } 0.8\end{array}$ & $\begin{array}{l}\text { 1) } 0.0022 t \\
\text { 2) } 0.015^{t}\end{array}$ & $\begin{array}{l}\text { 1) } 5 \times 10^{19+t} \\
\text { 2) } 4.5 \times 10^{18+t}\end{array}$ & $\begin{array}{l}\text { 1) } \mathrm{NM} \\
\text { 2) } \mathrm{NM}\end{array}$ & $\begin{array}{c}2.2 \times 1.7 \\
3.7\end{array}$ & $\begin{array}{l}\text { Epitaxial }{ }^{* * *} \\
\text { (Both Layers) }\end{array}$ \\
\hline$\frac{0 C L I .55}{(D L)}$ & $\begin{array}{l}\text { (100) S.C. Si } \\
2 \text { ohm-cm p-type } \\
\text { (Mech. Polished) }\end{array}$ & 1024 & $\begin{array}{l}\mathrm{H}_{2} \\
1.5\end{array}$ & 10.3 & $\begin{array}{l}\text { 1) } 150 \\
\text { 2) } 6\end{array}$ & $\begin{array}{l}\text { 1) } 4.0 \\
\text { 2) } 13\end{array}$ & $\begin{array}{l}\text { 1) } 0.8 \\
\text { 2) } 0.85\end{array}$ & $\begin{array}{l}\text { 1) } 0.002 t \\
\text { 2) } 0.014 t\end{array}$ & $\begin{array}{l}\text { 1) } 5 \times 10^{19 t t+} \\
\text { 2) } 5 \times 10^{18 t t}\end{array}$ & 1) NM & $\begin{array}{c}2.0 \times 1.3 \\
2.6\end{array}$ & $\begin{array}{l}\text { Epitaxial }{ }^{* * * *} \\
\text { (Both Layers) }^{\text {a }}\end{array}$ \\
\hline$\frac{0 C L 1.56}{(0 L)}$ & $\begin{array}{l}\text { (100) S.C. Si } \\
10 \text { ohm-cm p-type } \\
\text { (Mech. Polished) }\end{array}$ & 1024 & $\begin{array}{l}\mathrm{H}_{2} \\
1.5\end{array}$ & 10.3 & $\begin{array}{l}\text { 1) } 150 \\
\text { 2) } 6\end{array}$ & $\begin{array}{l}\text { 1) } 5.0 \\
\text { 2) } 14\end{array}$ & 1) 1.0 & $\begin{array}{l}\text { 1) } 0.0025 t^{t} \\
\text { 2) } 0.01 t^{t}\end{array}$ & $\begin{array}{l}\text { 1) } 4 \times 10^{19 t t} \\
\text { 2) } 3.5 \times 10^{18 t t}\end{array}$ & $\begin{array}{l}\text { 1) NM } \\
\text { t) } 2) \text { NM }\end{array}$ & $\begin{array}{c}1.8 \times 1.6 \\
2.9\end{array}$ & $\begin{array}{l}\text { Epitaxial*** } \\
\text { (Both Layers) }\end{array}$ \\
\hline$\frac{\text { OCLLI-5] }}{(D L)}$ & $\begin{array}{l}\text { (017̄2) Sapphire } \\
\text { (Polished) }\end{array}$ & 1030 & $\begin{array}{l}\mathrm{H}_{2} \\
1.5 \\
\end{array}$ & 10.4 & $\begin{array}{l}\text { 1) } 150 \\
\text { 2) } 6 \\
\end{array}$ & $\begin{array}{r}\text { 1) } 3.5 \\
\text { 2) } 11.5 \\
\end{array}$ & $\begin{array}{l}\text { 2) } 0.7 \\
\text { 2) } 0.8 \\
\end{array}$ & $\begin{array}{l}\text { 1) } 0.0025 \dagger \\
\text { 2) } 0.016 \dagger\end{array}$ & $\begin{array}{l}\text { 1) } 3.5 \times 1019 \mathrm{tt} \\
\text { 2) } 3.2 \times 1018 \mathrm{tt} \\
\end{array}$ & $\begin{array}{l}\text { 1) NM } \\
\text { 2) NM }\end{array}$ & $\begin{array}{c}2.2 \times 1.8 \\
4.0 \\
\end{array}$ & $\begin{array}{l}\text { Epitaxial }{ }^{* * *} \\
\text { (Both Layers) }\end{array}$ \\
\hline$\frac{0 C L I .34 A}{(D L)}$ & $\begin{array}{l}\text { (0112) Sapphire } \\
\text { (Polished) }\end{array}$ & 1025 & $\begin{array}{l}\mathrm{H}_{2} \\
1.5\end{array}$ & 10 & $\begin{array}{l}\text { 1) } 300 \\
\text { 2) } 6\end{array}$ & $\begin{array}{l}\text { 1) } 4^{* * * *} \\
\text { 2) } 17^{* * * *}\end{array}$ & 1) $1.3^{* * *}$ & $\begin{array}{l}\text { 1) } 0.005^{* * *} \\
\text { 2) } 0.1^{* * *}\end{array}$ & $\begin{array}{l}\text { 1) } 1 \times 10^{19} 9^{* * * *} \\
\text { 2) } 5 \times 10^{17 * * *}\end{array}$ & $\begin{array}{l}\text { 1) NM } \\
\text { 2) NM }\end{array}$ & $\begin{array}{l}\text { Quarter } \\
\text { Circle of } \\
\text { Radius } \\
1.9 \mathrm{~cm} \\
2.8\end{array}$ & $\begin{array}{l}\text { Epitaxial } \\
\text { (Both Layers) }\end{array}$ \\
\hline$\frac{\text { OCLLI-35A }}{\text { (DL) }}$ & $\begin{array}{l}\text { (0112) Sapphire } \\
\text { (Polished) }\end{array}$ & 1031 & $\begin{array}{l}\mathrm{H}_{2} \\
1.5\end{array}$ & 10 & $\begin{array}{l}\text { 1) } 295 \\
\text { 2) } 6\end{array}$ & $\begin{array}{l}\text { 1) } 6.5 \\
\text { 2) } 20.5\end{array}$ & $\begin{array}{l}\text { 1) } 1.1 \\
\text { 2) } 1.4\end{array}$ & $\begin{array}{l}\text { 1) } 0.0025 t \\
\text { 2) } 0.05 t\end{array}$ & $\begin{array}{l}\text { 1) } 5 \times 1019 t T \\
\text { 2) } 8 \times 1017 t t\end{array}$ & $\begin{array}{l}\text { 1) NM } \\
\text { 2) NM }\end{array}$ & $\begin{array}{l}\text { Quarter } \\
\text { Circle of } \\
\text { Radius } \\
1.9 \mathrm{~cm} \\
2.8 \\
\end{array}$ & $\begin{array}{l}\text { Epitaxial } \\
\text { (Both Layers) }\end{array}$ \\
\hline
\end{tabular}

OTE: Samples processed iato solar cell structures during quarter have number underlined

-Films B-doped from $\mathrm{B}_{2} \mathrm{H}_{6}$.in- $\mathrm{He}_{\mathrm{H}}(\mathbf{4 6} \mathrm{ppm})$

* Measured by ven der Pauw method

"**Estimate, based on deposition parame ters and/or measurement on companion film grown simultaneously

tMeasured by spreading resistance probe.

$t+$ Calculated from spreading resistance measurement.

NM $=$ not measured.

$D L$ = double layer; 1) deposited first, 2) deposited second 
$\sim 15 \mathrm{~min}$, using a Pocl source. This procedure was selected to produce a junction at a depth of $\sim 0.35 \mu \mathrm{m}$ in the control wafers. After the surface glasses were removed ( $1 \mathrm{HF}: 10 \mathrm{H}_{2} \mathrm{O}$ etch for $\sim 30 \mathrm{sec}$, followed by wash and blow-dry) the samples were $\exists l l$ found to be n-type at the surface. A fullsurface backside contact of Ti-Ag was then applied. A slmilar Ti-Ag frontsurface contact in the form of the conventional comb-like finger-grid structure (3-4 lines per $\mathrm{cm}$ ) was also applied. Both contacts were sintered (simultaneously) at $\sim 500^{\circ} \mathrm{C}$ in $\mathrm{a} \mathrm{H}_{2}$ atmosphere for $\sim 5 \mathrm{~min}$. No antireflection coating was applied to any of the samples in this group, all of which were initially processed as single full-area solar cells.

Preliminary evaluation of these experimental solar cell structures was carried out with the AMO solar simulator providing illumination. The results obtained in this series of measurements are summarized in Table 2-7; included are the corresponding responses of four single-crystal control cells processed and fabricated simultaneously with the sheet samples. The properties of the control cells compare favorably with the best single-crystal $2 \mathrm{~cm} \times 2 \mathrm{~cm} \mathrm{n} / \mathrm{p}$ cells routinely produced at OCLI, so it appears that the processing and fabrication steps used with this group of samples were properly executed.

The differences in measured response for the three sets of cells fabricated in single-layer $\mathrm{Si}$ sheet material doped to three different concentration ranges are striking. Thus, samples OCLI-46 and 47 , in which the Si layers were uniformly $\mathrm{B}$-doped (simultaneously) to produce measured carrier concentrations of $4 \times 10^{17}$ and $2 \times 10^{17} \mathrm{~cm}^{-3}$, respectively, gave good $\mathrm{V}$ values of 470 and $534 \mathrm{mv}$, respectively, compared with the average $v_{\text {for }}$ for ${ }^{\circ}$ he control samples of $580 \mathrm{mv}$. Samples OCLI-36 and 39 , in which the p-type Si layers were uniformly doped to produce measured carrier concentrations of $\sim 1 \times 10^{18}$ and $\sim 3 \times 10^{18}$, respectively, gave $v_{\text {ac }}$ values of 120 and $13 \mathrm{lmV}$, respectively. Samples OCLI-42, 44, and 45, which were more heavily doped to produce carrier concentrations of nearly $10^{19} \mathrm{~cm}^{-3}$ (OCLI-42) and $5-9 \times 10^{18} \mathrm{~cm}^{-3}$ (OCLI-44 and 45, grown simultaneously), exhibited $v_{o c}$ values of 16,27 , and $92 \mathrm{mV}$, respectively, for the test illumination. The measured short-circuit current densities obtained for these test conditions are seen to be similar for all of the samples in this group except OCLI-42 and 44, for which somewhat lower photogenerated current densities were observed.

These results clearly indicate that the more lightly doped p-type CVD Si produces far better photovoltaic response in junction devices formed by $P$ diffusion under the conditions employed. This apparent sensitivity to acceptor doping level in the base material appears to be considerably greater for the CVD sheet material than for comparably doped single-crystal Si wafers used for fabrication of conventional solar $\left.7_{7}{ }_{1}\right\}_{3}$. It appears that CVD sheet material doped at concentrations below $10^{17} \mathrm{~cm}^{-3}$ should be evaluated for fabrication of cell structures by the methods being used in this work, and experiments with such material will be undertaken in the coming quarter. The results also show - for the three sets of single-layer samples - that better results were consistently obtained for CVD sheet material grown on the 
Table 2-7. Photovoltaic Response* of P-diffused n/p Full-area Solar Cells Fabricated in B-doped CVD Si Sheet Material on Single-crystal Si and Sapphire Substrates

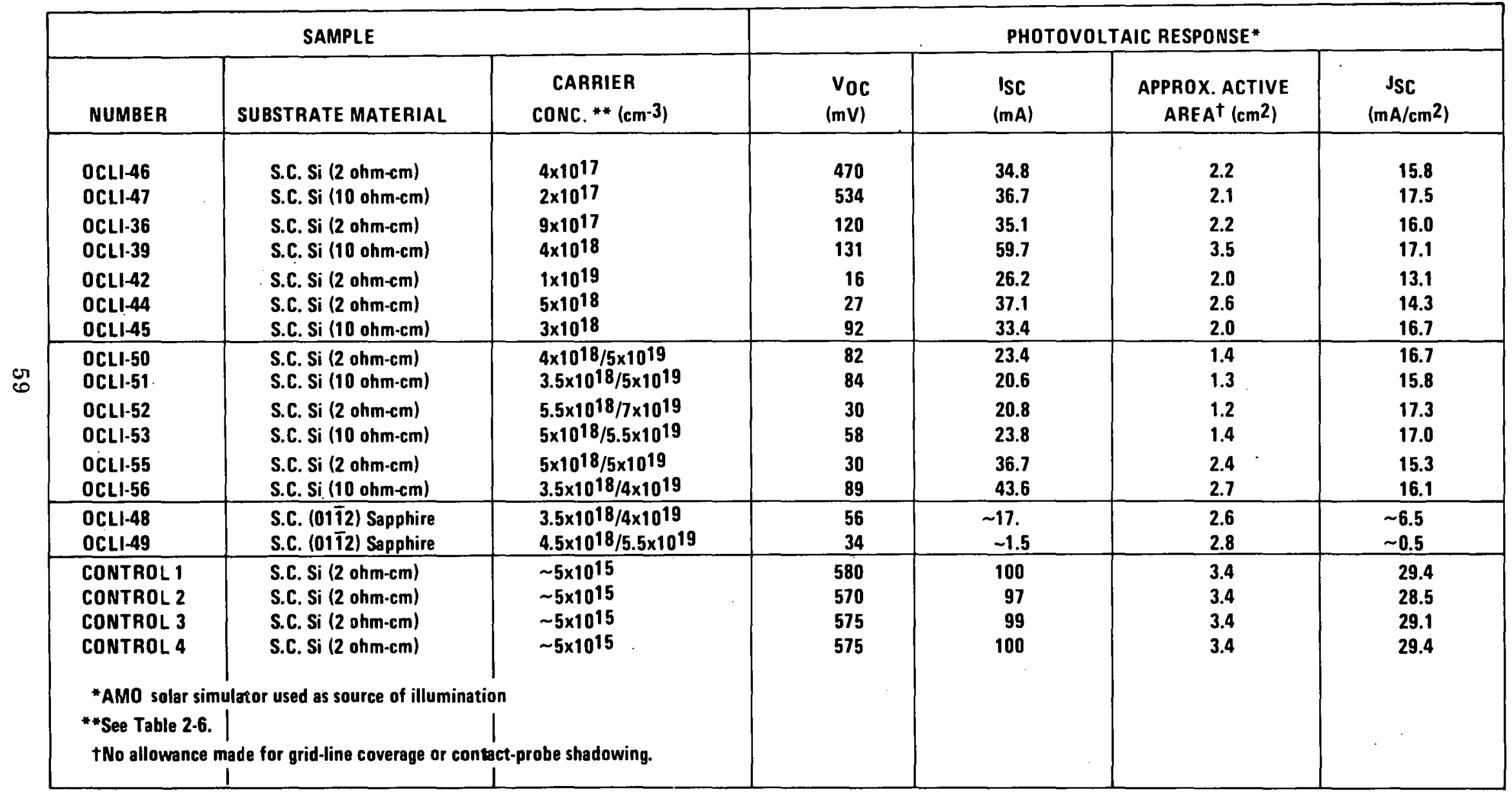


$10 \mathrm{ohm}-\mathrm{cm}$ single-crystal substrates than for layers grown on the high-lifetime $2 \mathrm{ohm}-\mathrm{cm}$ single-crystal substrates. There are several possible explanations for this result, one of which is the difficulty that was encountered in cleaning the OCLI substrate wafers adequately for use in epitaxy experiments, as discussed in section 2.3.3. These differences are being examined further.

The photovoltaic responses obtained with cells fabricated in $\mathrm{p} / \mathrm{p}^{+}$doublelayer Si sheet material were poorer than had been expected. However, reference to the data in the table indicates the $v$ values for these samples (OCLI-50 and 51, 52 and 53, 55 and 56) are fairly Consistent with the results obtained for the single-layer samples in which the doping concentration is in the same range as that in the upper ( $p$-type) region of the $p / p^{+}$double layers. The short-circuit current densities obtained with the cell structures fabricated in the double-layer samples are in the same range as those observed for the single-layer samples. Again the photovoltaic properties of those devices in sheet material grown on the $10 \mathrm{ohm}-\mathrm{cm}$ p-type single-crystal substrates exceed those found for the devices in the layers grown on the $2 \mathrm{ohm}-\mathrm{cm}$ single-crystal substrates.

It is interesting that the difference in photovoltaic performance between the Si sheet material on the $2 \mathrm{ohm}-\mathrm{cm}$ substrates and that on the $10 \mathrm{ohm}-\mathrm{cm}$ substrates is greatest for the pair of samples (OCLI-55 and 56) for which the thickness ratio $t_{p}: t_{+}$is $\sim 3: 1$, i.e., in which the $\mathrm{p}^{+}$layer is relatively thin and therefork fairly far from the $p-n$ junction. The performance difference is less--but still quite significant--for the pair of samples (OCLI-52 and 53) for which the $\mathrm{p}$ and $\mathrm{p}^{+}$regions are about equal in thickness and in which the $\mathrm{p}^{+}$layer is about $8 \mu \mathrm{m}$ from the diffused junction. The smallest difference in performance is for the two samples (OCLI-50 and 51) for which the $t_{p}: t_{p}$ ratio is $\sim 1: 3$, in which the $p^{+}$region extends to about $4 \mu \mathrm{m}$ from the diffused junction. To determine if the apparent tendency for the $\mathrm{p}^{+}$layer to isolate the $\mathrm{p}-\mathrm{n}$ junction (and thus its photovoltaic properties) from the influence of the properties of the substrate or if other factors present are really dominating the situation will require further evaluation of the present samples and additional experiments with other samples yet to be prepared.

Finally, the pair of double-layer samples grown on sapphire substrates (OCLI-48 and 49, Table 2-7) resulted in diffused-junction cells exhibiting $v$ values similar to those for cells in double-layer samples on $S i$ substrates for which the doping concentration in the p-type region is about the same (i.e. mid-10 $18 \mathrm{~cm}^{-3}$ range). There was no evidence in these full-area solar cells of the large open-circuit photovoltages found in the mesa-type cell structures fabricated in double-layer $\mathrm{Si}$ sheet grown on sapphire, as in the group of samples discussed earlier in this section (e.g., OCLI-34 and 35). In addition, short-circuit photocurrents were found to be very low for OCLI-48 and 49, indicating major carrier collection and/or junction leakage problems. 
Some of the questions raised by these initial results may be answered by the findings of work now in progress with these samples but not complete at the end of the report period. The samples are being processed into individual mesas to permit an investigation of junction (and base region) uniformity. The properties of the mesas will be carefully evaluated to attempt to correlate localized photovoltaic properties with any detectable variations in initial sheet material properties and/or local perturbations in processing and fabrication steps. Results of these studies will be given in later reports.

In particular, although there is evidence that properly doped epitaxial Si sheet material (e.g., OCLI-47) provides a base in which it is possible to form P-diffused junctions that exhibit very good open-circuit photovoltages, all of the full-area cells in this last group exhibited uniformly poor collected photocurrents. Furthermore, there is relatively little variation in the short-circuit current densities displayed by the sheet-sample devices for the test conditions used. The $J$ values (excluding those for the two samples on sapphire) were all in the range between 45 and 60 percent of the average of the short-circuit current densities produced by the four singlecrystal Si control samples. This variation is very small compared with the variations in observed $\mathrm{V}$ values. The continuing work with these and subsequent samples will be directed toward identifying the causes of these inconsistencies. 
THIS PAGE WAS INTENTIONALLY LEFT BLANK 


\section{CONCLUSIONS AND RECOMMENDATIONS}

The activities of the past quarter were concentrated in the following areas: (1) preparation of polished substrates of three new experimental glasses received in raw billet form from the manufacturer; (2) exploratory Si CVD growth on two experimental glazes (on aluminas), at temperatures below and above the softening points; (3) evaluation of several different surface cleaning procedures for glass substrates, with a procedure involving an acidcleaning step being adopted as standard; (4) determination of Si film crystallographic properties on glasses (and sapphire) as a function of deposition temperature and thickness in three different thickness ranges; (5) determination of the effect of $\mathrm{HCl}$ additions to $\mathrm{SiH}_{4}$ on the net growth rates and the properties of Si films grown by a two-step process at two different deposition temperatures; (6) investigation of the reproducibility of Si film growth rates when the $\mathrm{SiH}_{4}$ flow rate is controlled by a) the mass-flow controller and b) the conventional rotameter; (7) determination of further carrier density vs added dopant concentration data for B-doped $\mathrm{Si}$ films grown in He at low temperatures $\left(\sim 850^{\circ} \mathrm{C}\right) ;(8)$ preparation of p-type B-doped Si films in a range of carrier densities on substrates of single-crystal Si, sapphire, and several glasses for fabrication of experimental solar cell structures; (9) preparation of $\mathrm{p} / \mathrm{p}^{+}$films on substrates of sapphire and single-crystal $\mathrm{Si}$ for solar cell fabrication; (10) evaluation of the electrical properties of the various films prepared; and (11) fabrication and characterization of experimental cells made by $\mathrm{P}$ diffusion into the $\mathrm{p}$-type and the $\mathrm{p} / \mathrm{p}^{+} \mathrm{CVD}$ layers.

The emphasis of these investigations has continued to shift toward use of various glasses as substrates, consistent with the need for low-cost solar cell structures. On the basis of results obtained with more readily available glasses, both Owens-Illinois and corning have undertaken the preparation of new or improved glass formulations for evaluation in this program. Corning has prepared a glass similar but superior to Code 1715, although it is not yet available. Owens-Illinois has recently supplied three new glasses for evaluation and is also preparing higher purity grades of GS211 and GS213, the earlier samples of which have been colored (presumably by various impurities) and have appeared to contaminate neighboring substrates.

Ferro corporation has prepared glazed aluminas for evaluation; the glaze corrects the rough surfaces associated with as-fired aluminas and other ceramic substrates. Glazed aluminas also permit $\mathrm{Si}$ growth at temperatures greater than the $\sim 850^{\circ} \mathrm{C}$ which appears to be best for film growth in He on most of the glasses examined. It is possible to heat the glazes to their melting points without having the material adhere to the Sic-coated pedestal in the reactor chamber. One of the glazes heated to $1025^{\circ} \mathrm{C}$ in $\mathrm{H}$ did permit the growth of $\mathrm{Si}$ crystallites as large as $\sim 20 \mu \mathrm{m}$ across. Additional experiments with such glazes are recommended.

It was found that surprisingly good crystallographic properties result even in very thin $(\sim 0.1 \mu \mathrm{m})$ CVD Si films grown on several different glasses at $\sim 850^{\circ} \mathrm{C}$ in $\mathrm{He}$, with significant $\{100\}$ preferred orientation that increases with 
increasing film thickness. Films grown on the same substrate materials at $\sim 950^{\circ} \mathrm{C}$ are generally not as good structurally as those of comparable thickness but grown at $\sim 850^{\circ} \mathrm{C}$, although part of the difference may be attributable to growth rate differences and not just temperature differences alone. Grain size is also found to increase with film thickness on the glasses, in the thickness range studied. The interrelationships of grain size, preferred orientation, film thickness, and deposition temperature are very complex, and additional studies would be required to delineate the relationships in detail. It would be interesting to determine the effect of different He-to-H ${ }_{2}$ concentration ratios on glass stability and $\mathrm{Si}$ film growth, particularly at temperatures higher than $850^{\circ} \mathrm{C}$. Generally, grain size is temperature-dependent (increasing as temperature is increased), and if the $S i$ growth rate could be increased by $\mathrm{H}_{2}$ additions to $\mathrm{He}$ without producing gas-phase nucleation and thereby upsetting the growth process on glass, it might be possible to deposit at higher temperatures in the He atmosphere and still achieve some of the structural advantages observed at the lower temperature.

The two-step Si sheet growth process in which a first-grown region is deposited by direct pyrolysis of $\mathrm{SiH}_{4}$ in He followed by a second layer grown from a $\mathrm{SiH}_{4}$ - $\mathrm{HCl}$ mixture in He $\left(\mathrm{at}^{4} \sim 850^{\circ} \mathrm{C}\right)$ apparently produces no improvement in either overall film quality or average grain size in the upper portion of the sheet, relative to the properties of layers of comparable thickness grown in a single step without HCl. It appears that GS2l3 glass tolerates the HCl twostep treatment better than either GS211 or 1715 glass. Additional experiments are to be undertaken in which the etching effects of HCl vapor on partialcoverage Si films (i.e., films consisting of separate islands of various sizes, not yet fully coalesced into a continuous layer) on these glasses will be investigated, to determine if such attack will result in an increased proportion of larger islands to serve as nuclei for further growth of the layer.

Evaluation of a group of solar cell structures fabricated in B-doped CVD Si films on glass, polycrystalline alumina, and single-crystal sapphire was completed early in the quarter. $v$ values for the epitaxial films on sapphire compared favorably with those of simultaneously processed singlecrystal control wafers, but those for the polycrystalline films were much lower. Photogenerated currents for these film samples (including the epitaxial films) were quite low, resulting in poor conversion efficiencies. Spectral response measurements indicated short minority carrier diffusion lengths, in

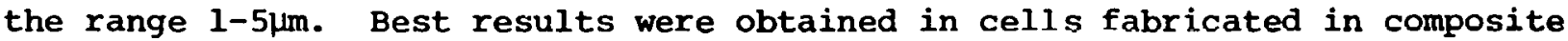
$\mathrm{p} / \mathrm{p}^{+}$CVD layers; curve fill factors up to 0.66 and a high degree of uniformity in properties were observed for mesa cells in epitaxial material on sapphire.

Based on these results, another group of CVD Si film structures was prepared on substrates of single-crystal $\mathrm{Si}$, sapphire, and several glasses, with a variety of $B$ doping levels and relative thicknesses of the $p$ and $\mathrm{p}^{+}$regions. P-diffused junctions $0.3-0.4 \mu \mathrm{m}$ deep were formed $\left(875^{\circ} \mathrm{C}\right.$ for $\left.15 \mathrm{~min}\right)$, and sintered Ti-Ag contacts were applied (including a back-surface base contact for the epitaxial film cells on $\mathrm{Si}$ substrates). Although characterization was not complete by the end of the quarter, it appears that performance of these CVD cells is critically dependent on base region doping density (more so than in single-crystal Si cells), and low photogenerated currents again 
indicate seriously reduced charge collection efficiencies--even in the epitaxial material. Additional film structures prepared with systematically modified properties using changed CVD parameters are to be processed to attempt to identify the cause of the observed performance.

The results obtained with the photovoltaic structures described above emphasize the importance of work to be initiated in the coming quarter, in which $\mathrm{n} / \mathrm{p} / \mathrm{p}^{+}$ solar cell structures will be formed in situ by deposition in the reactor. comparison will then be made of the photovoltaic properties of those structures with the properties of cells made by diffusion of donor impurities into p-type sheet material, the procedure that has been used to date. 


\section{THIS PAGE \\ WAS INTENTIONALLY \\ LEFT BLANK}




\section{PLANS FOR NEXT QUARTER}

The planned work for the next three months will follow the Updated Technical Program Plan given in Appendix B of this report. The planned work, summarized by task, is as follows:

\section{TASK 1}

The work of this task was completed during the second quarter.

TASK 2

1. Complete evaluation of new Owens-Illinois glasses as substrates for Si CVD for solar cells

2. Evaluate polished glass-ceramics as substrates to determine if they provide any advantages for nucleating and/or enhancing large-grain growth in polycrystalline Si grown by CVD

3. Evaluate polished steatite substrates for Si CVD

4. Prepare and evaluate composite-layer substrate structures for. Si sheet growth by CVD

5. Continue investigation of effects of controlled substrate surface processing on quality of deposited Si sheet material.

\section{TASK 3}

1. Investigate and correlate effects of various in situ and postdeposition annealing cycles on structural (e.g., grain size) and electrical properties of partial- and full-coverage Si layers on various low-cost substrates

2. Determine usefulness of dichlorosilane as $\mathrm{Si}$ source material for CVD growth on low-cost substrate materials

3. Establish preferred CVD parameters for producing $\mathrm{p} / \mathrm{p}^{+} \mathrm{Si}$ CVD sheet material on glasses for photovoltaic applications

4. Evaluate various modifications of two-step Si CVD growth process and make decision regarding its applicability to this program

5. Obtain calibration of $\mathrm{SiH}_{4}$ rotameter and recalibration of $\mathrm{SiH}_{4}$ mass flow controller

6. Continue Si CVD growth experiments with Ferro glazes on aluminas and/or other substrates and with other candidate low-cost substrate materials 
7. Continue deposition experiments with thick ( $\sim 100 \mu \mathrm{m})$ Si layers on glasses, ceramics, and single-crystal substrates

8. Conclude simultaneous Si growth experiments on polycrystalline and/ or amorphous substrates and single-crystal sapphire to compare electrical properties of doped films in the two cases

9. Initiate experiments to produce deposited junctions in $\mathrm{n} / \mathrm{p}$ and $\mathrm{n} / \mathrm{p} / \mathrm{p}^{+}$structures on polycrystalline alumina, single-crystal sapphire, and various low-cost substrates (e.g., glasses) for fabrication of solar cells for comparison with diffused-junction cells.

TASK 4

1. Prepare samples of appropriately doped single-layer epitaxial si on single-crystal $\mathrm{Si}$ and single-crystal sapphire substrates, for processing into solar cell structures

2. Prepare samples of appropriately-doped single-layer CVD Si films on selected glass and polycrystalline alumina substrates for fabrication of experimental solar cell structures

3. Prepare $p / p^{+}$Si films on substrates of single-crystal Si, singlecrystal sapphire, and selected glasses and aluminas for fabrication and evaluation of solar cell structures

4. Prepare $n / p$ and $n / p / p^{+} \mathrm{si}$ films on substrates of single-crystal sapphire, polycrystalline aluminas, and various glasses for evaluation of material propertioc and fabrioation and cualuation of solar cell structures

5. Prepare various CVD Si samples and solar cell structures for evaluation and demonstration and for delivery to JPL.

TASK 5

1. Continue analyses of Si film and substrate structural properties by surface profilometry, x-ray diffraction, metallographic sectioning, reflection electron diffraction, and scanning electron microscopy techniques

2. Continue application of x-ray diffraction methods for determination of preferred orientation and grain size in polycrystalline CVD Si films on various substrates

3. Continue determination of film electrical properties by van der Pauw and/or Hall bridge measurements, and attempt to identify applicable model of conduction mechanism(s) in polycrystalline si 
4. Continue use of spreading resistance measurements to determine carrier concentration profiles and locate possible impurity contamination in polycrystalline Si films on glass and alumina substrates

5. Undertake examination of experimental solar cell structures by EBICmode analysis in SEM.

TASK 6

1. Submit additional samples of CVD Si sheet to OCLI for solar cell processing and evaluation, emphasizing films with $\mathrm{p} / \mathrm{p}^{+}$double layers and $\mathrm{n} / \mathrm{p} / \mathrm{p}^{+}$deposited junctions on various substrates. 


\section{THIS PAGE WAS INTENTIONALLY LEFT BLANK}


No reportable items of new technology have been identified during the conduct of the fifth quarter of work on this contract, which is the period covered by this report.

\section{REFERENCES}

1. R. P. Ruth, H. M. Manasevit, R. E. Johnson, J. L. Kenty, L. A. Moudy, W. I. Simpson, and J. J. Yang, "Chemical Vapor Deposition Growth," Annual Report, I October 1976, Rockwell International, Electronics Research Center, Anaheim, CA 92803. JPL Contract No. 954372, performed for the Jet Propulsion Laboratory, California Institute of Technology, under NASA Contract NAS7-100 for the U. S. Energy Research and Development Administration, Divișion of Solar Energy.

2. E. Rasmanis, The Electrochemical Society, Spring Meeting, Pittsburgh, April 1963, Paper No. 72.

3. See, e.g., Y. S. Chiang, The Electrochemical Society, Spring Meeting, Chicago, May 1973, Paper No. 119; also, P. Ral-Choudhury and P. L. Hower, J. Electrochem. Soc. 120, 1761 (1973).

4. R. P. Ruth, H. M. Manasevit, R. E. Johnson, L. A. Moudy, W. I. Simpson, and J. J. Yang, "Chemical Vapor Deposition Growth,"Quarterly Report No. 3, 1 January 1977, Rockwell International, Electronics Research Center, Anaheim, CA 92803. JPL Contract No. 954372, performed for the Jet Propulsion Laboratory, California Institute of Technology, under NASA Contract NAS7-100 for the U. S. Energy Research and Development Administration, Division of Solar Energy.

5. T. I. Kamins and T. R. Cass, Thin Solid Films $\underline{16}, 147$ (1973).

6. P. Rai-Choudhury and P. L. Hower, J. Electrochem. Soc. 120, 1761 (1973).

7. John Y. W. Seto, J. Appl. Phys. 46, 5247 (1975).

8. M. E. Cowher and T. O. Sedgwick, J. Electrochem. Soc. 119, 1565 (1972). 
This report covers the fifth quarter of the contract, through the fifteenth month. Through the fourteenth month of the contract (that is, through February 26, 1977) a cumulative total of 6103 engineering and support manhours and a cumulative total of $\$ 202,731$ (excluding fee and commitments) were expended.

For the fifteenth month of the contract (February 27 through April 2, 1977) a total of 319 engineering and support manhours and a total of $\$ 14,519$ (excluding fee and commitments) were expended.

The cumulative manpower expenditure total through April 2, 1977, is thus 6422 manhours, and the cumulative cost total (excluding fee and commitments) through that date is $\$ 217,250$. 
The initial Technical Program Plan was approved by the JPL Technical Manager on February 4, 1976.

Since that time several changes have been made in the Technical Program Plan. The changes that were agreed upon with the JPL Technical Manager at the Bimonthly Program Review Meeting on December 7, 1976, were formally approved by JPL on January 14, 1977. The Opdated Technical Program Plan that follows includes those approved changes.

Additional major changes have been necessitated by the additional woxk now to be included in the contract program as a result of JPL Contract unilateral Modification No. 11 (dated January 24, 1977). The modification requires fabrication and evaluation of solar cells in CVD Si sheet material in which $\mathrm{n} / \mathrm{p}$ junctions have been formed in situ by deposition in the reactor, and comparison of the properties with those obtained by diffusion of donor impurities to form the junctions in p-type deposited sheet material. It is now planned that work on these additional tasks will begin in May.

However, because the extensive changes to be made in the overall program plan have not yet been agreed upon with the JPL Technical Manager the Updated Technical Program plan given here does not include these changes. The plan is updated to show the achieved technical goals (filled-in triangles) through April 2, 1977, and the actual manpower and funding expenditures through that same date. 
CHEMICAL VAPOR DEPOSITION GROWTH

SILICON SHEET GROWTH DEVELOPMENT

\section{JPL CONTRACT NO. 954372}

TASK 2: LARGE AREA SILICON SHEET

JPL/ERDA LOW COST SILICON SOLAR ARRAY PROJECT

UPDATED TECHNICAL PROGRAM PLAN

(Note: Numbered technical goals are listed at end of each task)

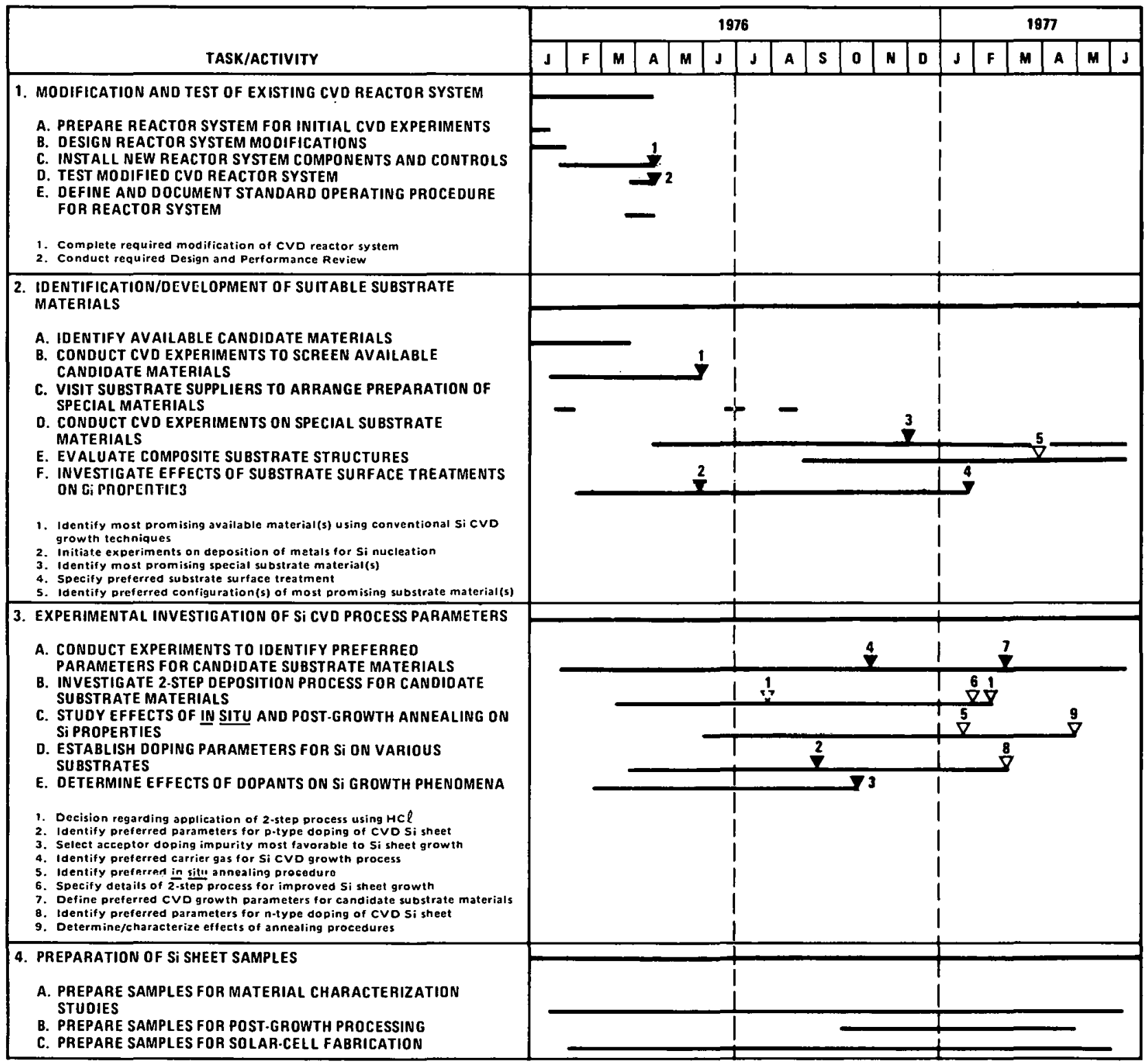




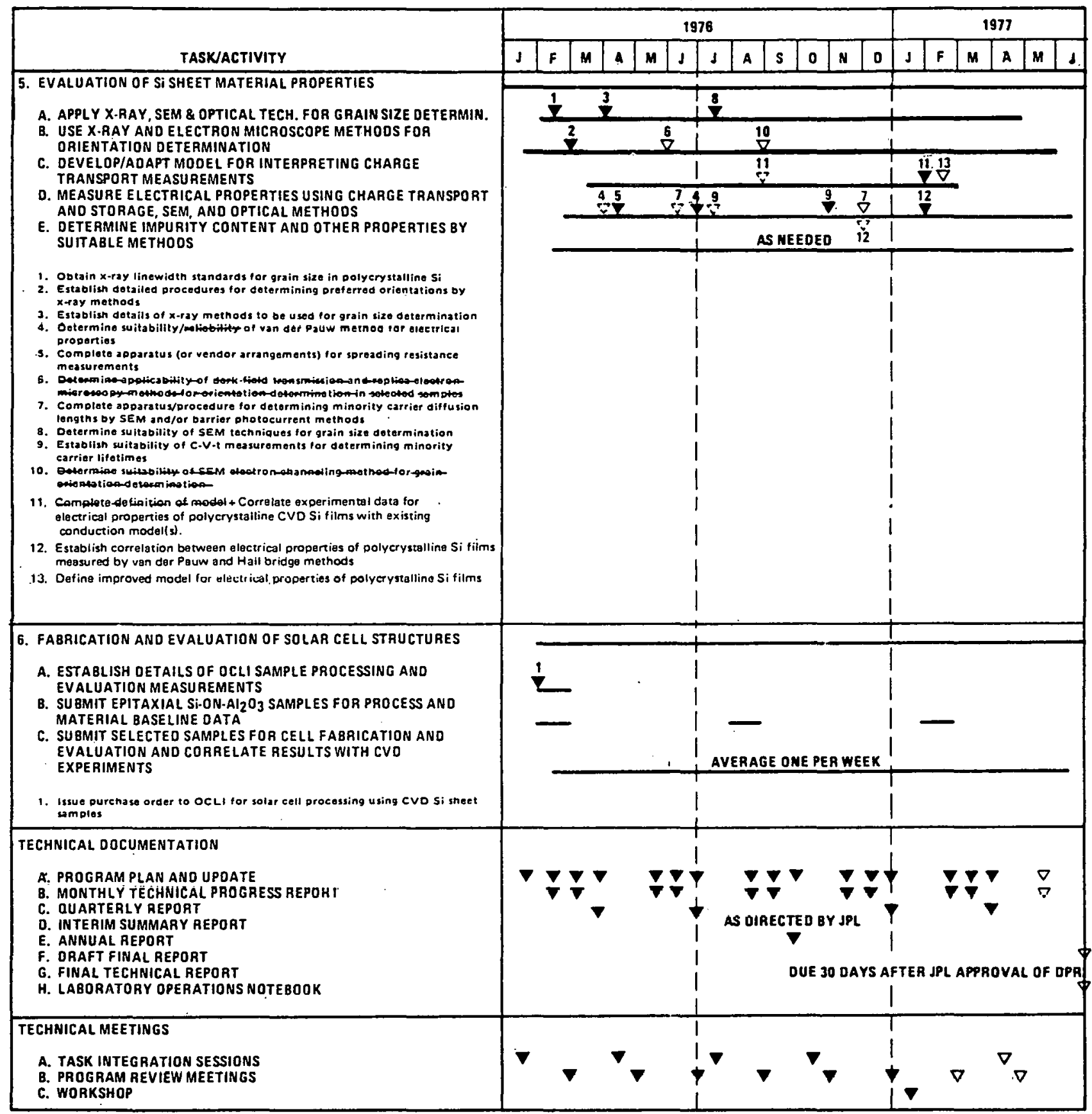




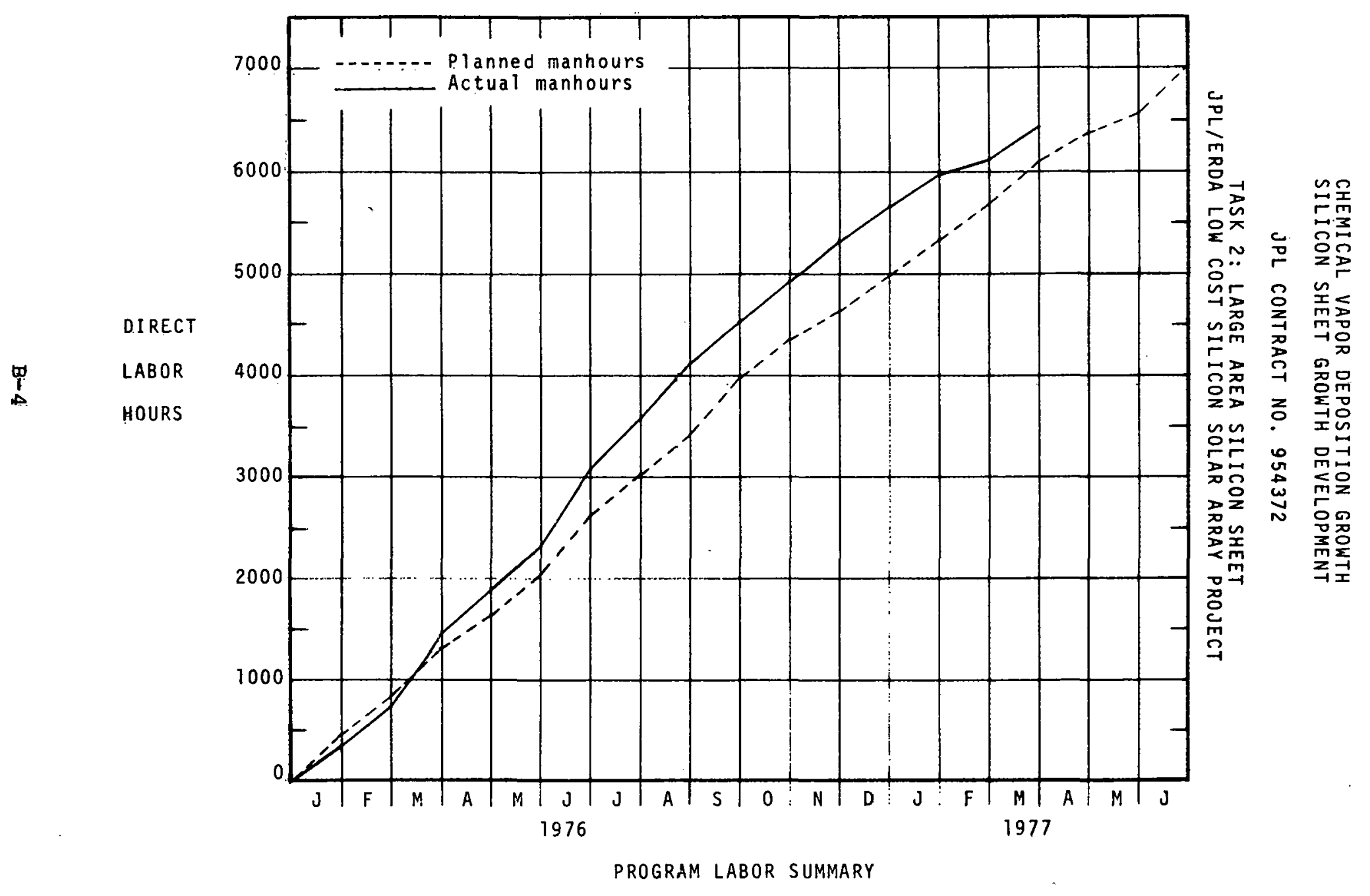




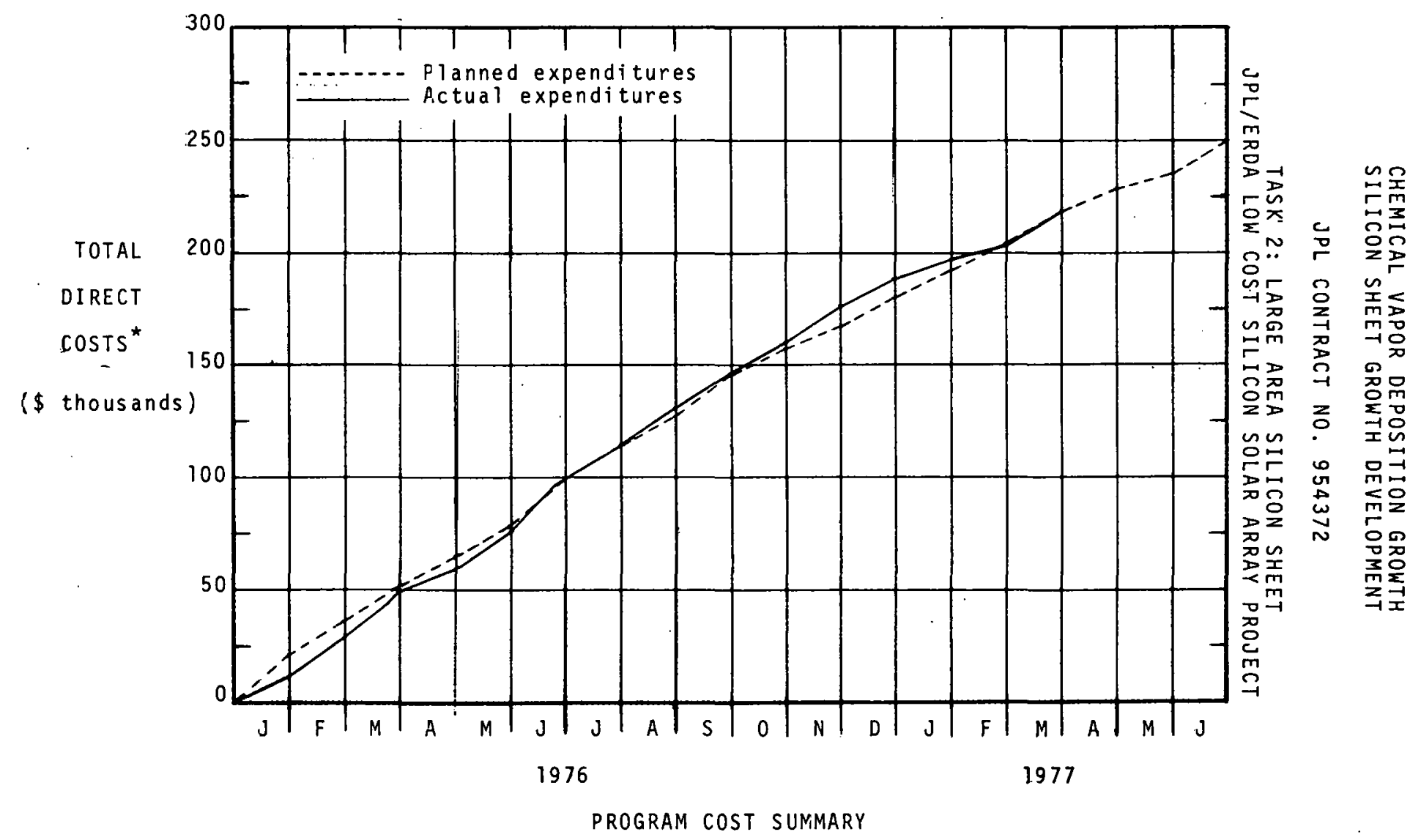

*excluding fee 